\title{
Effect of Natural Gas Fuel Composition on Gaseous and Particle NumberMass Emissions from a Heavy-duty Natural Gas Engine used in Unconventional Well Development Operations
}

\author{
Sashank Jammalamadaka
}

Follow this and additional works at: https://researchrepository.wvu.edu/etd

\footnotetext{
Recommended Citation

Jammalamadaka, Sashank, "Effect of Natural Gas Fuel Composition on Gaseous and Particle NumberMass Emissions from a Heavy-duty Natural Gas Engine used in Unconventional Well Development Operations" (2018). Graduate Theses, Dissertations, and Problem Reports. 5878.

https://researchrepository.wvu.edu/etd/5878
}

This Thesis is protected by copyright and/or related rights. It has been brought to you by the The Research Repository @ WVU with permission from the rights-holder(s). You are free to use this Thesis in any way that is permitted by the copyright and related rights legislation that applies to your use. For other uses you must obtain permission from the rights-holder(s) directly, unless additional rights are indicated by a Creative Commons license in the record and/ or on the work itself. This Thesis has been accepted for inclusion in WVU Graduate Theses, Dissertations, and Problem Reports collection by an authorized administrator of The Research Repository @ WVU. For more information, please contact researchrepository@mail.wvu.edu. 
Effect of Natural Gas Fuel Composition on Gaseous and Particle Number/Mass

Emissions from a Heavy-duty Natural Gas Engine used in Unconventional Well Development Operations

\title{
Sashank Jammalamadaka
}

\author{
Thesis submitted to the \\ Benjamin M. Statler College of Engineering and Mineral Resources \\ at West Virginia University
}

in partial fulfillment of the requirements for the degree of

\author{
Master of Science \\ in \\ Mechanical Engineering
}

Marc Cyrill Besch, Ph.D., Chair

Arvind Thiruvengadam Padmavathy, Ph.D.

Derek R. Johnson, Ph.D.

Department of Mechanical and Aerospace Engineering

Morgantown, West Virginia

2018

Keywords: Natural Gas, Heavy-duty, Fuel Composition

Copyright 2018 Jammalamadaka, Sashank 


\section{Abstract \\ Effect of Natural Gas Fuel Composition on Gaseous and Particle Number/Mass Emissions from a Heavy-duty Natural Gas Engine used in Unconventional Well Development Operations}

\section{Sashank Jammalamadaka}

Natural gas (NG) reserves have been discovered in abundance with the aid of various technological advancements in the field of directional drilling and hydraulic fracturing. Prime movers of unconventional well development were previously identified to be over-the-road (OTR) trucks, drilling engines, and hydraulic stimulation engines. The increased NG reserves have driven the industry to shift from using diesel fueled engines to natural gas engines. This allows the industries to take advantage of the produced natural gas to be directly used as energy source to fuel the prime movers involved with unconventional well development.

The primary objective of this study is to characterize gaseous emissions, Particle Number (PN) concentrations and the Particulate Matter (PM) mass emissions from an engine operated on different natural gas fuel compositions, namely; i) 'pump quality' CNG, and blends with ii) higher ethane, and iii) higher propane contents. These fuel blends were selected as their properties are typical of extracted and untreated shale gas within major US shale gas formations and will potentially be used to fuel prime movers during hydrocarbon extraction. For this purpose, a Cummins 8.9L ISL-G engine was operated over three custom designed test cycles to replicate the prime movers' in-use engine speed and load conditions, pertinent to drilling, fracturing and over-the-road (OTR) activities. The ISL-G engine, a spark-ignited, and three-way catalyst (TWC) equipped heavy-duty engine typically used in on-road vocational applications was utilized as a surrogate for a Waukesha LI7044 engine, typically applied for drilling operations, due to its similarity in technology. The minimum recommended methane number for the ISL-G engine is 75 and thus, the methane numbers for the custom fuel blends were targeted at 75.5 (propane blend) and 75.3 (ethane blend).

The OTR truck cycle produced higher brake-specific emissions of $\mathrm{CO}_{2}, \mathrm{CO}, \mathrm{NO}_{\mathrm{x}}$ and lower $\mathrm{HC}$ emissions compared to the FTP cycle when operated with 'pump' CNG fuel. For the same fuel the drilling and fracturing cycles tended to have lower $\mathrm{CO}_{2}$ and $\mathrm{HC}$ emissions but higher $\mathrm{CO}$ emissions when compared to the off-road engine certification cycle. The two custom fuel blends were only used on the in-use cycles. As expected, $\mathrm{CO}_{2}$ emissions increased with increasing alkane concentration, while opposite trends were shown for THC and $\mathrm{CH}_{4} \cdot \mathrm{NO}_{\mathrm{x}}$ emissions also tended to increase with higher ethane and propane blends, across all cycles. For all cycles and fuels, $\mathrm{HC}$ emissions were predominately $\mathrm{CH}_{4}-94-97 \%$. The $\mathrm{PN}$ concentrations were, in general, lower for the fracturing cycle, which was expected from a high load operating cycle. The OTR truck cycle, which is characterized by increased idle time, low load activity, and transient operation produced the highest PN concentrations when compared to the other two in-use cycles. When operating on 'pump' CNG, PN concentrations emitted over the OTR truck cycle were similar to the FTP. The custom fuel blends showed higher PN concentrations when compared to CNG over all test cycles. The drilling cycle being a high load cycle showed, generally, lower PM emissions when compared to the other cycles. In comparison to $\mathrm{CNG}$, the two blends produced lower PM emissions over all cycles except when operated over the OTR truck cycle. 


\section{Acknowledgements}

I would like to begin by expressing my heartful gratitude to my research advisor and committee chair, Dr. Marc C. Besch. Your unwavering support and guidance has helped me to reach a certain stage in my life. I appreciate your patience, especially, during the times where I did not live up to your expectations. You have taught me to be disciplined and I certainly aspire to become as meticulous as you are when it comes to organization and work.

I would also like to thank Dr. Arvind Thiruvengadam. Without you, I would never have been a part of CAFEE. I thank you for introducing me to Dr. Marc and for going out of the way to help me in numerous occasions. I thank Dr. Derek Johnson, for his valuable feedback and helping me by providing essential data whenever necessary.

I take this opportunity to thank Mr. Bradley Ralston, who helped me during my initial days at CAFEE and taught me every tiny little thing about the lab. I also thank Robert Heltzel, for being patient with me and providing me the necessary information for this study.

I thank Hemanth Bommisetty for helping me with vital things that were required to complete this thesis. He made sure I didn't have to walk around town and was always present to take me to any place I had to. I thank Vivek Komarina and Sai Pushpitha Vudata for being of constant support, especially when I was going through difficult phases of life. They made sure I need not worry about food and prepared the yummiest of meals every time without complaining. I thank all my

friends, here in Morgantown, Satish, Satya, Chakri, Ranjith, Rasik, and Anirudh for being an amazing company throughout.

Finally, I would like to thank my mother, Nirmala Jammalamadaka, for everything she has done for me. If it weren't for her hard work and sacrifices, I wouldn't be where I am today. I will strive to make her proud every day. I thank my brother, Siddhartha, for supporting and motivating me throughout my master's. I thank Anurag and Shivasai for bearing through my complaints about life and work throughout. I also thank Pragnahitha and Prathyusha for helping me peacefully breeze through, what, otherwise, would have been a stressful completion period. 


\section{Table of Contents}

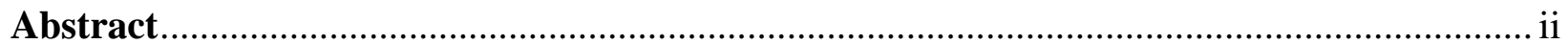

Acknowledgements............................................................ iii

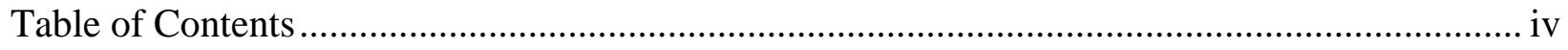

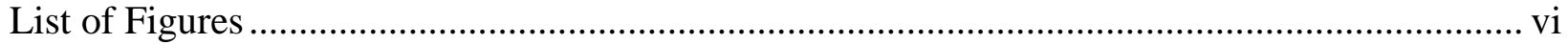

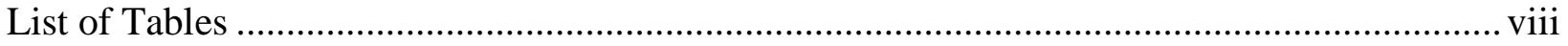

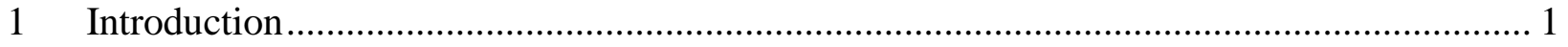

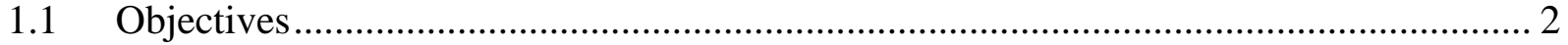

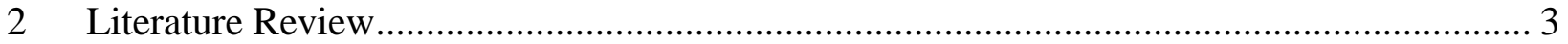

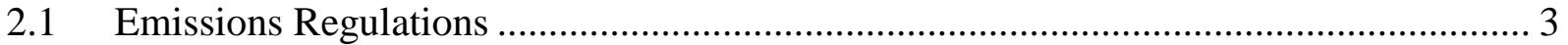

2.1.1 On-Road Heavy-Duty Engines ....................................................................... 4

2.1.2 Non-Road Heavy-Duty Engines .................................................................. 4

2.2 Particle Emissions, Characteristics and Composition ................................................. 6

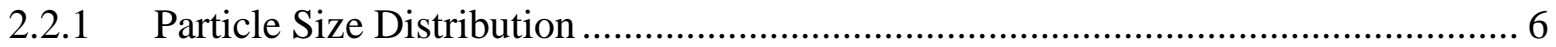

2.2.2 Particle Physical Characteristics ................................................................. 7

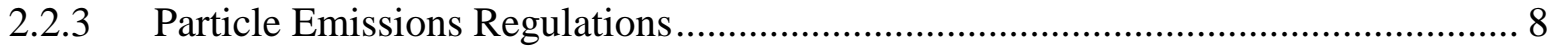

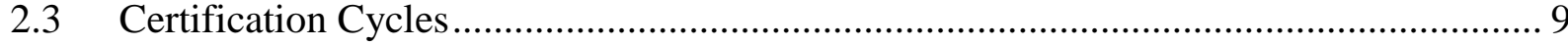

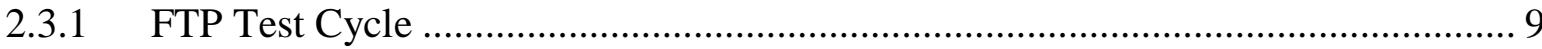

2.3.2 D2 Mode Cycle .................................................................................................... 10

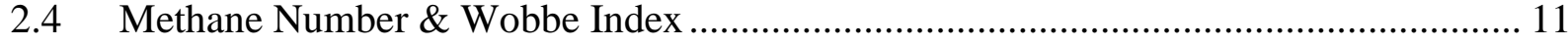

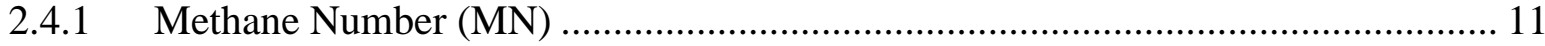

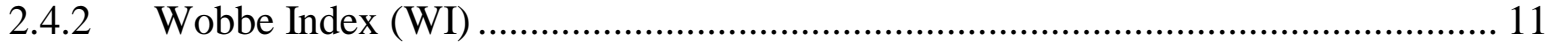

2.5 Emissions and Performance Results from Gaseous Fuel Combustion ........................ 12

2.6 Procedure of Generation of the Test Cycles........................................................... 14

2.7 Engines Used for Unconventional Well Development ............................................ 16

2.8 Association of Shale Gas Composition with the Blends of Fuels Selected .................. 18

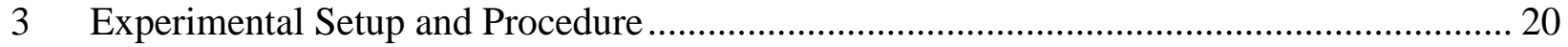

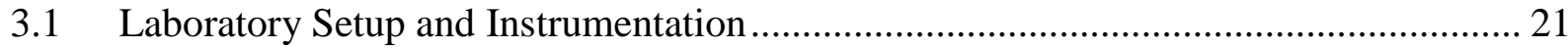

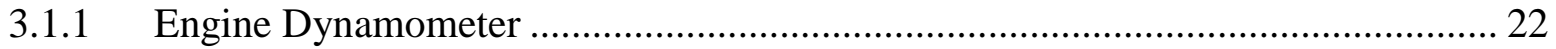

3.1.2 Constant Volume Sampling (CVS) Dilution Tunnel ......................................... 22

3.1.3 Gaseous Emissions Sampling and Measurement Systems ................................. 23

3.1.4 Crankcase Emissions Sampling and Measurement System ................................ 24

3.2 PM Sampling, Measurement and Handling System............................................... 25

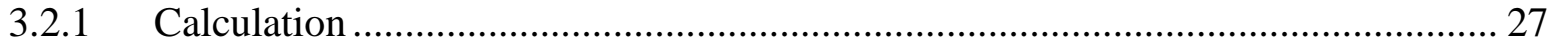




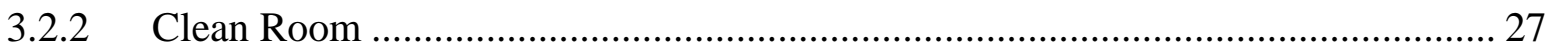

3.3 Particle Sizing and Sampling System................................................................... 28

3.4 Particle Number Concentration and Size Spectrum Characterization via TSI-EEPS .... 29

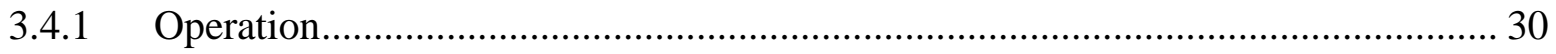

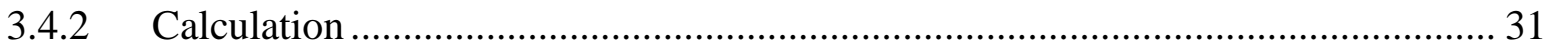

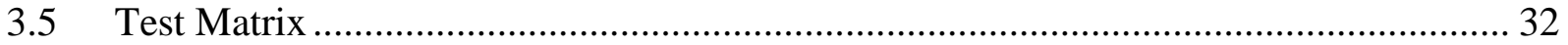

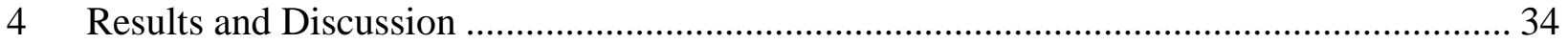

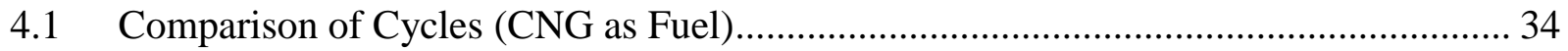

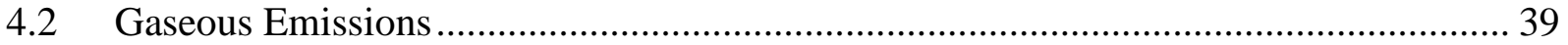

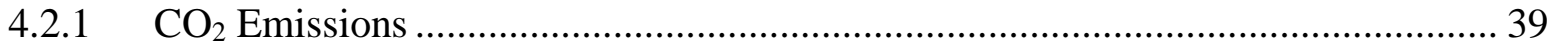

4.2.2 CO Emissions............................................................................................. 41

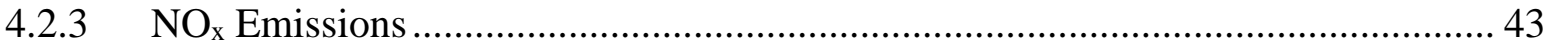

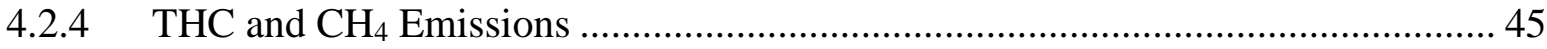

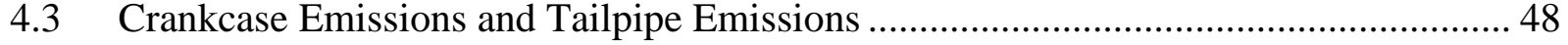

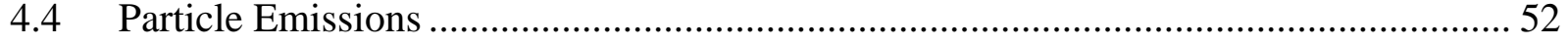

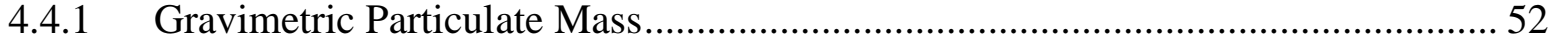

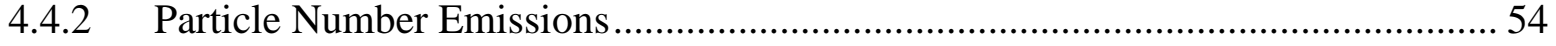

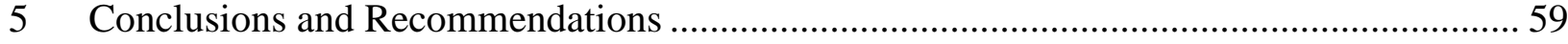

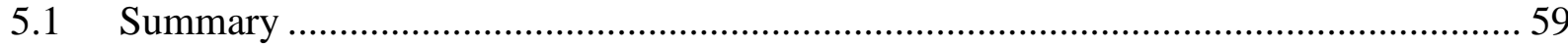

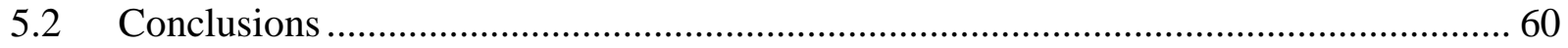

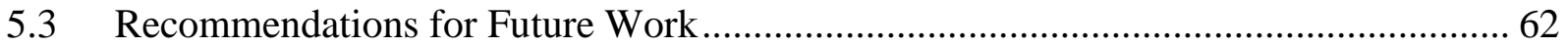

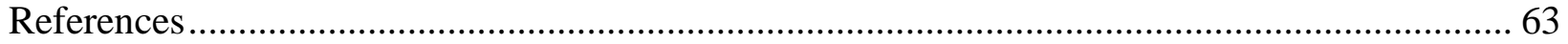




\section{List of Figures}

Figure 2.1: Typical engine exhaust particle size distribution with mass and number weightings.. 7

Figure 2.2: Typical composition and structure of engine exhaust particles .............................. 8

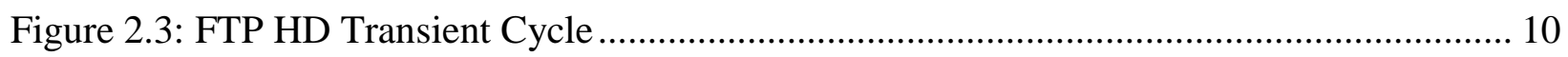

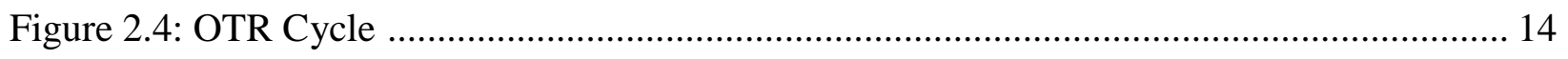

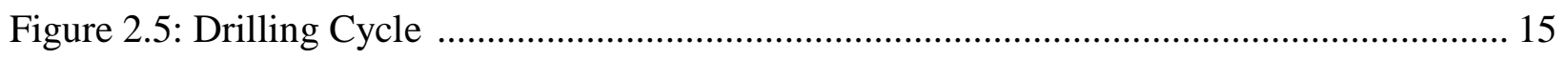

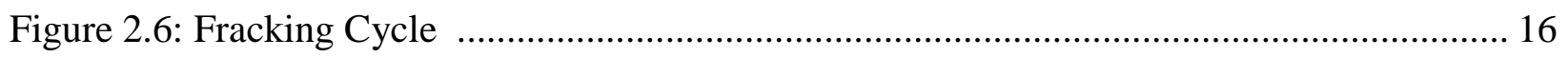

Figure 3.1: Full flow Constant Volume Sampling System [shown in 1] with sub-sonic venturi

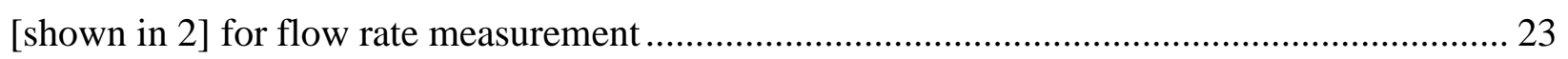

Figure 3.2: Horiba Automotive Emissions analyzer system MEXA-7200D with oven at the EERL,

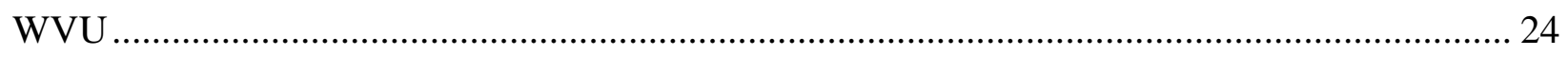

Figure 3.3: Los Gatos Research (LGR) Ultraportable Greenhouse Gas Analyzer ................... 25

Figure 3.4: 40 CFR 1065 compliant PM sampling system at WVU CAFEE's EERL facility ..... 26

Figure 3.5: Clean Room at the WVU CAFEE's EERL facility ........................................... 28

Figure 3.6: Experimental setup for particle number and mass measurement ........................... 29

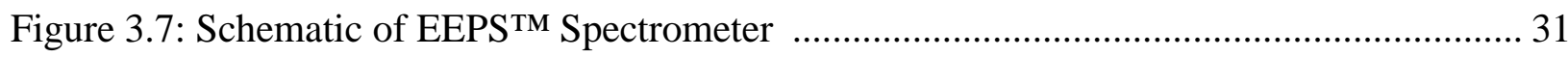

Figure 4.1: Cycle integrated work performed over the Test Cycles [bhp-hr] ........................... 35

Figure 4.2: Diesel-gallon equivalent BSFC for Test Cycles with CNG as Fuel....................... 36

Figure 4.3: $\mathrm{CO}_{2}$ Emissions for the Test Cycles with $\mathrm{CNG}$ as Fuel ........................................ 37

Figure 4.4: CO Emissions for the Test Cycles with CNG as Fuel.......................................... 37

Figure 4.5: $\mathrm{NO}_{\mathrm{x}}$ Emissions for the Test Cycles with CNG as Fuel ......................................... 38

Figure 4.6: THC and $\mathrm{CH}_{4}$ Emissions for the Test Cycles with CNG as Fuel........................... 39

Figure 4.7: Effect of $\mathrm{NG}$ fuel blends on $\mathrm{CO}_{2}$ Emissions ................................................ 40

Figure 4.8: Effect of NG fuel blends on CO emissions ....................................................... 42

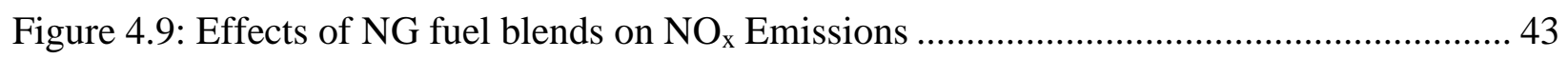

Figure 4.10: Comparison of measured raw $\mathrm{NO}_{\mathrm{x}}$ and background corrected $\mathrm{NO}_{\mathrm{x}}$ emissions ....... 44

Figure 4.11: Effects of NG fuel blends on THC Emissions ................................................... 46

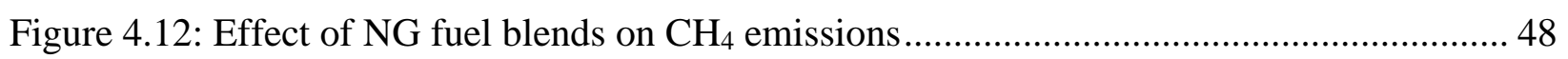

Figure 4.13: Crankcase Methane Emissions in comparison to Tailpipe Methane Emissions (CNG as fuel)....... 
Figure 4.14: Crankcase FSME in comparison to the Tailpipe FSME (Blend 1 as fuel)............. 50

Figure 4.15: Crankcase FSME in comparison to Tailpipe FSME (Blend 2 as fuel) ................. 51

Figure 4.16: Effect of NG Blends on the particulate matter mass emissions (in milligrams) ...... 53

Figure 4.17: Effect of NG blends on the PN Emissions (\#/bhp-hr) ....................................... 54

Figure 4.18: Size distribution of PN concentration for Trucking Cycle .................................. 56

Figure 4.19: Size distribution of PN concentration for Drilling Cycle .................................... 57

Figure 4.20: Size distribution of PN concentration for Fracking Cycle .................................. 58 


\section{List of Tables}

Table 2.1: US EPA Emissions Standards for Heavy-Duty Engines in $\mathrm{g} / \mathrm{bhp}-\mathrm{hr}$....................... 4

Table 2.2: Tier 4 Emissions Standards for Non-Road Compression Ignition Heavy-Duty Engines

Table 2.3 Non-road Emissions Standards for Non-road Spark-ignited Engines ........................ 5

Table 2.4: Type D2 Speed and Torque along with weighting factors .................................... 10

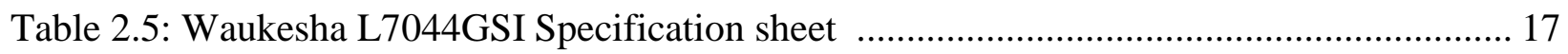

Table 2.6: Cummins ISL-G Specification sheet ................................................................ 18

Table 2.7: Marcellus Shale Gas Composition ..................................................................... 19

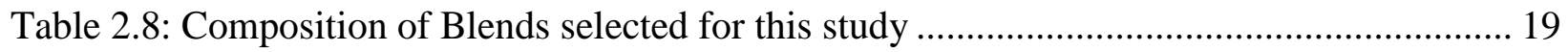

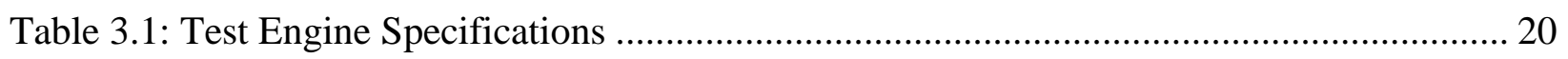

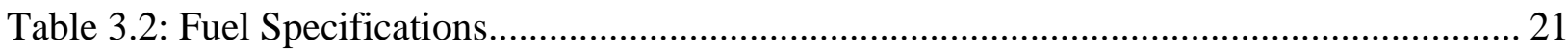

Table 3.3: List of gas analyzers comprising the Horiba MEXA-7200D analyzer system........... 23

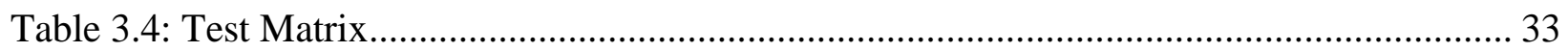

Table 4.1: $\mathrm{CO}_{2}$ Emissions Data used in this study.......................................................... 41

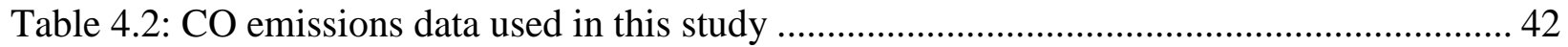

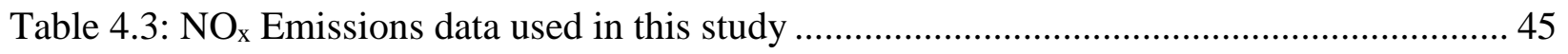

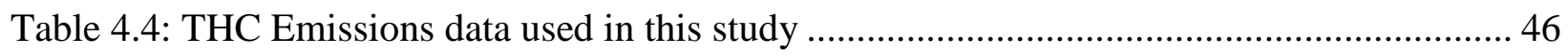

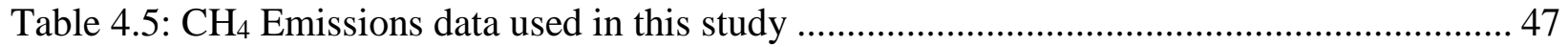

Table 4.6: Comparison of total methane emissions from CC and TP with comparison of the CC

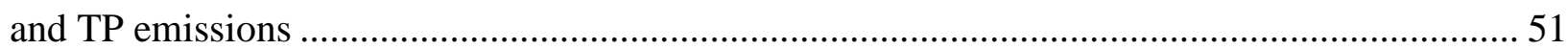

Table 4.7: Gravimetric PM emissions data used in this study ............................................... 53

Table 4.8: PN emissions data for nucleation mode particles .............................................. 55

Table 4.9: PN Emissions data for accumulation mode particles ............................................ 55

Table 5.1 Summary of correlations of fuel properties with the gaseous and particle emissions .. 61 


\section{Introduction}

Natural gas reserves have been found in abundance in the United States of America (USA). The U.S. Energy Information Administration (EIA) estimates about 2,418 trillion cubic feet (Tcf) of natural gas reserves in the USA, as of January 1, 2016. At a consumption rate of 27.5 Tcf per year these sources are enough to last about 90 years [1]. This increased supply has led to a gradual shift from diesel engines to dedicated natural gas engines. Recent technologies and extraction methods have led to an increase of shale gas development [2]. These new extraction methods have seen radical development of technologies such as horizontal/directional drilling and hydraulic fracturing. As of 2016, EIA estimates that there are 553,495 gas producing wells in the USA [3]. This availability of natural gas resource suggests that natural gas could serve as a source of fuel until around 2100 [4]. The US EIA has recognized areas with large number of wells as "shale plays". These are the areas in which pockets of natural gas are available deep below the surface. The important shale plays in US are the Barnett shale play and the Marcellus shale play as these regions have the largest natural gas reserves [5]. In addition to these two, there are shale formations in more than 30 states of the USA [3].

Significant quantities of natural gas can be obtained from these wells if they are horizontally drilled and hydraulically fractured. This process of constructing, drilling and hydraulically fracturing a well is energy intensive. A single unconventional natural gas well construction can consume thousands of gallons of fuel [6]. The fuel, generally diesel fuel, is consumed by what are known as "prime-movers" [7]. These prime-movers are responsible for the process required to complete an unconventional natural gas well; over-the-road (OTR) truck, high-horsepower drilling, and high-horsepower hydraulic fracturing engines. The preparation of the site involves OTR trucks for delivery and removal of gravel, dirt and other materials. Then the sites are drilled where highhorsepower engines are used to power drilling rigs. The most energy intensive step is the hydraulic fracturing which involves the use of high-horsepower fracturing engines and large amounts of truck traffic for delivery of water, sand and fracturing chemicals.

To reduce the diesel fuel costs involved in production of unconventional gas wells and to move towards substituting domestic natural gas for diesel fuel, the U.S. Department of Energy (DOE) contracted West Virginia University (WVU) to assess the fugitive methane emissions from using natural gas engines in unconventional resource development. Under this agreement, DE- 
FE0013689, WVU was tasked to examine the gaseous emissions of a high power dedicated natural gas engine (representative engine) [8].

To use a specific composition of fuel as fuel for the prime movers, it's emissions must be within the regulated standards. The fuel compositions at various shale play regions where unconventional well developments are in progress were surveyed [9]. These regions include the Marcellus shale play, the Barnett shale play, and Fayetteville shale play. Two natural gas fuel blends were selected to be representative of the fuel compositions obtained from the above-mentioned shale play regions. Commercially available compressed natural gas (CNG) that complies with the standards and has the required methane content was used as a reference fuel. Tests were performed on an 8.9-L stoichiometric operating natural gas engine installed on a 500 horse-power (HP) engine dynamometer capable of running both steady state and transient type test cycles. Gaseous emissions were measured using the Horiba ${ }^{\circledR}$ MEXA 7200D and particle number emissions were measured using TSI ${ }^{\circledR}$ Engine Exhaust Particle Sizer (EEPS ${ }^{\mathrm{TM}}$ ).

\subsection{Objectives}

Natural gas composition variety poses challenges with respect to performance and emissions. Using natural gas also presents the problem of greenhouse gas (GHG) emissions as the GHG potential of natural gas is 21 times that of carbon dioxide $\left(\mathrm{CO}_{2}\right)$. This motivates the need of additional understanding of regulated and unregulated emissions associated with dedicated natural gas technologies employed at shale gas development.

The global objective of this study is to demonstrate the effects of using natural gas blends as fuel for the prime movers of the unconventional well development. In order to achieve this global objective, this study has been focused at the following specific objectives.

- Examining the gaseous emissions of the natural gas blends and comparing them with the emissions of CNG. A detailed analysis would be presented comparing the emissions of the in-use activity cycles to that of the standard regulatory test cycles.

- Examining the crankcase methane emissions and comparing it to the tailpipe methane emissions.

- Particle emissions (both PM and PN) would be examined for the natural gas blends and CNG. 


\section{Literature Review}

The literature review will begin by detailing the emissions regulations that all the engine manufactures must adhere to in Section 2.1. Particle emissions, size, characteristics and distribution will be explained in Section 2.2. A detailed explanation will be provided on the Particle Mass (PM) Emissions and Particle Number (PN) emissions and their regulations. Having established the emission regulations of, both, the gaseous and particle emissions, Section 2.3 will shed light on the certification cycles over which the engines are certified by the Environmental Protection Agency (EPA). Section 2.4 details the fundamental concept of Methane Number (MN) and Wobbe Index (WI) to understand their effects on emissions that will be discussed in the results chapter. Section 2.5 provides an insight into studies conducted by other researchers along with their research methodology, their results and shows how we build on the research conducted by them. It also mentions how this research differs from their focus of work.

Being a part of DOE funded research project, a part of the research work was conducted prior to this study, especially, the generation of the in-use test cycles for the drilling and hydraulic fracturing activities [4]. Section 2.6 briefly explains the methodology of cycle generation. It also highlights the data that was collected to create the test cycles which in turn reflects our scope of study.

Section 2.7 will be an area of primary interest as it covers the engine selected to represent the large engines used for unconventional well development. This section also proves why the engine selected is an apt representation of the large engines. For this study, a selection of natural gas fuel blends was used as representative of the natural gas compositions obtained in the shale play regions. Section 2.8 highlights the various natural gas compositions at different shale and emphasizes on why these specific blends of natural gas were selected for this study.

\subsection{Emissions Regulations}

All engines, used for on-road and non-road applications, must conform to the emissions standards put forward by the United States Environment Protection Agency (US EPA) and the California Air Resource Board (CARB). These engines are certified over certification test cycles as mentioned in 40 CFR Part 1065 (for on-road engines) and 40 CFR 1048 (for non-road engines). 


\subsubsection{On-Road Heavy-Duty Engines}

Emissions standards for engines and vehicles, including the GHG emissions are set by the US EPA and they are established based on the Clean Air Act which was last ammended in 1990. Emissions regulations have become stringent over the years, especially for on-road heavy-duty vehicles with a gross vehicle weight rating (GVWR) above 8,500 lbs. Table 2.1 shows the current mandatory emissions standards for heavy-duty engines that were phased-in over 2007-2010.

Table 2.1: US EPA Emissions Standards for Heavy-Duty Engines in g/bhp-hr [10]

\begin{tabular}{|c|c|c|c|c|c|c|c|}
\hline Year & $\begin{array}{c}\text { Gross } \\
\text { Vehicle } \\
\text { Weight } \\
\text { (lbs.) }\end{array}$ & $\begin{array}{c}\text { CO } \\
\text { (g/bhp- } \\
\text { hr) }\end{array}$ & $\begin{array}{c}\text { NMHC } \\
\text { (g/bhp- } \\
\text { hr) }\end{array}$ & $\begin{array}{c}\text { HC } \\
\text { (g/bhp- } \\
\text { hr) }\end{array}$ & $\begin{array}{c}\text { NOx } \\
\text { (g/bhp- } \\
\text { hr) }\end{array}$ & $\begin{array}{c}\text { NOx + } \\
\text { NMHC } \\
\text { (g/bhp-hr) }\end{array}$ & $\begin{array}{c}\text { PM } \\
\text { (g/bhp- } \\
\text { hr) }\end{array}$ \\
\hline $\begin{array}{l}\text { Prior to } \\
\text { Control }\end{array}$ & - & 155 & - & 12.7 & - & 6.86 & - \\
\hline $1970-73$ & - & $1.50 \%$ & - & $275 \mathrm{ppm}$ & - & - & - \\
\hline $1974-78$ & - & 40 & - & - & 16 & - & - \\
\hline 1979-84 & - & 25 & - & 1.5 & 10 & & \\
\hline $1985-86$ & & 37.1 & - & 1.9 & - & 10.6 & - \\
\hline \multirow{2}{*}{1987} & $\leq 14,000$ & 14.4 & - & 1.1 & - & 10.6 & - \\
\hline & $\geq 14,000$ & 37.1 & - & 1.9 & - & 10.6 & - \\
\hline \multirow{2}{*}{$1988-90$} & $\leq 14,000$ & 14.4 & - & 1.1 & - & 6.0 & - \\
\hline & $\geq 14,000$ & 37.1 & - & 1.9 & - & 6.0 & - \\
\hline \multirow{2}{*}{1990} & $\leq 14,000$ & 14.4 & - & 1.1 & - & 6.0 & - \\
\hline & $\geq 14,000$ & 37.1 & - & 1.9 & - & 6.0 & - \\
\hline \multirow{2}{*}{$1991-97$} & $\leq 14,000$ & 14.4 & - & 1.1 & - & 5.0 & - \\
\hline & $\geq 14,000$ & 37.1 & - & 1.9 & - & 5.0 & - \\
\hline \multirow{2}{*}{$\begin{array}{l}1998- \\
2004 \\
\end{array}$} & $\leq 14,000$ & 14.4 & - & 1.1 & - & \multirow{2}{*}{4.0} & - \\
\hline & $\geq 14,000$ & 37.1 & - & 1.9 & - & & - \\
\hline \multirow{2}{*}{$\begin{array}{l}2005- \\
2007\end{array}$} & $\leq 14,000$ & 14.4 & - & 1.1 & - & - & - \\
\hline & $\geq 14,000$ & 37.1 & - & 1.9 & - & - & - \\
\hline $2008+$ & All & 14.4 & 0.14 & - & 0.20 & - & 0.01 \\
\hline
\end{tabular}

\subsubsection{Non-Road Heavy-Duty Engines}

In this study, an engine that is representative of the non-road engines used for unconventional well development was selected. Hence, it is important to look at the non-road emissions standards for heavy-duty engines. The non-road heavy-duty emissions regulations are shown in Table 2.2. The 
emissions regulations presented for Tier 4, model year (MY) 2011-2013 represents the phase-out emissions standards. Engine manufacturers are allowed not more than 50 percent of engine production in each model year of the phase out period [11]. The emissions standards shown for Tier 4, MY 2014+ are final and at least 50 percent of a manufacurer's engine production must meet these standards [11]. The emissions standards presented in Table 2.2 are converted from $\mathrm{g} / \mathrm{kW}$-hr to $\mathrm{g} / \mathrm{bhp}$-hr to be consistent with the results of this study. The standards, in $\mathrm{g} / \mathrm{kW}$-hr, were divided by a factor of 1.341 to convert them to g/bhp-hr [12].

Table 2.2: Tier 4 Emissions Standards for Non-Road Compression Ignition Heavy-Duty Engines [11]

\begin{tabular}{|c|c|c|c|c|c|c|c|}
\hline $\begin{array}{l}\text { Rated } \\
\text { Power }\end{array}$ & Tier & Model Year & $\begin{array}{l}\text { NMHC } \\
\text { (g/bhp-hr) }\end{array}$ & $\begin{array}{c}\text { NMHC+NOx } \\
\text { (g/bhp-hr) }\end{array}$ & $\begin{array}{c}\text { NOx } \\
(\mathrm{g} / \mathrm{bhp}-\mathrm{hr})\end{array}$ & $\begin{array}{c}\text { PM } \\
\text { (g/bhp- } \\
\text { hr) }\end{array}$ & $\begin{array}{c}\text { CO } \\
\text { (g/bhp- } \\
\text { hr) }\end{array}$ \\
\hline \multirow{5}{*}{$\begin{array}{c}175 \leq \mathrm{hp} \\
\quad<300\end{array}$} & 1 & 1996-2002 & 1.0 & - & 6.9 & 0.40 & 8.5 \\
\hline & 2 & 2003-2005 & - & 4.9 & - & 0.15 & 2.6 \\
\hline & 3 & $2006-2010$ & - & 3.0 & - & 0.15 & 2.6 \\
\hline & \multirow{2}{*}{4} & 2011-2013 & - & 3.0 & - & 0.01 & 2.6 \\
\hline & & $2014+$ & 0.1 & - & 0.3 & 0.01 & 2.6 \\
\hline \multirow{5}{*}{$\begin{array}{c}300 \leq \mathrm{hp} \\
<600\end{array}$} & 1 & 1996-2000 & 1.0 & - & 6.9 & 0.40 & 8.5 \\
\hline & 2 & 2001-2005 & - & 4.8 & - & 0.15 & 2.6 \\
\hline & 3 & 2006-2010 & - & 3.0 & - & 0.15 & 2.6 \\
\hline & \multirow{2}{*}{4} & 2011-2013 & - & 3.0 & - & 0.01 & 2.6 \\
\hline & & $2014+$ & 0.1 & - & 0.3 & 0.01 & 2.6 \\
\hline
\end{tabular}

Table 2.3 Non-road Emissions Standards for Non-road Spark-ignited Engines [13]

\begin{tabular}{|c|c|c|c|c|c|c|c|}
\hline \multirow{2}{*}{ Tier } & \multirow{2}{*}{ Year } & \multicolumn{2}{|c|}{$\begin{array}{c}\text { General Duty-Cycle } \\
\text { Standards }\end{array}$} & \multicolumn{2}{c|}{$\begin{array}{c}\text { Alternative standards for } \\
\text { Severe-duty engine }\end{array}$} & \multicolumn{2}{|c|}{$\begin{array}{c}\text { Field Testing } \\
\text { Standards }\end{array}$} \\
\cline { 3 - 8 } & & $\begin{array}{c}\text { HC+NOx } \\
\text { (g/bhp-hr) }\end{array}$ & $\begin{array}{c}\text { CO } \\
\text { (g/bhp-hr) }\end{array}$ & $\begin{array}{c}\text { HC+NOx } \\
\text { (g/bhp-hr) }\end{array}$ & $\begin{array}{c}\text { CO } \\
(\mathbf{g} / \mathbf{b h p}- \\
\text { hr) }\end{array}$ & $\begin{array}{c}\text { HC+NOx } \\
\text { (g/bhp-hr) }\end{array}$ & $\begin{array}{c}\text { CO } \\
\text { (g/bhp- } \\
\text { hr) }\end{array}$ \\
\hline 1 & $2004-2006$ & 3.0 & 37.3 & 3.0 & 96.9 & - & - \\
\hline 2 & $2007+$ & 2.0 & 3.3 & 2.0 & 96.9 & 2.8 & 4.8 \\
\hline
\end{tabular}

Table 2.3 presents the emissions standards for non-road spark-ignited engines. The engine selected for this study is a 2008 MY SI engine, hence, interest lies in the Tier 2, 2007+ emissions standards. 


\subsection{Particle Emissions, Characteristics and Composition}

The atmosphere is a multiphase system consisting of solid and gaseous particles which, together, are termed as 'aerosol'. The atmospheric aerosols are broadly classified into i) natural background aerosol dominated by biological, biogenic, oceanic and geogenic particles and ii) anthropogenic aerosols contributing through combustion, material disintegration (e.g. unpaved road surfaces) and sundry high-temperature industrial processes [14]. This conglomerate of particles can cause adverse health effects and their emissions must be regulated [15]. The size of particles is of specific importance as it determines the effect on health aspects, such as respiratory tract deposition as well as adverse environmental effects such as smog, visibility reduction, solar forcing and atmospheric photochemistry. In this study, the discussion is limited to the anthropogenic aerosol particles originating from internal combustion engine sources. The literature provided, also addresses the particle characteristics from engine exhaust and tries to provide insight on the compositions of these exhaust particles.

\subsubsection{Particle Size Distribution}

The variation of the size of aerosol particles is vast, ranging from the minutest molecular cluster to, by comparison, large particles of hundreds of microns. The particle size emitted as a by-product of combustion from an engine typically ranges from 0.005-0.3 $\mu \mathrm{m}$ [16]. The size distribution of particles is effectively continuous. Figure 2.1 shows the typical engine exhaust particle number and mass weighted size distribution.

The three characteristic particle size modes are termed as the nucleation mode, accumulation mode and the coarse mode. The number weighting is represented by the solid curve and the dotted curve represents the mass weighting (assuming spherical particles and constant density). This distribution presented by Kittelson is trimodal, lognormal in form. The area under the curve of a size range represents the concentration of particles in the corresponding size range. It may be observed from the above figure that most of the particle mass is contributed by the particles in accumulation mode, i.e., particles with diameter in the 0.1-0.3 $\mu$ m range. The nuclei mode mostly contains particles of the size $<50 \mathrm{~nm}$ or $0.05 \mu \mathrm{m}$ [16]. 


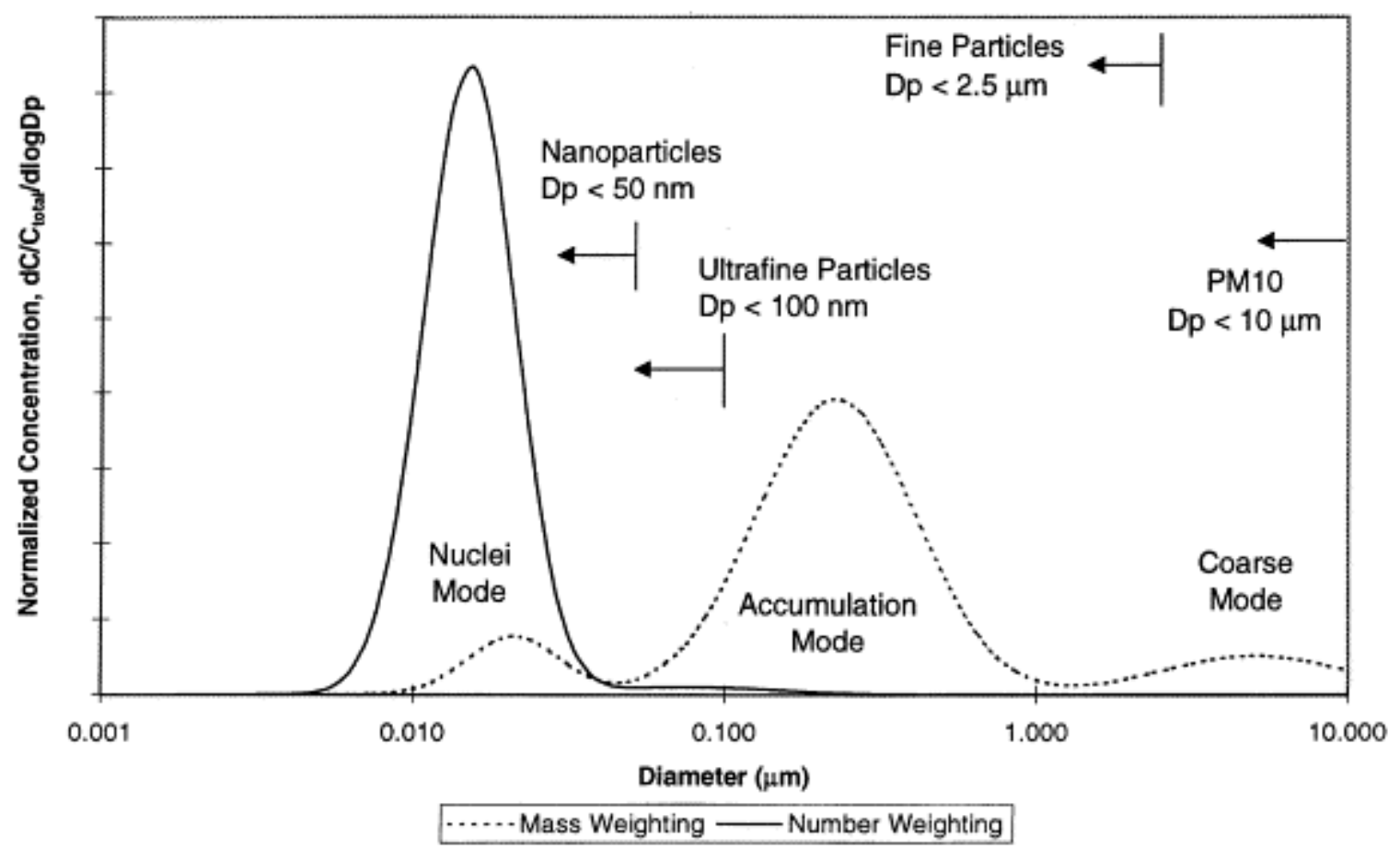

Figure 2.1: Typical engine exhaust particle size distribution with mass and number weightings [16]

\subsubsection{Particle Physical Characteristics}

The particle emissions from an internal combustion engine are a mixture of volatile materials (organics, sulfates, and nitrate fraction) and non-volatile materials (soot and ash) [17]. The engine soot particles may have complex physical and chemical properties depending on the engine operating conditions and the fuel composition [18]. Eastwood divides the particle composition into four fractions namely the carbonaceous fraction, the ash fraction, the organic fraction and the sulfate fraction [14]. Figure 2.2 shows the typical composition and structure of engine exhaust particles.

Solid carbon particles are formed due to the combustion of locally rich regions. The volatile or soluble organic fraction (SOF) is formed when fuel and lube oil escape oxidation. When sulfur is oxidized, a fraction of it oxidizes to form $\mathrm{SO}_{3}$ which leads to the formation of sulfates and sulfuric acid in the exhaust particles [16]. Incomplete combustion inside the combustion chamber is the prime reason for the emission of soot particles from the engine. 


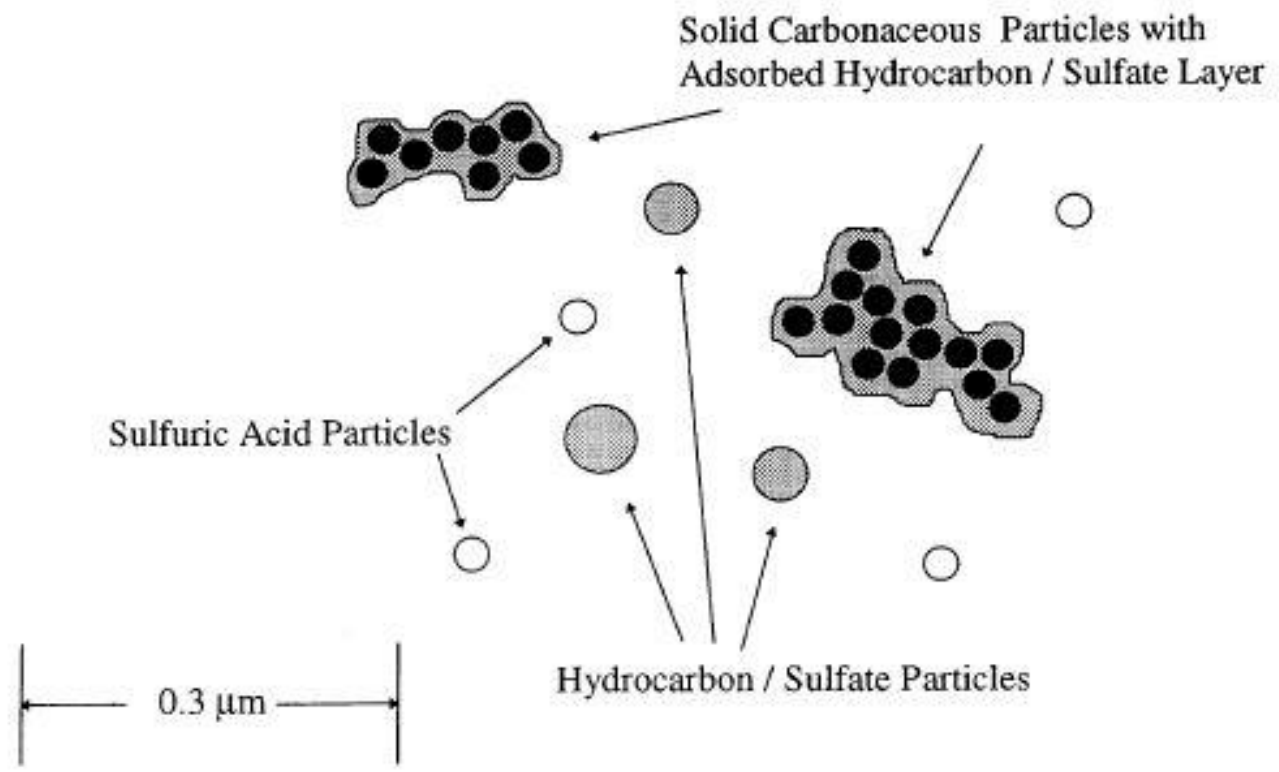

Figure 2.2: Typical composition and structure of engine exhaust particles [16]

\subsubsection{Particle Emissions Regulations}

United States (US) and Europe (EU) follow different standards when it comes to particle emissions. US standards focuses on the PM emissions and the EU regulations focuses both on the $\mathrm{PM}$ and $\mathrm{PN}$ emissions.

United States (US) Regulations: According to EPA, the term particulate matter encompasses the solid and liquid particles found in the air. Two size ranges, known as $\mathrm{PM}_{10}$ and $\mathrm{PM}_{2.5}$ are monitored. $\mathrm{PM}_{10}$ signifies the particles that have aerodynamic diameters less than 10 microns $(\mu \mathrm{m})$, approximately equal to one-seventh the diameter of human hair. $\mathrm{PM}_{2.5}$ is a subset of PM10 and has particles with aerodynamic diameter less than $2.5 \mu \mathrm{m}$. PM is a mass quantity and the regulated quantity, like all other gaseous emissions, is given in g/bhp-hr. As Table 2.1 shows, the regulated quantity for heavy-duty engines is $0.01 \mathrm{~g} / \mathrm{bhp}-\mathrm{hr}$. This includes particles that are less than $10 \mu \mathrm{m}$ in size. The pre-cyclonic separator installed as part of the PM sampling system removes at least $50 \%$ of the PM at an aerodynamic diameter of $10 \mu \mathrm{m}$ and no more than $1 \%$ of PM at an aerodynamic diameter of $1 \mu \mathrm{m}$ [19]. There has been a drop in the regulated emission quantity from 2004 to 2007 owing to the adverse health effects of PM emissions [20].

European (EU) Regulations: Euro VI emissions standards were introduced by Regulation 595/2009 [21]. These emission limits are comparable to US 2010 standards, and, were enforced 
starting from 2013/2014. PN emission limits were introduced in the May 2011 revision of Euro VI regulations. The PN emissions for World Harmonized Stationary Cycle (WHSC) is $8 \times 10^{11}$ $(\# / \mathrm{kWh})$ and for World Harmonized Transient Cycle is $6 \times 10^{11}$ (\#/kWh) [21]. In this study, though, PN emissions would be discussed in terms of \#/bhp-hr instead of \#/kWh. Thus, the regulated emissions may be represented as $5.96 \times 10^{11} \# / \mathrm{bhp}-\mathrm{hr}$ and $4.4 \times 10^{11} \# / \mathrm{bhp}-\mathrm{hr}$ respectively.

\subsection{Certification Cycles}

To evaluate the engine's compliance with emissions regulations, all heavy-duty engines intended for sale in USA are subjected to engine certification and compliance testing by the US EPA. There are specific emissions standards for different types of engines as a function of their size, and power rating, and the code of federal regulations (CFR) describes test procedures for each of them based on their mode of combustion, and power rating. For this project, interest lies in the on-road heavyduty engine testing procedure and non-road heavy-duty engine testing procedure. Heavy-duty highway engines must be certified over the FTP Transient cycle and the Supplemental Emissions Test (SET), according to 40 CFR Part 1065.

Non-road heavy-duty spark-ignited engines are certified according to the emission standards and certification requirements mentioned in 40 CFR Part 1048 [22]. The 40 CFR Part 1048 illustrates testing procedures for various kinds of steady-state engines. These testing procedures include duty cycles for discrete-mode testing and ramped-model (includes transition modes) testing [23]. The engine selected for this project, an on-road HD SI engine, has been simulated to represent a constant speed auxiliary engine. According to 40 CFR Part 1048, engines from engine family that would be used only at a single, rated speed, use the 5-mode duty cycle as per 40 CFR 1039, Appendix II (\$1048.505) [23]. The discrete-mode duty cycle that applies for constant speed engines is the D2 mode cycle [24].

\subsubsection{FTP Test Cycle}

The FTP (Federal Test Procedure) heavy-duty transient cycle is used for certifying on-road heavyduty engines over federal regulatory emission limits. This cycle considers a variety of driving patterns in major American population centers, including traffic on expressways and in urban areas. It consists of four phases, including (1) New York Non-Freeway (NYNF) phase typical of urban traffic with frequent starts and stops, (2) Los Angeles Non-Freeway (LANF) phase typical 
of urban traffic with few stops, (3) Los Angeles Freeway (LAFY) phase consisting of crowded expressway traffic of Los Angeles, and (4) a repetition of the first NYNF phase. As shown in Figure 2.3, the first phase of NYNF is a cold start phase and the last phase of NYNF is a hot start phase.
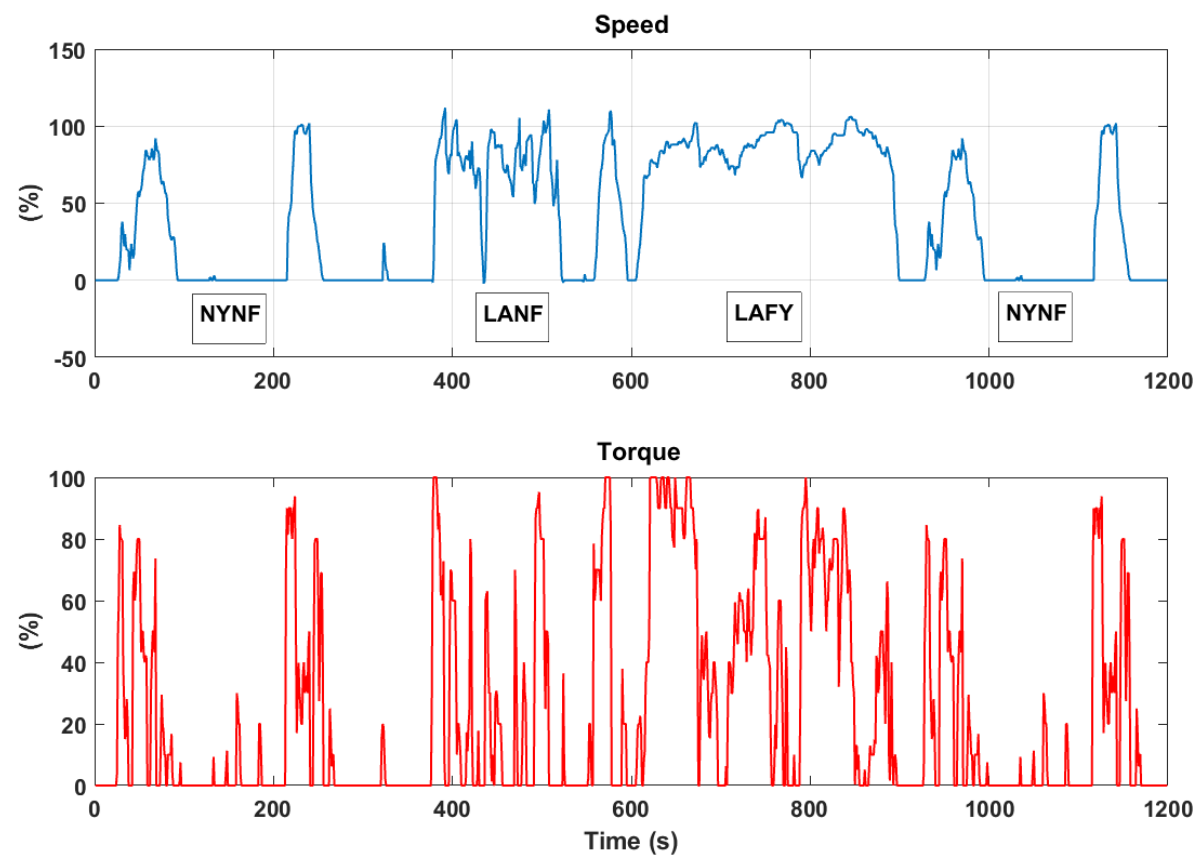

Figure 2.3: FTP HD Transient Cycle

\subsubsection{D2 Mode Cycle}

As mentioned earlier, nonroad SI engines are certified as per the emissions standards and certification requirements mentioned in 40 CFR 1048 [23]. D-2 mode cycle is used as duty cycle for engine operated over constant-speeds [24]. The D2 duty cycle contains a sequence of steadystate modes with different weighing factors as shown in Table 2.4.

Table 2.4: Type D2 Speed and Torque along with weighting factors [24]

\begin{tabular}{|l|c|c|c|c|c|}
\hline Mode Number & 1 & 2 & 3 & 4 & 5 \\
\hline Torque \% & 100 & 75 & 50 & 25 & 10 \\
\hline Speed & \multicolumn{5}{|c|}{ Rated Speed } \\
\hline \begin{tabular}{l} 
Type D2 $\begin{array}{l}\text { Weighting } \\
\text { Factors }\end{array}$ \\
\hline
\end{tabular} & 0.05 & 0.25 & 0.3 & 0.3 & 0.1 \\
\hline
\end{tabular}


The weighting factors are used to calculate emission values for each mode respectively.

\subsection{Methane Number \& Wobbe Index}

Before this study presents information about the different test fuels and results of their effects on emissions, it is important to know about two important characteristics of CNG; Methane Number (MN) and Wobbe Index (WI). These two characteristics of a natural gas fuel determine the combustion performance and emissions characteristics of the engine.

\subsubsection{Methane Number (MN)}

Methane number is a measure of knock resistance of a gas fuel. This knock occurs due to the autoignition of the fuel-air mixture ahead of the flame propagation. $\mathrm{MN}$ is determined by comparing the compression ratio at which the fuel knocks to a reference fuel blend that knocks at the same compression ratio [25]. Pure methane has a $\mathrm{MN}$ of 100 and Hydrogen has a $\mathrm{MN}$ of 0 . If $\mathrm{MN}$ is too low, it may reduce the efficiency of the engine and lead to harmful engine emissions [26].

MN cannot be directly derived as a function of thermodynamic properties. Instead, MN is represented as a function of Motor Octane Number (MON). CARB determines the following relationship between $\mathrm{MN}, \mathrm{MON}$ and $\mathrm{H} / \mathrm{C}$ ratio [25]: For this study, a commercially available tool was used to calculate MN, based on engine manufacturer's recommendation [27].

$$
\begin{gathered}
M O N=-406.14+508.04 *\left(\frac{\mathrm{H}}{\mathrm{C}}\right)-173.55 *\left(\frac{H}{C}\right)^{2}+20.17 *\left(\frac{H}{C}\right)^{3} \\
M N=1.624 * M O N-119.1
\end{gathered}
$$

\subsubsection{Wobbe Index (WI)}

Wobbe Index (WI) is a measure of the interchangeability of a gaseous fuel. WI is used to compare the combustion energy output with different compositions of fuels [28]. Specifically, the WI is defined as the ratio of the Higher Heating Value (HHV) of the gas to the square root of the relative density (or specific gravity) of the gas.

$$
W I=\frac{H H V}{\sqrt{\text { Specific Gravity }}}
$$


Thus, WI also helps to determine the energy output of gaseous fuel. Two fuels of different compositions having the same Wobbe Index will have the same energy output [28] [29] [30].

\subsection{Emissions and Performance Results from Gaseous Fuel Combustion}

Virtually, no PM or soot is emitted from natural gas engines due to the absence of aromatic and sulfur compounds [31]. The $\mathrm{C} / \mathrm{H}$ ratio of natural gas is lowest among hydrocarbon fuels which results in the lowest $\mathrm{CO}_{2}$ emissions per unit of energy released [32]. Prior research has been done on the comparison of emissions from natural gas and diesel engines. Wang, et al. 1997, conducted extensive research on over 300 buses and trucks operating on alternative fuels such as natural gas, methanol and ethanol. Their results showed that natural gas had the lowest PM emissions when compared to other fuels [33]. A variety of alternate fuels were used by Wang et.al., such as M100 (100\% methane), E93 (93\% ethanol, 5\% methanol, 2\% K-1 kerosene by volume), E95 (95\% ethanol, 5\% gasoline) and other biodiesel fuels, and their emissions were compared with the emissions of diesel fuel operated engines. Their results concluded that NOx emissions from diesel and NG fuel were similar and that the alchohol fuels have lower NOx emissions. Hydrocarbon (HC) emissions reported in this study were also higher for the alternate fuels, including NG, when compared to diesel. The HC emissions reported in their work are total hydrocarbons (THC) measured using a flame ionization detector (FID). However, the report suggested that careful design of charge motion and proper air-fuel mixing might lower the HC emissions levels from NG and alchohol engines.

Karavalakis et. al. selected five CNG fuels with different compositions (blends). The MN of the fuels selected varied from 99 to 75.1. The blends were used to operate a $2003 \mathrm{C}$ Gas Plus, lean burn, spark ignited engine equipped in a transit bus. The engine, equipped with three-way catalyst (TWC), was operated over the Central Business District (CBD) test cycle. The report suggests that $\mathrm{CO}$ emissions were higher for gases containing higher hydrocarbon molecules and lower MN. NOx emissions were reported to increase with decreasing MN and increasing WI [32]. This is in line with the results from Wang et.al [33]. The PM mass emissions from the engine when operated with the different fuel blends showed no definitive trend. The PN emissions increased for lower methane number fuel blends when compared to the fuel blend with MN of 99. Lower PN emissions were observed from fuel blends with lower $\mathrm{MN}$ and heavier hydrocarbons. The PN size was concentrated towards the nucleation mode with a peak particle diameter of $10.8 \mathrm{~nm}$. It was also 
observed that the PN size concentration was virtually absent at the accumulation mode which justified the low PM mass emissions [32].

Min et.al. reported the effects of gas composition on performance and emissions of a CNG engine using a modified $1.5 \mathrm{~L}$ gasoline engine. The air-fuel $(\mathrm{A} / \mathrm{F})$ ratio was control using a fabricated engine control system. They used a wide variety of CNG fuel compositions with methane mole percent ranging from $100 \%$ to $75 \%$. NOx emissions slighlty increased with increasing WI. WI indicates the heating capacity per unit volume of gas, thus higher WI results in higher temperature of the gas in the cylinder, and thus, resulting in higher NOx emissions. The report also shows that the THC emissions increase with decreasing WI. For fuels with lower WI, larger quantities had to be supplied to the cylinder for optimum combustion, which in turn resulted in more hydrocarbon emissions [34].

Fiest, Landau and Harte conducted research to determine the feasibility of operating HD natural gas engines over a wide range of natural gas fuel compositions. For this, they selected five heavyduty natural gas engines, spanning a range of model years and technologies. Keeping the current study in mind, the trends and results obtained for the 2008 Cummins 8.9L ISL-G engine were of major interest. The engine was equipped with a TWC and $\mathrm{A} / \mathrm{F}$ ratio was controlled using an adaptive AF ratio controller. The test fuels selected ranged from MN of 75 to 100. The ISL-G engine showed little variation of NOx emissions for any test fuel. No correlation could be determined with WI and MN as the R-square value from the regression analysis was less than 0.5. The consistent low NOx emissions may be attributed to the high efficiency of the passive, threeway catalyst. CO emissions slightly decreased with increasing MN. No clear emission trend was observed for HC and PM emissions [35].

As this study focuses on the emissions from the prime movers of the unconventional well development it is important to observe the results of the emissions from in-use drilling and fracturing activitites. Johnson et.al. conducted a study where they selected three in-use engines operated over diesel, dual fuel and dedicated natural gas and analyzed the gaseous emissions produced from these engines [36]. The dedicated natural gas engine equipped with a three-way catalyst showed very low NOx emissions, that were 11.5 times lower than advertised values, when the engine was operated over steady-state and low-load transient activity [36]. 


\subsection{Procedure of Generation of the Test Cycles}

As part of the DOE project, Mr. Robert S. Heltzel, generated three test cycles to be representative of the real-world activity of the prime-movers of unconventional well development. These test cycles were i) over-the-road truck cycle, that represented the trucks servicing the unconventional well development industry, ii) drilling cycle, that represented the drilling activities involved for development of horizontal wells and iii) hydraulic fracturing cycle (fracking cycle), that represented the fracturing activities involved in the hydraulic fracturing. Data was collected meticulously to be able to accurately represent the real-world activities [4].

Over-the-Road Trucks: To generate a cycle representing the activities of over-the-road trucks, data were collected from heavy-duty diesel vehicles traveling to and from the site of unconventional natural gas wells in the Marcellus shale play region. These vehicles consisted of those hauling water, sand and gravel. Twenty-five vehicles were sampled of which 18 were water haulers, six were sand haulers and one carried gravel for site preparation. The engines powering these vehicles consisted of Cummins ISX-15 engines, Caterpillar C-15 engines, Volvo D13 engines and Mack MP8 engines. A HEM DAWN J1939 Mini Logger was used to record at a rate of one Hz. Continuous data, engine parameters, were collected from 30-seconds after start to keyoff event. 'Engine percent load at current speed', and 'engine speed' were the engine parameters of interest for the creation of cycles. Figure 2.4 shows the normalized over-the-road truck cycle.

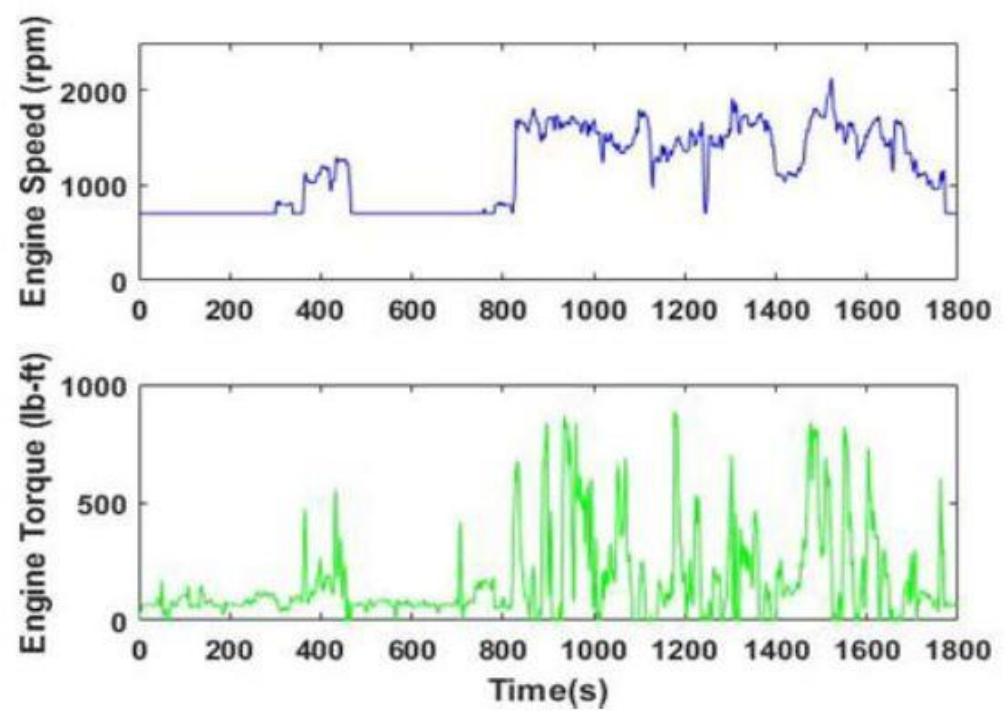

Figure 2.4: OTR Cycle [4] 
Drilling: To generate a representative drilling cycle, data was collected from dilling rigs of two horizontal wells at West Virginia (WV). These drilling rigs utilized three Caterpillar 3512C generator units, rated at $1476 \mathrm{hp}$ and were outfitted with DGB kits that allowed these engines to run in either dual-fuel or diesel only mode. The data recorded consisted of activities involved in rig setup, preparation, low-load transient pipe tripping, and steady-state drilling (SSD). A nine pin Deutsch connecter specifically wired for off-road Caterpillar engines was used to retrive data from engine control unit (ECU). All data collected exclusively were J1939. Again, the engine percent load and engine speed were considered necessary for cycle development. Figure 2.5 shows the Drilling Cycle.

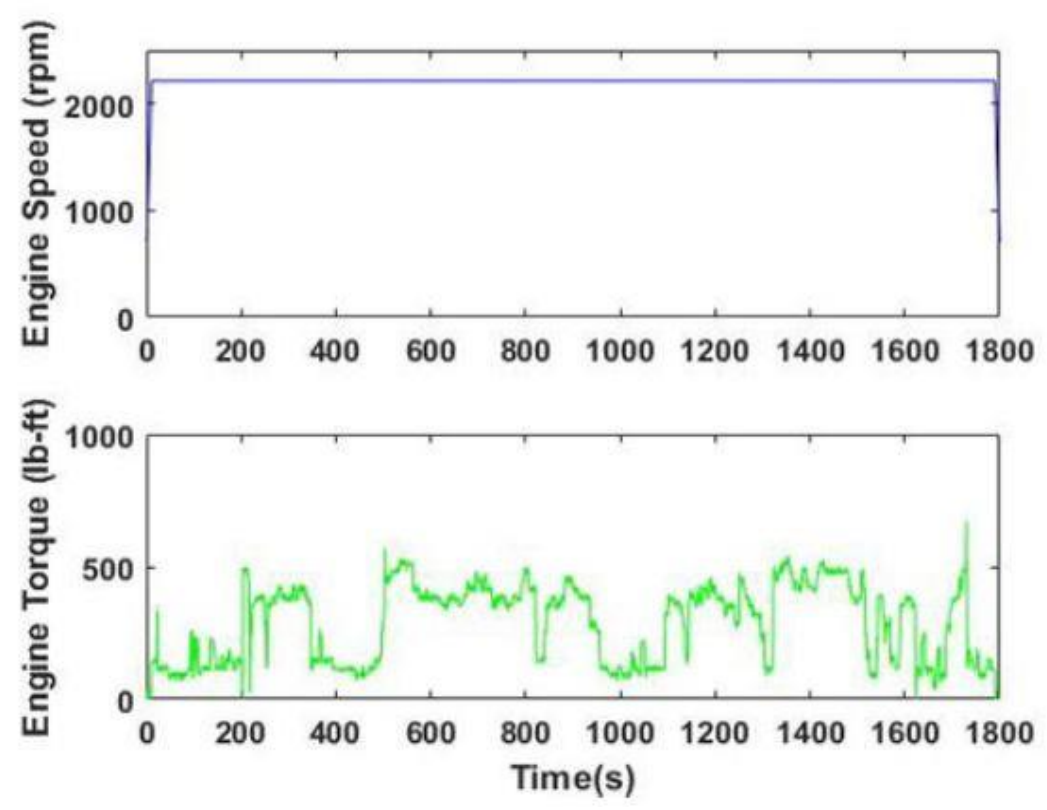

Figure 2.5: Drilling Cycle [4]

Hydraulic Fracturing: Data was collected from two different fleets of hydraulic fracturing, one from a well pad in central West Virginia and the other from the well pad located at WV. The hydraulic fracturing pumps were powered by Cummins QSK50, and 2008 Caterpillar 3512B HD engines, both rated at $2250 \mathrm{hp}$. Majority of data was collected similar to the drilling cycle, but using an auto-record feature of the data acquisition system that saved a file every hour. The engines operated typically on rated speed, hence, the engine percent load was of major importance. Figure 2.6 shows the normalized hydraulic fracturing cycle. 


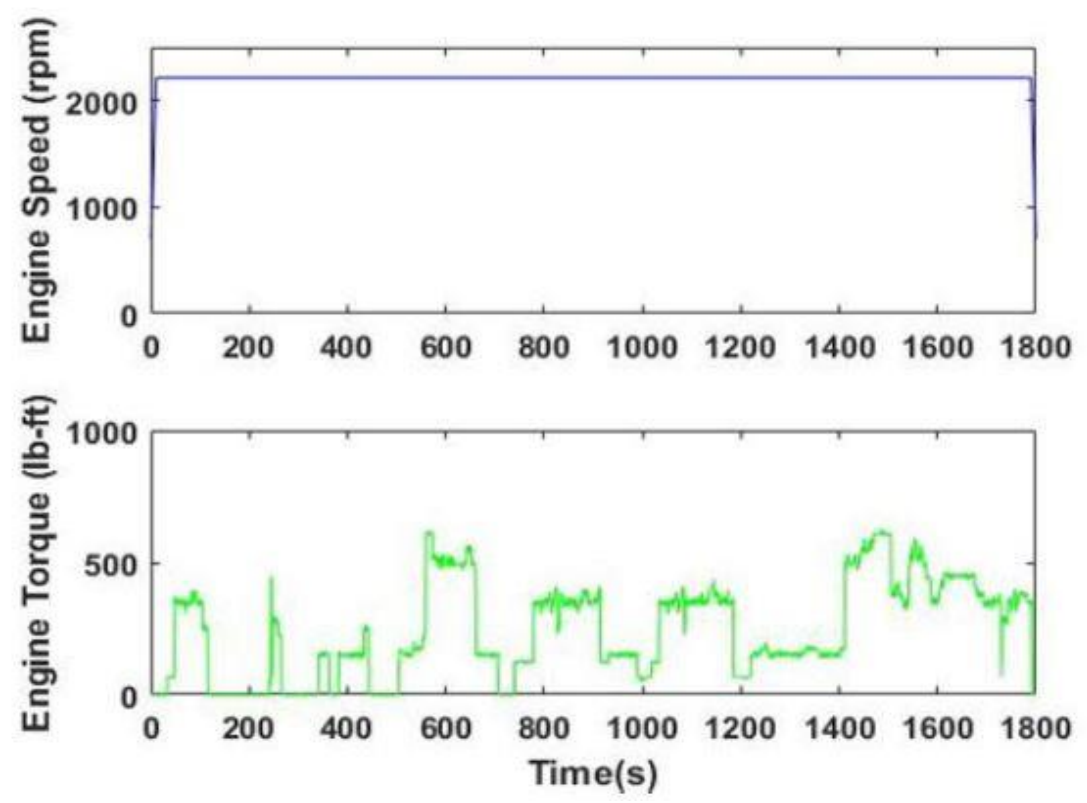

Figure 2.6: Fracking Cycle [4]

\subsection{Engines Used for Unconventional Well Development}

The major component of gas-driven drilling or fracturing operations is a prime mover in the form of an engine or turbine. The advantage of lower harmful emissions from a natural gas engine has led to the shift of using compression-ignition diesel engines to spark-ignited natural gas engines with either lean-burning or rich-burning capabilities [37]. The availability of natural gas is motivating the shift from diesel engines to natural gas heavy-duty engines. One such example of a natural gas engine for OTR trucks is by Cummins. Cummins-Westport has developed dual fuel engines as well as dedicated natural gas engines. Cummins has two dedicated natural gas engines, the ISL $\mathrm{G}$ and the ISX12 G that are used for OTR trucks. The ISX12 G, a 11.9-liter, six-cylinder, in-line engine and is rated up to $400 \mathrm{HP}$ with $1450 \mathrm{lb}-\mathrm{ft}$ of torque, is commonly used for line-haul and regional-haul truck/tractor applications [38]. The Westport dual-fuel HDPI 2.0 engine uses natural gas as the primary fuel and diesel fuel as a pilot for compression ignition. Westport HPDI engine efficiency under highway operation is claimed to be better than dedicated natural gas engine at approximately $44 \%$ compared with spark ignited natural gas engines at approximately $37 \%$ [39]. The most common engine for the OTR trucks was observed to be the Cummins ISX15, a heavyduty diesel engine operating over a range of 400 to 600 horsepower [40]. 
Fewer engines are available for drilling and fracturing purposes. The engines often used for these applications are Caterpillar, Cummins and Waukesha.

Cummins QSX50 and QSX60 are used by hydraulic fracturing fleet. The QSX60 has a rating of 2647 horsepower at $1800 \mathrm{rpm}$. The emissions are certified at Tier 2 level [41]. Caterpillar produces several engines used in the industry. The Caterpillar 3512 and 3516 are two engines commonly used for drilling and hydraulic fracturing. The 3512 is a V12 diesel engine, generally used to power drill rigs, and is rated at 1500 horsepower at $1800 \mathrm{rpm}$. [42].

Caterpillar has the 3516 which runs exclusively on natural gas. Another dedicated natural gas engine used for drill rig applications is the Waukesha L7044GSI EPA. They have a power rating of 1680 brake horsepower. This engine has the advantages associated with a natural gas engine, such as lower regulated emissions and lower operating cost and is capable of providing power equivalent to a similar diesel engine. The emissions have been certified by US Environmental Protection Agency (EPA) as non-road mobile [43]. The Waukesha Specifications are listed in Table 2.5.

Table 2.5: Waukesha L7044GSI Specification sheet [43]

\begin{tabular}{|l|l|}
\hline Cylinders & V12 \\
\hline Piston Displacement & 7040 cu.in. (115 L) \\
\hline Compression Ratio & $8: 1$ \\
\hline Bore \& Stroke & $9.375^{\prime \prime}$ x 8.5” \\
\hline Jacket Water System Capacity & 100 gal. \\
\hline Lube Oil Capacity & 190 gal. \\
\hline Power (bhp) & 1680 \\
\hline BSFC (Btu/bhp-hr) & 7881 \\
\hline
\end{tabular}

For experimental purpose, it was needed to replicate this Waukesha engine or engines using similar technologies. So, the Cummins ISL-G was selected as the surrogate for the Waukesha engine as it 
has a similar dedicated natural gas engine. The Cummins ISL G is an 8.9 L natural gas engine with a rating of 280 horsepower and produces a peak torque of $900 \mathrm{lb}-\mathrm{ft}$ at $1300 \mathrm{rpm}$. It has a three-way catalyst (TWC) aftertreatment system [44]. The specifications of a Cummins ISL G are listed in Table 2.6.

Table 2.6: Cummins ISL-G Specification sheet [44]

\begin{tabular}{|l|l|}
\hline Maximum Horsepower & $280 \mathrm{HP}$ \\
\hline Type & 4-cycle, spark-ignited, in-line 6 cylinder \\
\hline Engine Displacement & $8.9 \mathrm{~L}$ \\
\hline After-treatment system & Three-Way Catalyst (TWC) \\
\hline Fuel Type & CNG or Liquified Natural Gas (LNG) or Renewable \\
& Natural Gas (RNG) (MN greater than 75) \\
\hline
\end{tabular}

\subsection{Association of Shale Gas Composition with the Blends of Fuels Selected}

Researchers at Bryan Research and Engineering Inc. examined various compositions from different shale plays and the challenges it presented for processing the fuels [9]. In this research, the shale gas compositions from popular areas like Barnett, Haynesville and Fayetteville shales were recorded in terms of $\mathrm{CH} 4$ (methane), $\mathrm{C} 2 \mathrm{H} 6$ (ethane), $\mathrm{C} 3 \mathrm{H} 8$ (propane), $\mathrm{CO} 2$ (carbon dioxide) and N2 (nitrogen). The wells showed high N2 content (around 7\%) in some areas and very low content $(<1.0 \%)$ in other areas [9]. Table 2.7 is extracted from their report, presents the shale gas composition from the Marcellus shale play region. U.S. EIA reports 410 Tcf of technically recoverable NG resource from Marcellus region [45].

Table 2.7 clearly shows the variability of the shale gas composition from the different wells of the same shale play region. To be able to use fuel from shale gas to operate the prime-movers it would be necessary to test the efficiency and emissions from the engines when operated on such compositions. Thus, for this test, it was decided to select two fuel blends, a high propane blend (5.187\% propane) and a high ethane blend (11.992\% ethane), namely Blend 1 and Blend 2 
respectively, that best represents the variation of the fuel composition. Table 2.8 gives the details of the fuel blends selected for testing.

Table 2.7: Marcellus Shale Gas Composition [9]

\begin{tabular}{|l|l|l|l|l|l|}
\hline Well & $\mathbf{C H}_{\mathbf{4}}(\boldsymbol{\%})$ & $\mathbf{C}_{2} \mathrm{H}_{\mathbf{6}}(\%)$ & $\mathbf{C}_{\mathbf{3}} \mathrm{H}_{\mathbf{8}}(\boldsymbol{\%})$ & $\mathbf{C O}_{\mathbf{2}}(\mathbf{\%})$ & $\mathbf{N}_{\mathbf{2}}(\boldsymbol{\%})$ \\
\hline $\mathbf{1}$ & 79.4 & 16.1 & 4.0 & 0.1 & 0.4 \\
\hline $\mathbf{2}$ & 82.1 & 14.0 & 3.5 & 0.1 & 0.3 \\
\hline $\mathbf{3}$ & 83.8 & 12.0 & 3.0 & 0.9 & 0.3 \\
\hline $\mathbf{4}$ & 95.5 & 3.0 & 1.0 & 0.3 & 0.2 \\
\hline
\end{tabular}

Table 2.8: Composition of Blends selected for this study

\begin{tabular}{|l|l|l|l|}
\hline & CNG & Blend 1 & Blend 2 \\
\hline Methane & $95.032 \%$ & $86.327 \%$ & $86.002 \%$ \\
\hline Ethane & $3.219 \%$ & $2.599 \%$ & $11.992 \%$ \\
\hline Propane & $0.581 \%$ & $5.187 \%$ & $1.002 \%$ \\
\hline I-Butane & $0.091 \%$ & $0.000 \%$ & $0.000 \%$ \\
\hline N-Butane & $0.133 \%$ & $0.000 \%$ & $0.000 \%$ \\
\hline I-Pentane & $0.051 \%$ & $0.000 \%$ & $0.000 \%$ \\
\hline N-Pentane & $0.035 \%$ & $0.000 \%$ & $0.000 \%$ \\
\hline Nitrogen & $0.499 \%$ & $4.385 \%$ & $0.502 \%$ \\
\hline Oxygen & $0.014 \%$ & $0.000 \%$ & $0.000 \%$ \\
\hline Carbon Dioxide & $0.266 \%$ & $1.502 \%$ & $0.502 \%$ \\
\hline Hexanes+ & $0.079 \%$ & $0.000 \%$ & $0.000 \%$ \\
\hline
\end{tabular}




\section{Experimental Setup and Procedure}

This chapter provides descriptions of the equipment and the procedures that were used in this study. Significant in-use engine activity data for the prime-movers of unconventional well development was previously collected. As part of an earlier work, a Markov-Chain, Monte Carlo simulation with genetic algorithms was employed to develop engine activity cycles that were representative of in-use activity [4]. On-road engines are tested with the transient Federal Test Procedure (FTP), while off-road engines are tested over the steady-state 5-mode ISO-8178 D-2 cycle. The conventional and developed test cycles were implemented in the Engine and Emissions Research Laboratory (EERL) at WVU using a Cummins 8.9 L ISL-G engine. Table 3.1 provides engine specifications. This engine is directly representative of current on-road natural gas engines and employees the same technologies as some off-road natural gas engines, which include stoichiometric/rich operation, turbocharging, and TWC.

Table 3.1: Test Engine Specifications

\begin{tabular}{|l|l|}
\hline Manufacturer & Cummins \\
\hline Model & ISL-G 280 \\
\hline Model Year & 2008 \\
\hline Configuration & 6 cylinders, Inline \\
\hline Aspiration & Turbocharger / Intercooler \\
\hline Maximum Torque & $900 \mathrm{ft}-\mathrm{lbs}(1220 \mathrm{Nm})$ @ 1300 RPM \\
\hline Maximum Power & $280 \mathrm{bhp}(208.8 \mathrm{~kW})$ @ 2200 RPM \\
\hline Displacement & $8.9 \mathrm{~L}$ (543 cu-in) \\
\hline Bore x Stroke & 114 x 145 mm (4.49 x 5.71'’) \\
\hline After-treatment & Three-Way Catalyst (TWC) \\
\hline
\end{tabular}


Table 3.2 shows the fuel composition of the three blends used during these tests. The CNG fuel was purchased from a local CNG station. The Blend 1 and Blend 2 fuel were purchased from a local gas supplier and made with high purity mixed gases. For comparison, Table 3.2 also includes the high ethane (Gas \#4) and high propane (Gas \#5) blends used by Karavalakis et al. [32] Note, that Cummins recommends a MN of 75 or greater, which limited the propane and ethane content of the fuel blends. The MN of blends Gas \#4 and Gas \#5 were recalculated using the Cummins Westport Fuel Calculator to compare with the Blend 1 and Blend 2 fuel used in this study [27].

Table 3.2: Fuel Specifications

\begin{tabular}{|c|c|c|c|c|c|}
\hline Component & Gas\#5 & Blend 1 & Gas\#4 & Blend 2 & CNG \\
\hline $\mathbf{C H}_{4}(\%)$ & 87.2 & $\mathbf{8 6 . 3}$ & 83.7 & $\mathbf{8 6 . 0}$ & $\mathbf{9 5 . 0}$ \\
\hline $\mathbf{C}_{2} \mathbf{H}_{6}(\%)$ & 4.5 & $\mathbf{2 . 6}$ & 10.8 & $\mathbf{1 2 . 0}$ & $\mathbf{3 . 2}$ \\
\hline $\mathbf{C}_{3} \mathbf{H}_{\mathbf{8}}(\%)$ & 4.4 & $\mathbf{5 . 2}$ & 2.7 & $\mathbf{1 . 0}$ & $\mathbf{0 . 6}$ \\
\hline $\mathbf{N}_{2}(\%)$ & 2.7 & $\mathbf{1 . 5}$ & 2.7 & $\mathbf{0 . 5}$ & $\mathbf{0 . 5}$ \\
\hline $\mathbf{C O}_{2}(\%)$ & 0.0 & $\mathbf{4 . 4}$ & 0.0 & $\mathbf{0 . 5}$ & $\mathbf{0 . 3}$ \\
\hline $\mathbf{M N}_{(-)}$ & 69.5 & $\mathbf{7 5 . 5}$ & 71.1 & $\mathbf{7 5 . 3}$ & $\mathbf{8 5 . 2}$ \\
\hline $\mathbf{H H V}(\mathbf{M J} / \mathbf{k g})$ & 52.30 & $\mathbf{4 9 . 2 1}$ & 52.33 & $\mathbf{5 3 . 6 3}$ & $\mathbf{5 4 . 3 3}$ \\
\hline $\mathbf{W o b b e}$ & 41.55 & $\mathbf{3 9 . 2 4}$ & 41.53 & $\mathbf{4 1 . 4 0}$ & $\mathbf{3 9 . 1 4}$ \\
$\left(\mathbf{M J} / \mathbf{m}^{\mathbf{3}}\right)$ & & & & & \\
\hline $\mathbf{H} / \mathbf{C}$ & 3.77 & $\mathbf{3 . 6 7}$ & 3.75 & $\mathbf{3 . 8 3}$ & $\mathbf{3 . 9 2}$ \\
\hline
\end{tabular}

\subsection{Laboratory Setup and Instrumentation}

All measurements performed for the study presented herein were conducted at the Engine and Emission Research Laboratory (EERL) at West Virginia University. The EERL is part of West Virginia University's Center for Alternative Fuels, Engines and Emissions (CAFEE) and the transient engine dynamometer test cell and associated emissions quantification instruments are designed and operated according to recommendations outlined in the Code of Federal Regulations (CFR), Title 40, Part 1065. [46] 


\subsubsection{Engine Dynamometer}

Engine testing was conducted on a 500hp General Electric ${ }^{\circledR}$ (GE) motoring/absorbing dynamometer capable of performing both steady-state and transient test cycles up to speeds of $2500 \mathrm{rpm}$. The engine was instrumented with K-type thermocouples and pressure transducers (Omega, Inc.) to quantify the thermodynamic states of different engine components and flow streams (i.e. exhaust, EGR flow, intake flow, coolant, etc.).

Instantaneous natural gas flow measurements were performed using an Endress-Hauser Gas Flow Meter (model 8DFO8-AG15AAAABAON, max. error: $\pm 0.50 \%$ of value) based on the Coriolis principle. Furthermore, carbon balance calculations based on recovered carbon fractions in the exhaust stream (i.e. $\mathrm{CO} 2, \mathrm{CO}$, THC) were performed to corroborate direct fuel measurement.

\subsubsection{Constant Volume Sampling (CVS) Dilution Tunnel}

Regulated gaseous emissions, including total hydrocarbons (THC), carbon monoxide (CO), oxides of nitrogen $\left(\mathrm{NO}_{\mathrm{x}}\right)$ and particulate matter $(\mathrm{PM})$, as well as carbon dioxide $\left(\mathrm{CO}_{2}\right)$, nitric oxide $(\mathrm{NO})$ and methane $\left(\mathrm{CH}_{4}\right)$ were measured on a diluted basis using a full-flow subsonic venturi (SSV) constant volume sampling (CVS) system coupled with a variable speed blower. The exhaust stream is routed through a transfer pipe from the after-treatment system (in this case, a three-way catalyst) outlet to the CVS tunnel and introduced upstream a mixing orifice allowing for homogeneous mixing of dilution air and exhaust gas. The purpose of the dilution tunnel is to reduce the water condensation in sample transfer lines and analyzers by lowering the water vapor concentration in the exhaust sample. The CVS dilution tunnel at EERL facility is not actively heated, however, the water vapor content and dewpoint temperatures are closely monitored to prevent operations in regions where water condensation may occur. Figure 3.1 shows the CVS system in the laboratory. 


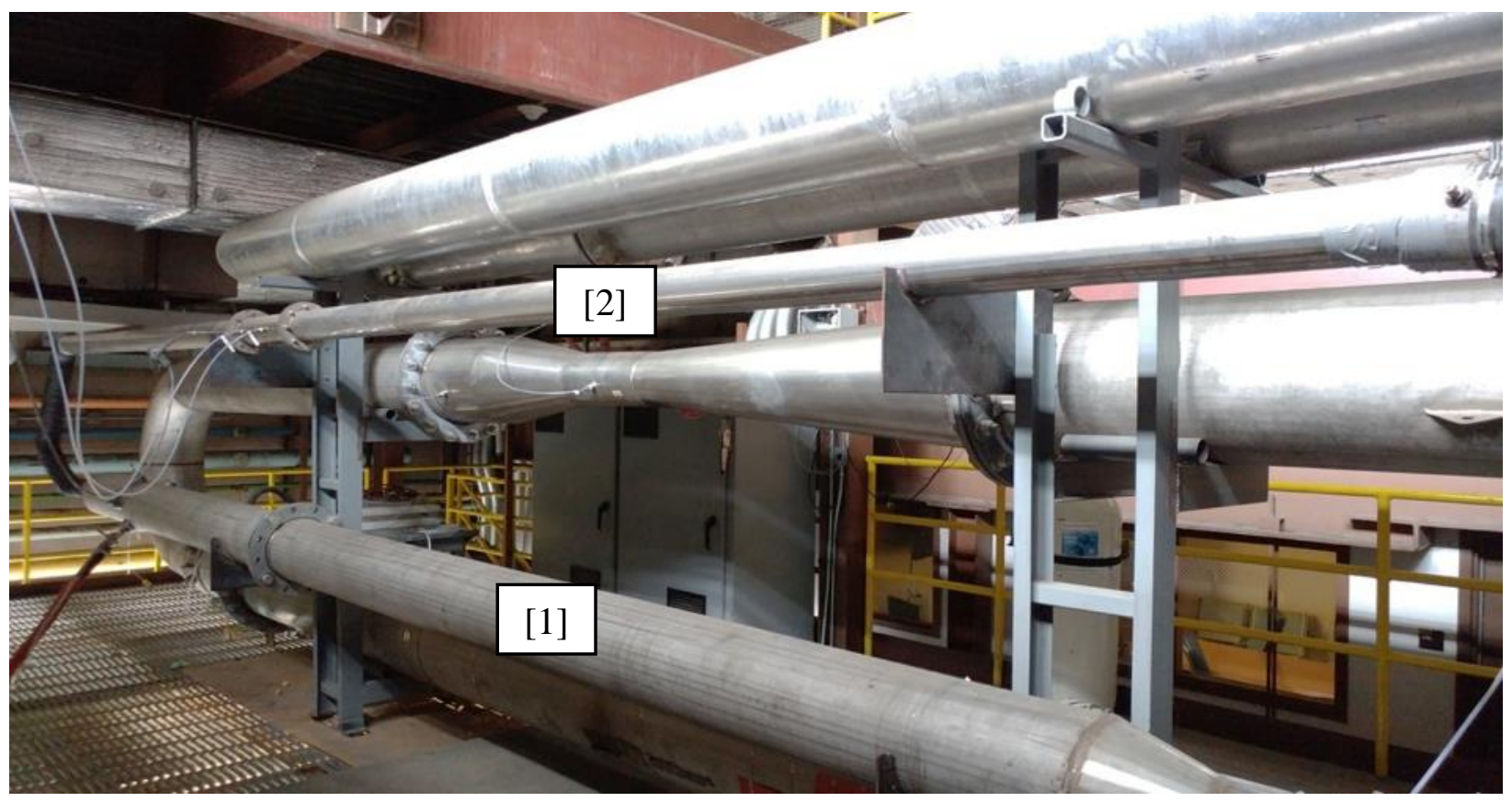

Figure 3.1: Full flow Constant Volume Sampling System [shown in 1] with sub-sonic venturi [shown in 2] for flow rate measurement

\subsubsection{Gaseous Emissions Sampling and Measurement Systems}

Gaseous emissions sampling was performed on a continuous basis using a Horiba ${ }^{\circledR}$ MEXA 7200D Automotive Emissions Analyzer System; with $\mathrm{CO}$ and $\mathrm{CO}_{2}$ being detected by the non-dispersive infrared (NDIR) method (cold dry sample), $\mathrm{NO}_{\mathrm{x}}$ (heated dry atmospheric sample) and NO (cold dry atmospheric sample) using the chemiluminescence (CLD) method; THC and $\mathrm{CH}_{4}$ using heated-flame ionization detectors (HFID) with the latter being routed through a non-methane cutter before entering the HFID. All sample lines and probes were heated to prevent water and hydrocarbon condensation prior to analyzer inlet. Table 3.3 provides an overview of the different analyzers used. Figure 3.2 shows the Horiba MEXA 7200D with the analyzers and the FID oven which is present at the EERL facility, WVU.

Table 3.3: List of gas analyzers comprising the Horiba MEXA-7200D analyzer system

\begin{tabular}{|c|c|c|}
\hline Constituents (diluted) & Analysis Method & Analyzer (type) \\
\hline $\mathrm{CO}$ & NDIR (cold, dry) & AIA-721 \\
\hline $\mathrm{CO}_{2}$ & NDIR (cold, dry) & AIA-722 \\
\hline THC & HFID (heated, wet) & FIA-725A \\
\hline
\end{tabular}




\begin{tabular}{|c|c|c|}
\hline $\mathrm{CH}_{4}$ & HFID (NMC, heated, wet) & FIA-721HA \\
\hline $\mathrm{NO}$ & CLD (cold, dry) & CLA-720 \\
\hline $\mathrm{NO}_{\mathrm{x}}$ & CLD $\left(\mathrm{NO}_{2}\right.$-to-NO, heated, dry $)$ & CLA-720MA \\
\hline
\end{tabular}

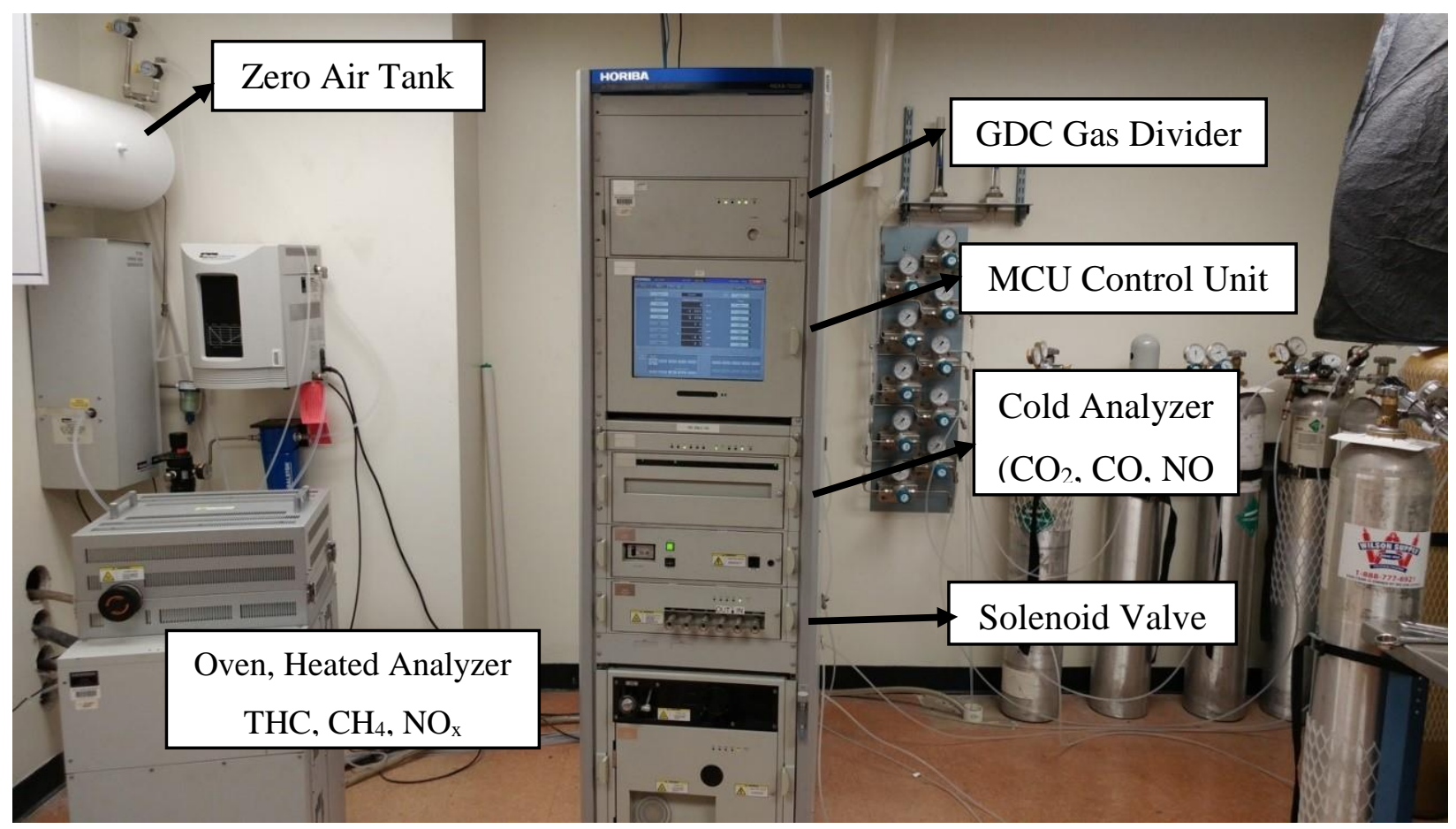

Figure 3.2: Horiba Automotive Emissions analyzer system MEXA-7200D with oven at the EERL, WVU

\subsubsection{Crankcase Emissions Sampling and Measurement System}

A mixture of intake air and gas is pressurized inside the combustion cylinders of the engine. A portion of this mixture may leak into the crankcase from the piston rings. This results in methane emissions/crankcase emissions. To quantify this, a full flow sampler (FFS), similar in concept to the constant volume sampler was used. A blower drew air through an automotive mass airflow sensor from a sampling hose. Sample methane concentration was measured with a Los Gatos Research (LGR) Ultraportable Greenhouse Gas (GHG) Analyzer [47]. Figure 3.3 shows the typical setup of a LGR greenhouse gas analyzer. 


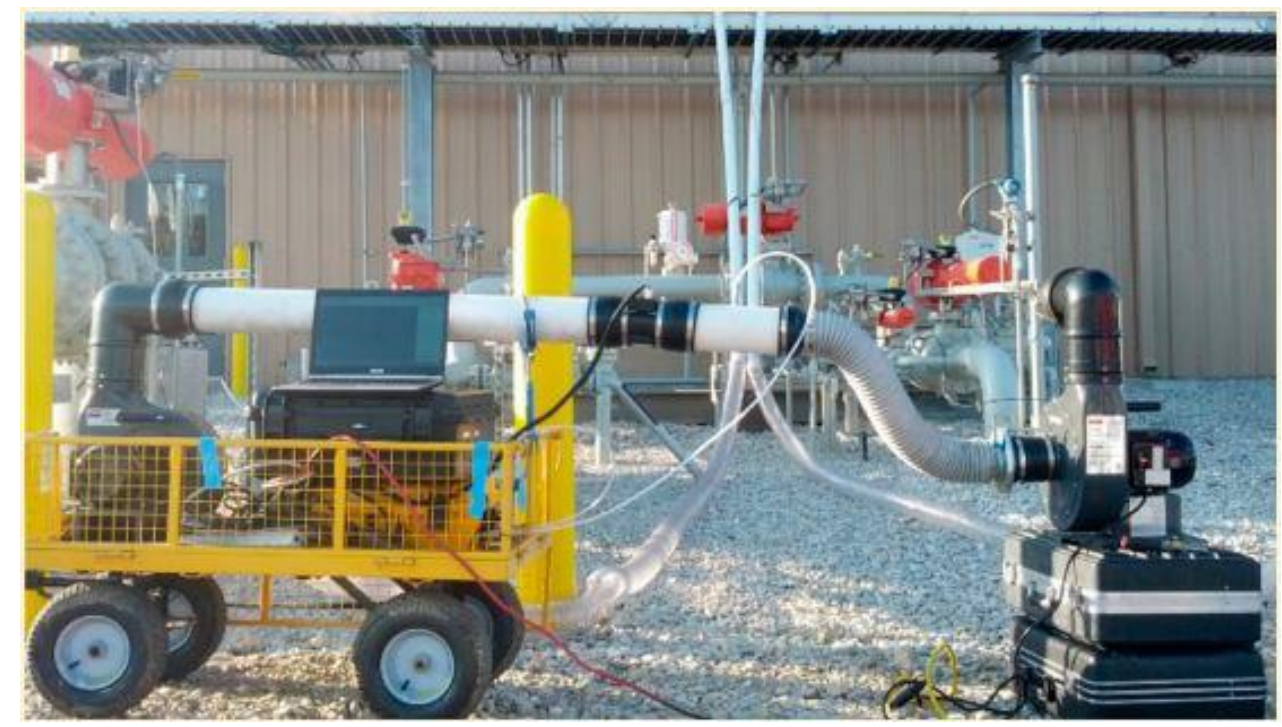

Figure 3.3: Los Gatos Research (LGR) Ultraportable Greenhouse Gas Analyzer [48]

\subsection{PM Sampling, Measurement and Handling System}

PM characterization was performed using the gravimetric method as outlined in 40 CFR, Part 1065. A slip stream of diluted exhaust gas was sampled from the main dilution tunnel through a secondary dilution system and subsequently sampled onto $47 \mathrm{~mm}$ Pallflex ${ }^{\circledR}$ quartz-fiber filter (TX40) membranes (Pall Corporation). An environmentally controlled clean room (Class 1000, maintained at $21^{\circ} \mathrm{C}$ and $50 \% \mathrm{RH}$ ) was utilized for PM filter media handling, storage and weighing using a Sartorius microbalance with an accuracy of $0.1 \mu \mathrm{g}$. An in-house developed software helps in the PM weight measurement and enables to store the weight in a server which can be accessed anywhere and monitored accordingly.

A sample of PM was withdrawn proportionally from the primary dilution tunnel into a secondary dilution tunnel through a 0.5 -inch transfer tube. The probe was fixed such that the inlet of the probe is upstream allowing to draw sample from the exhaust. The total flow and the secondary dilution air flow through the secondary tunnel is controlled using two Sierra Instruments Smart-Trak mass flow controllers [49]. The total flow can vary from 0 to 2.5 standard cubic feet per minute (scfm) and the secondary dilution air flow also varies between 0 to $2.5 \mathrm{scfm}$. 40 CFR Part 1065 suggests a minimum overall dilution ratio of $5: 1$ to $7: 1$ and at least $2: 1$ for any primary dilution stage [50]. For this study, as natural gas engines have traditionally low PM emissions, only primary stage dilution of 2 scfm was used. 


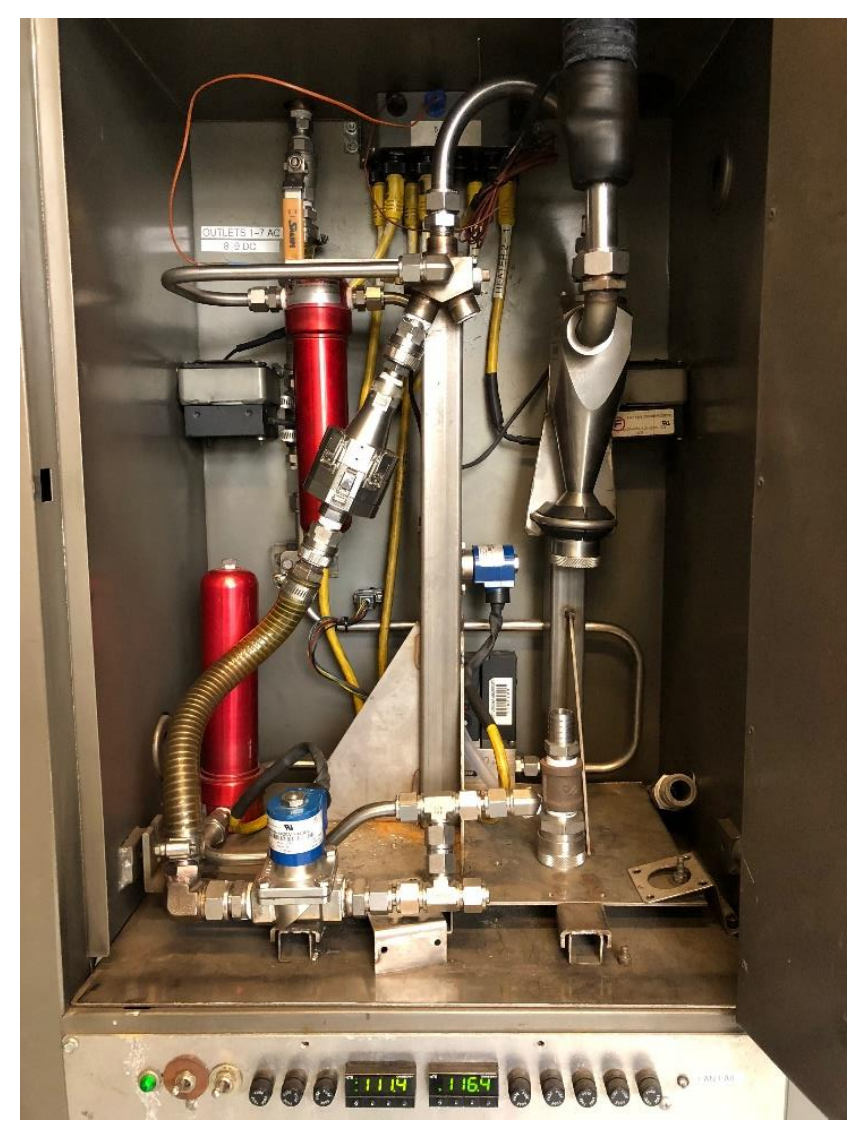

Figure 3.4: 40 CFR 1065 compliant PM sampling system at WVU CAFEE's EERL facility

After the sample is extracted from the CVS dilution tunnel, it is allowed into a $\mathrm{PM}_{2.5}$ cyclone separator to remove particles bigger than $2.5 \mu \mathrm{m}$ [19]. The filter holder is made up of stainless steel and was connected to the end of the secondary dilution tunnel. The stainless-steel construction prevents reactions with the corrosive exhaust sample and is designed to allow easy access to the filters. The setup is shown in Figure 3.4. The PM filters are placed in a cassette made up of polycarbonate as per specifications given in 40 CFR Part 1065 (1065.170, 1 (vii)). The cassettes are kept clean by periodically wiping them with a compatible solvent applied lint-free cloth.

The PM samples were collected on separate filters for each test. After every test, the filter holder was carried to the clean room and the sample filter was placed carefully inside a covered glass Petri dish. Glass dishes are preferred over plastic to avoid loss of PM due to static electrical charges in the plastic Petri dishes. 


\subsubsection{Calculation}

The calculation of the total PM emissions from the engine was performed using gravimetric analysis. To perform the calculation of the PM emissions it is necessary to calculate the exhaust flow through the tunnel ( $\mathrm{V}_{\mathrm{exh}}$ ) and the Dilution Ratio (DR). Dilution ratio, as mentioned earlier, is the ratio of total flow to the sample flow. The following equation to calculate the PM emissions collected on the sample filter as per 40 CFR 1065 ,

$$
P M_{\text {total }}=M_{P M} \cdot D R \cdot V_{\text {exh }}
$$

Where:

$$
\begin{aligned}
& M_{P M}=\text { PM mass obtained by subtracting the pre-weight and post-weight of the PM filters } \\
& D R=\text { Dilution Ratio } \\
& V_{\text {exh }}=\text { Total Exhaust Flow }
\end{aligned}
$$

\subsubsection{Clean Room}

All PM sample handling and weighing was performed inside a Class 1000 or Class Six (as conformed according to ISO 14644-1 standards) clean room located at the WVU CAFEE EERL facility, as shown in Figure 3.5. The weighing room floor area is $10 \mathrm{ft}$. $\mathrm{x} 10 \mathrm{ft}$. and was designed to allow for two personnel to be present at a time. A gowning room $6 \mathrm{ft}$. x 10ft., climate-controlled environment the same way as the clean room acts as a buffer between the outside area and the clean room air conditions. The conditions constantly maintained inside the clean room are as follows,

- Temperature: $22 \pm 3^{\circ} \mathrm{C}$

- Dew Point: $9.4 \pm 3^{\circ} \mathrm{C}$

- Relative Humidity (RH): $45 \pm 8 \%$

The clean room temperature and RH is constantly verified to check for any anomalies. If any of the above-mentioned conditions are not met, then the conditions are stabilized at least one hour prior to the measurement of the PM sample filter measurement. 
Sartorius SE2F Ultra-Micro Filter Balance was used to weigh the PM sample filters. This scale is accurate up to 0.1 micro-grams $(\mu \mathrm{g})$. All the filters of the tests are conditioned for at least 60 minutes before and after the tests.

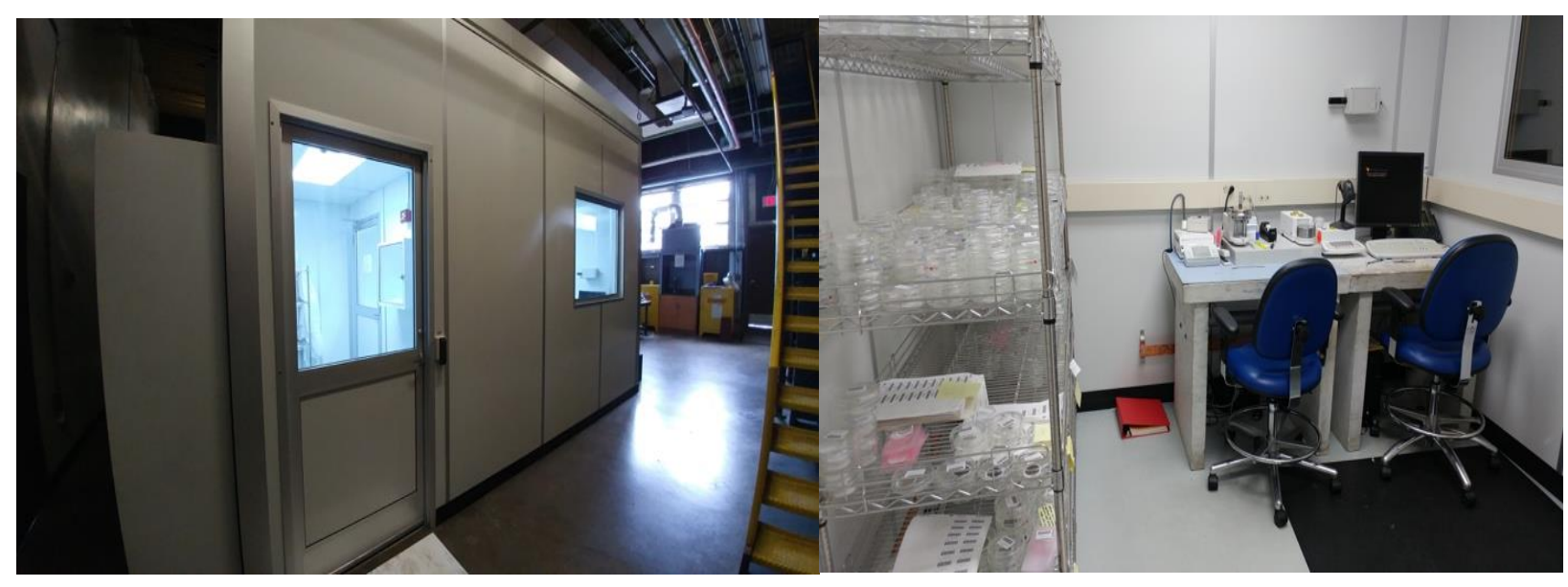

Figure 3.5: Clean Room at the WVU CAFEE's EERL facility

\subsection{Particle Sizing and Sampling System}

This study employed, additionally, the TSI EEPS (TSI Model 3090) for transient particle size distribution measurement. The EEPS was set up for sampling as shown in Figure 3.6. Tests were conducted using single stage and double-stage dilution methods. To dilute the sample, a minidilution tunnel was used to which dry and pressurized air at $25^{\circ} \mathrm{C}$ was supplied through an ejector dilutor (Air-Vac Model TD-H110). The pressurized air (in-house air) is dried and filtered at three stages using HEPA filters and was regulated to be at $60 \mathrm{psi}$ using pressure regulators. This specific pressure was used to allow $16 \mathrm{lpm}$ of sample to flow from the ejector dilutor to the instrument and to not over-dilute the sample. For tests where 2-stage dilution was employed, a secondary minidilution tunnel was connected in series to the primary mini-dilution tunnel. The secondary dilution tunnel was allowed a flow of $5 \mathrm{lpm}$ through the ejector dilutor. The dilution air pressure was optically monitored and is subjected to errors induced due to the fluctuations of a manual pressure gauge. The temperature of the dilution air was around $5-10^{\circ} \mathrm{C}$. Based on ejector dilutor calculations provided by the manufacturer, the following dilution ratios were approximately estimated as;

Dilution Ratio 1 , for primary (first-stage) dilution, DR $1 \approx 8$

Dilution Ratio 2, for secondary (second-stage) dilution, DR2 $\approx 24$ 
These values are estimated based on data provided by the manufacturer. The actual flow rates might vary.

The sample was collected at the instrument using a Tygon ${ }^{\circledR}$ tube. Tygon ${ }^{\circledR}$ tubes are doped with carbon particles, thus making them conductive and thereby preventing the build-up of static charges that could lead to particle losses within the sample tube. The instrument was cleaned before the commencement of this study, and the electrometers were zeroed before the start of day. Figure 3.6 shows the schematic of the setup.

The PN concentration measured using the Particle Number Counter (PNC), as per the UNECE Regulation 49, Revision 7, Addendum 48, implies that particle sizes of more than $23 \mathrm{~nm}$ shall be considered as part of the Euro VI regulations mentioned in the EU 595/2009, May 2011 amendment [21] [51]. However, in this study, the particle number emissions calculated include all the particle sizes ranging from $6.04 \mathrm{~nm}$ to $523.3 \mathrm{~nm}$. This allows to compare the PN emissions and divide them into nucleation mode and accumulation mode. This further facilitates the ability to compare PN emissions to PM emissions.

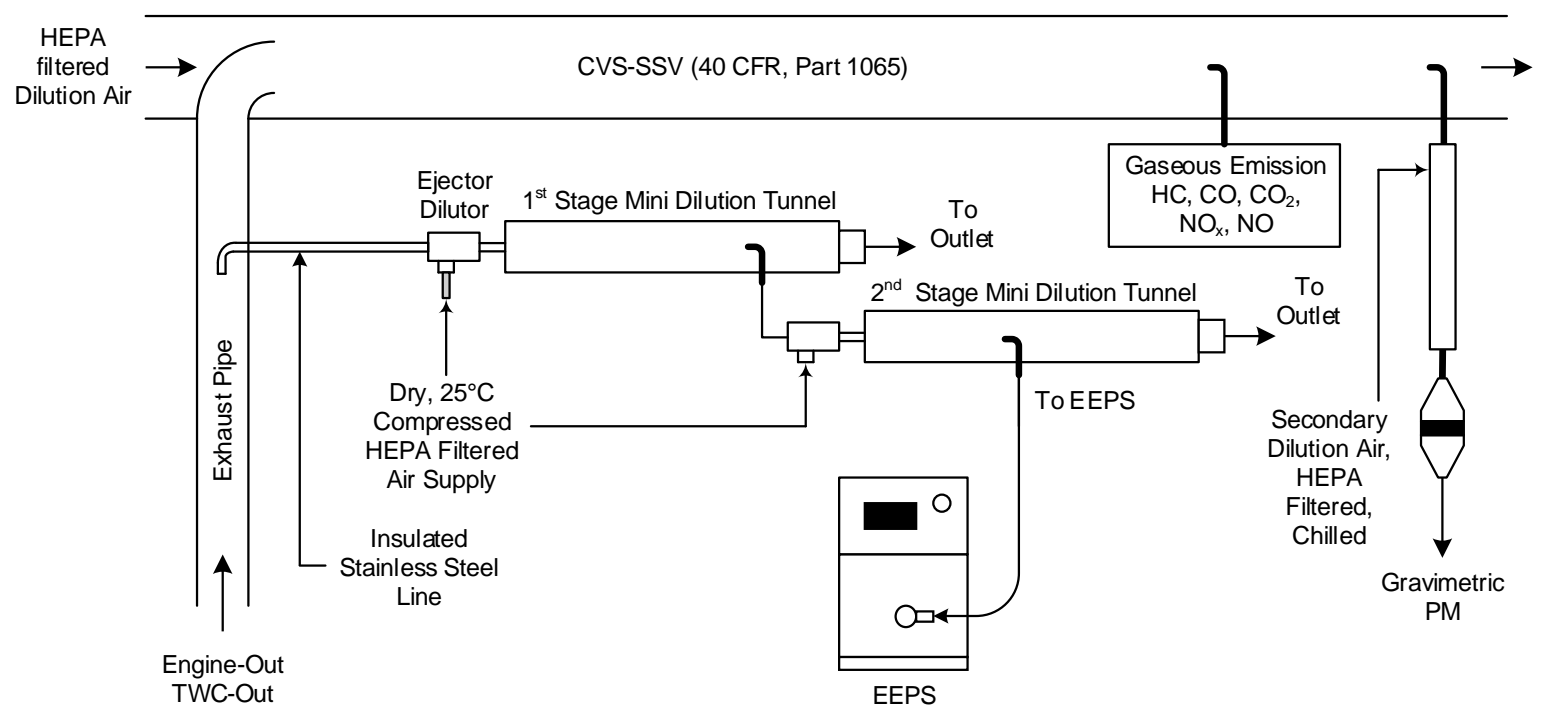

Figure 3.6: Experimental setup for particle number and mass measurement

\subsection{Particle Number Concentration and Size Spectrum Characterization via TSI-EEPS}

The EEPS ${ }^{\mathrm{TM}}$, Engine Exhaust Particle Sizer Spectrometer (TSI Inc.), is an instrument used to measure the exhaust particle size spectrum and number concentration in real-time. This instrument is very responsive and has high-resolution and can measure very low particle number 
concentrations in diluted exhaust. Thus, it became the obvious choice of instrument to measure the particle number emissions from a natural gas engine. The EEPS has a time resolution of $10 \mathrm{~Hz}$ which makes it ideal for transient tests. The instrument operates over a wide size range and can measure particles from 5.6 to $560 \mathrm{~nm}$. It operates at ambient pressure to eliminate any concern about evaporating volatile and semi-volatile particles that may occur at high pressures [52].

\subsubsection{Operation}

As shown in Figure 3.7 the exhaust sample enters the instrument after passing through a series of filters to eliminate large particles that are above the instrument's size range. The particles then pass through an electrical diffusion (corona) charger and are charged based on particle size. Charged particles then enter the annular space between the two cylinders that are filled with clean sheath air. The particles pass next to a central high voltage electrode that produces an electric field to repel the particles outwards to the electrometer rings. The particles impact the electrometer as a function of their electrical mobility. Smaller particles carry lesser charge as compared to larger particles. The smaller particles are detected at the top of the column and larger particles at the bottom [53]. The electrometers are read 10 times per second by high performance microprocessor which then inverts the data in real time to get the particle sizing distribution data.

During engine testing, the particles that enter the EEPS at the same time are detected at different times on different electrometers, depending upon size and charge. Also, the particles of the same size are not charged equally, they are charged based on a charge distribution, and are, thus, detected on multiple electrometers. The data inversion algorithm accounts for these factors and generates a curve of concentration versus particle size. 


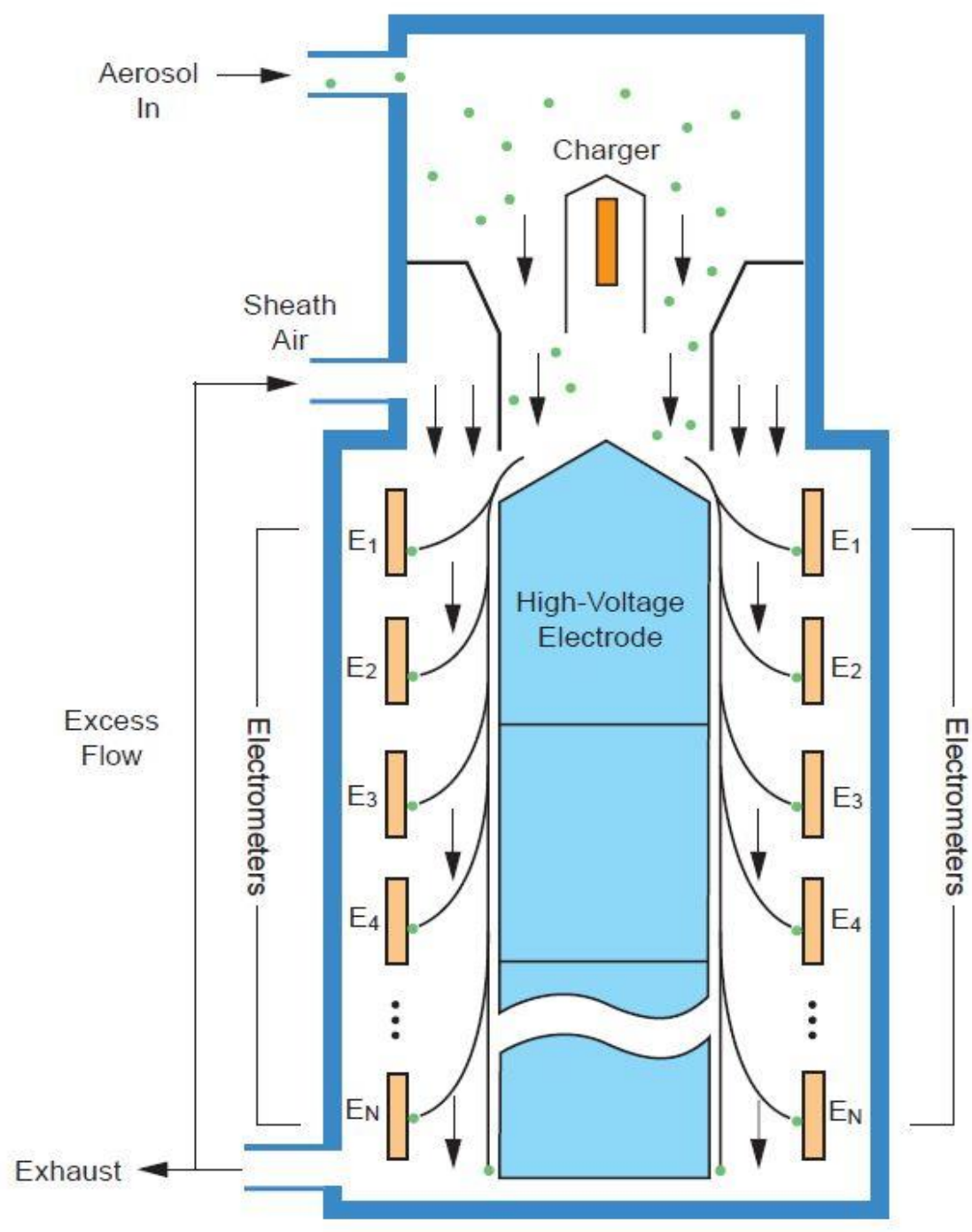

Figure 3.7: Schematic of EEPSTM Spectrometer [53]

\subsubsection{Calculation}

The data recorded by the instrument has a channel-wise distribution with the respective particle concentrations. The size ranges from $6.04 \mathrm{~nm}$ to $523.3 \mathrm{~nm}$. To calculate the instantaneous particle number concentrations, the particle concentrations of all the channels at that instant are added and then averaged over the number of channels. In this study, we calculated the particle number concentrations for nucleation mode (particle size < 50nm) and accumulation mode (particle size > $50 \mathrm{~nm})$. To calculate the particle number concentration, the following equation was used: 


$$
P N_{\text {total }}=\sum_{i=1}^{\text {end of test }} C \cdot D R \cdot V_{\text {exh }}
$$

Here, $\mathrm{C}$ is the number concentration of particles per unit volume of exhaust measured instantaneously by the instrument. $\mathrm{V}_{\text {exh }}$ is the total exhaust flow measured using the chemical balance as per 40 CFR part 1065 . The unit of the value obtained from the above equation is particle number count (\#). To obtain the brake-specific particle concentration, we divide the value with the work done over the cycle. The resulting value would be in \#/bhp-hr. The following calculation has been showed to explain the typical PN calculation for the two modes;

$$
P N_{i}=\sum_{i=1}^{\text {end of test }} C_{i} \cdot D R \cdot V_{\text {exh }}
$$

Where,

$$
\begin{aligned}
& C_{i}=\text { concentration of nucleation/accumulation mode particles }\left(\# / \mathrm{cm}^{3}\right) \\
& D R=\text { Dilution Ratio } \\
& V_{\text {exh }}=\text { Total exhaust flow }\left(\mathrm{cm}^{3}\right)
\end{aligned}
$$

\subsection{Test Matrix}

The 8.9L Cummins ISL-G engine was tested over a period of four days to determine the gaseous as well as particulate mass and number emissions. For the first two days, natural gas (CNG) obtained from local gas stations was utilized and the engine was tested over 5 FTP cycles, 3 drilling cycles, 3 trucking cycles and 3 fracking cycles. One test of the engine operating over D-2 cycle was performed at the end of Day 2. Tests with engine operating with CNG as fuel were conducted to obtain the baseline CNG emissions and to facilitate comparison with the fuel blends. Testing initially with CNG also enabled the study group to verify the engine conditions and prepare for testing the fuel blends. On Day 3 and Day 4, the engine was tested with Blend 1 and Blend 2, respectively as the engine fuel. the engine was operated on trucking, drilling and fracking cycles. On the final day of testing, CNG was used as the fuel and the engine was operated over four FTP cycles to make sure the engine operating conditions and the engine output didn't differ from Day 
1 of testing. Also, at the start of every day of testing a cold FTP was run with the engine operating on CNG fuel to condition the engine. Table 3.4 provides the exact test schedule that was followed.

Table 3.4: Test Matrix

\begin{tabular}{|c|c|c|c|}
\hline S. No. & Test Fuel & Test Cycle & No. of Repeats \\
\hline 1 & CNG & Cold FTP & 2 \\
\hline & & Hot FTP & 3 \\
\hline & & Trucking & 3 \\
\hline & & Drilling & 3 \\
\hline & & Fracking & 3 \\
\hline 2 & Blend 1 & Trucking & 3 \\
\hline & & Drilling & 3 \\
\hline & & Fracking & 3 \\
\hline 3 & Blend 2 & Trucking & 2 \\
\hline & & Drilling & 2 \\
\hline & & Fracking & 2 \\
\hline
\end{tabular}




\section{Results and Discussion}

All experiments conducted for the herein presented study were executed at the Engine and Emissions Research Laboratory (EERL) at West Virginia University (WVU). This chapter presents the average gaseous emissions calculated for the different test cycles as well as discussion of the implications of those results. Furthermore, this chapter will provide insight to particle number and mass emissions measured and with an analysis of the results. A comparison of the crankcase and tailpipe methane emissions is also presented in this chapter.

The engine was tested over four test cycles namely FTP, trucking cycle, drilling cycle and the fracking cycle. These cycles were generated as part of a DOE project where WVU was responsible for assessing the impact of fugitive methane emissions where natural gas engines are used in unconventional well development. These cycles are representative of the well development activity [4].

All the plots presented in this chapter consists of error bars that represent one standard deviation $( \pm 1 \sigma$, std. dev) of the repetitive tests. For the PN emissions plots, the axes are plotted on a logarithmic scale. This was done in order to avoid obscuring interesting features of the particle size distribution, which spans orders of magnitudes.

This chapter is divided into four sections. Section 4.1 illustrates the difference between the operating cycles based on the work done and brake-specific fuel consumption (BSFC) along with the gaseous emissions for the different cycles. Section 4.2 provides us the comparison of gaseous emissions for the different test cycles when the engine is operated with CNG and the two natural gas fuel blends. Section 4.3 sheds light on the crankcase methane emissions in comparison to the tailpipe methane emissions for the three gaseous test fuels. Section 4.4 deals exclusively with particle emissions characterization. Gravimetric PM emissions are presented for the CNG and the different NG blends. This section also presents the PN emissions with the size distribution of the particle emissions for different test cycles and the different NG blends.

\subsection{Comparison of Cycles (CNG as Fuel)}

This section will exclusively present and discuss emissions results over the different test cycles for CNG fuel only. The trucking cycle represents on-road driving conditions of the prime movers used 
for well development and is comparable to the FTP cycle. The drilling and fracking cycles are comparable to the D-2 mode cycle. For all the plots presented in this section, the FTP cycle and trucking cycle are compared, and the drilling and fracking cycles are compared to the D2 cycle.

Figure 4.1 shows the engine work performed over the different test cycles used when the engine was operated on CNG fuel. The average cycle work for the trucking cycle was $21.93 \mathrm{bhp}-\mathrm{hr}$. This was $15.79 \%$ higher than the cycle work of FTP cycle (18.94 bhp-hr). The drilling cycles and the fracking cycles are comparable to the D-2 cycle (non-road emissions test standards), where the drilling cycle had a cycle-integrated work that was $71.09 \%$ higher than the D-2 cycle and the fracking cycle was $41.84 \%$ higher. The temperature, atmospheric pressure and other conditions were consistent throughout the testing procedures (approximate ambient temperature: $60^{\circ} \mathrm{F}$, and atmospheric pressure: 13.99 psi, RH: 54.18\%).

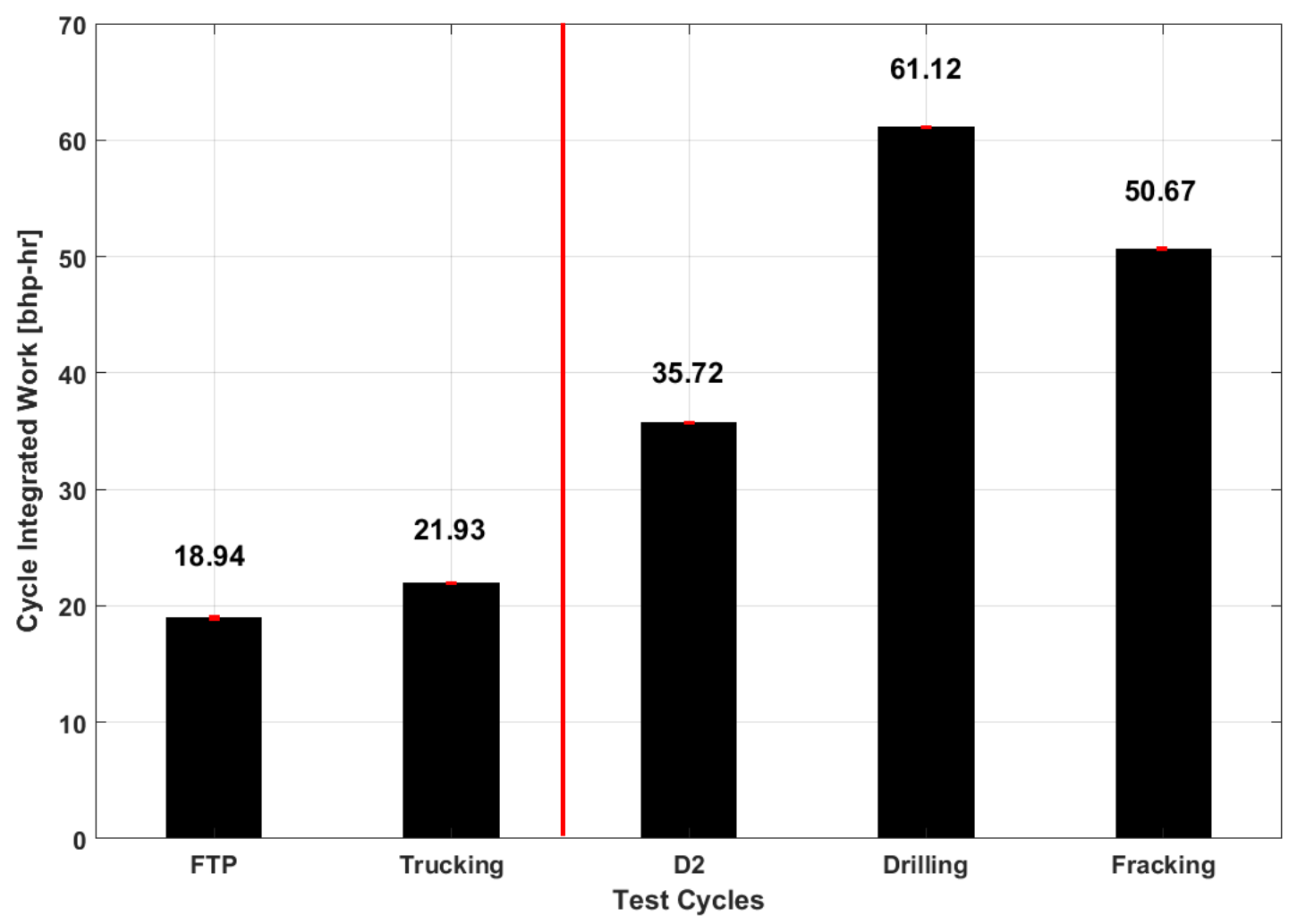

Figure 4.1: Cycle integrated work performed over the Test Cycles [bhp-hr]

Figure 4.2 illustrates BSFC for all the test cycles when the engine is operated on CNG. To obtain a better understanding, the units used are diesel gallon equivalent per brake horsepower-hour (DGE/bhp-hr) which compares the energy equivalent of the NG blends with respect to one gallon 
of diesel (refer Table 3.2) [54]. The BSFC for trucking cycle was $5 \%$ higher than that of FTP. The D-2 cycle has high BSFC and, comparatively, the BSFC of drilling cycle and fracking Cycle was $12 \%$ and $8 \%$ lower respectively.

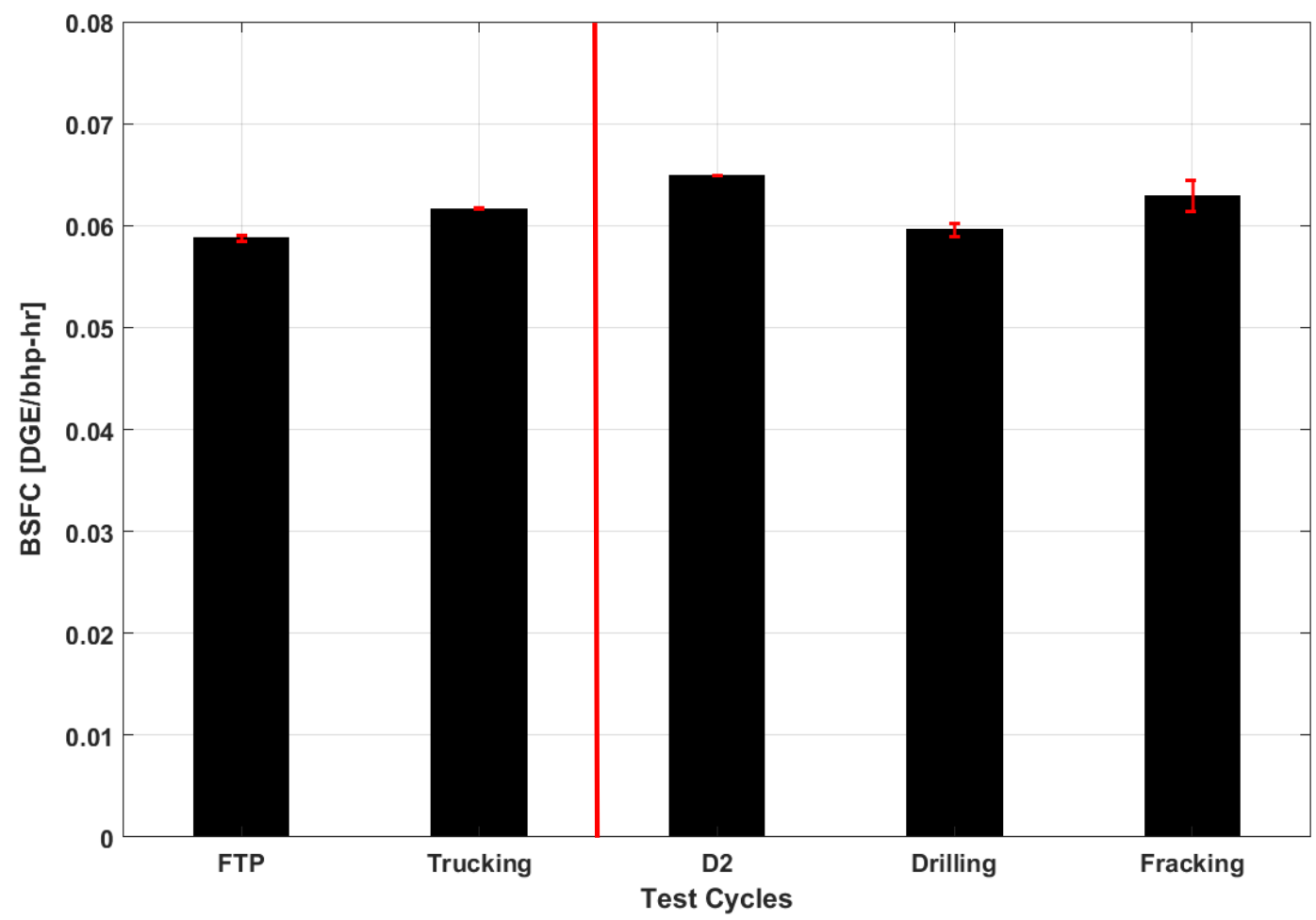

Figure 4.2: Diesel-gallon equivalent BSFC for Test Cycles with CNG as Fuel

Figure 4.3 shows the $\mathrm{CO}_{2}$ emissions for the different test cycles when the engine was operated with $\mathrm{CNG}$ as fuel. The trucking cycle showed an increase of $5.3 \%$ of $\mathrm{CO}_{2}$ emissions when compared to the FTP cycle. D-2 cycle had the highest $\mathrm{CO}_{2}$ emissions with drilling and fracking cycle being $12 \%$ and $5.4 \%$ lower.

Figure 4.4 shows the $\mathrm{CO}$ emissions for the different test cycles when the engine was operated with CNG as fuel. The trucking cycle yielded CO emissions that were $14.6 \%$ higher than that of FTP cycle. The drilling and fracking cycles also yielded higher $\mathrm{CO}$ emissions when compared to D-2 cycle and were $44 \%$ and $35 \%$ higher, respectively. 


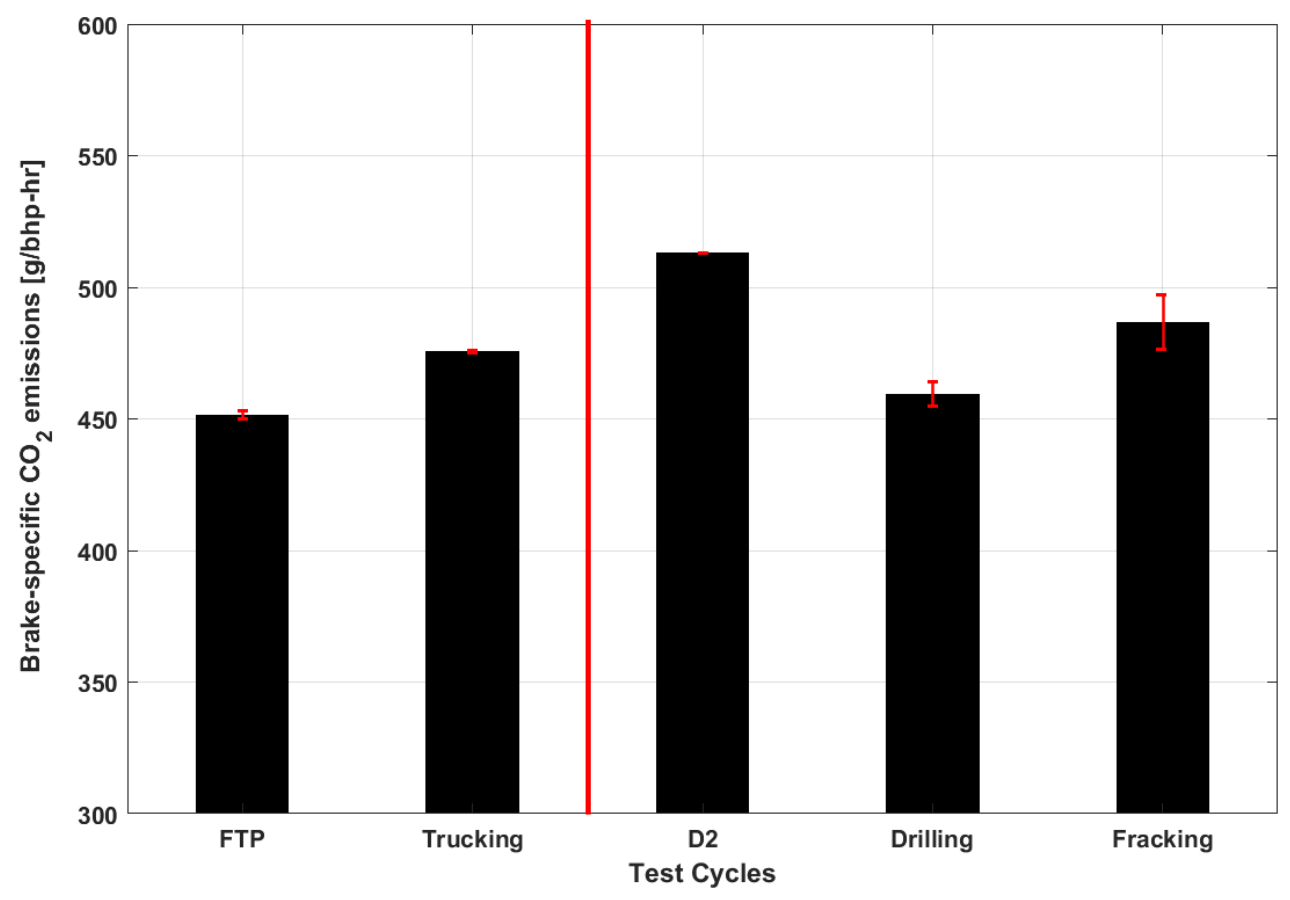

Figure 4.3: $\mathrm{CO}_{2}$ Emissions for the Test Cycles with $\mathrm{CNG}$ as Fuel

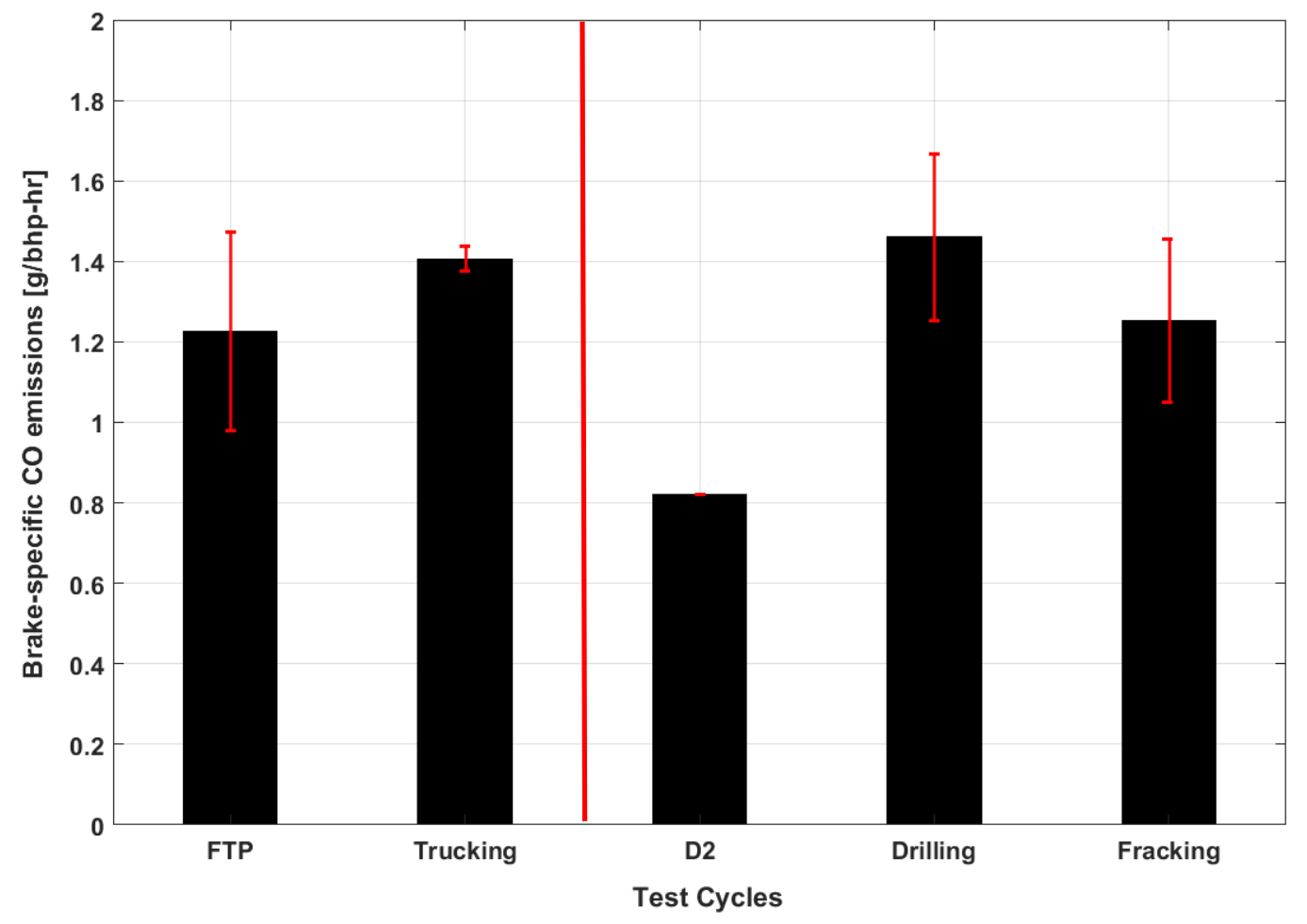

Figure 4.4: CO Emissions for the Test Cycles with CNG as Fuel 
Figure 4.5 shows the $\mathrm{NO}_{\mathrm{x}}$ emissions for the different test cycles when the engine is operated with $\mathrm{CNG}$ as fuel. The trucking cycle yielded $17.4 \%$ higher $\mathrm{NO}_{\mathrm{x}}$ emissions than the FTP cycle, though the difference was within one standard deviation, For the off-road cycles, the measured $\mathrm{NO}_{\mathrm{x}}$ was below detection limits and was mostly noise. The higher levels of $\mathrm{NO}_{\mathrm{x}}$ emissions from FTP and trucking cycle may be attributed to their transient behavior. Higher efficiency of TWC under steady-state operating conditions may have resulted in lower $\mathrm{NO}_{\mathrm{x}}$ emissions for non-road test cycles.

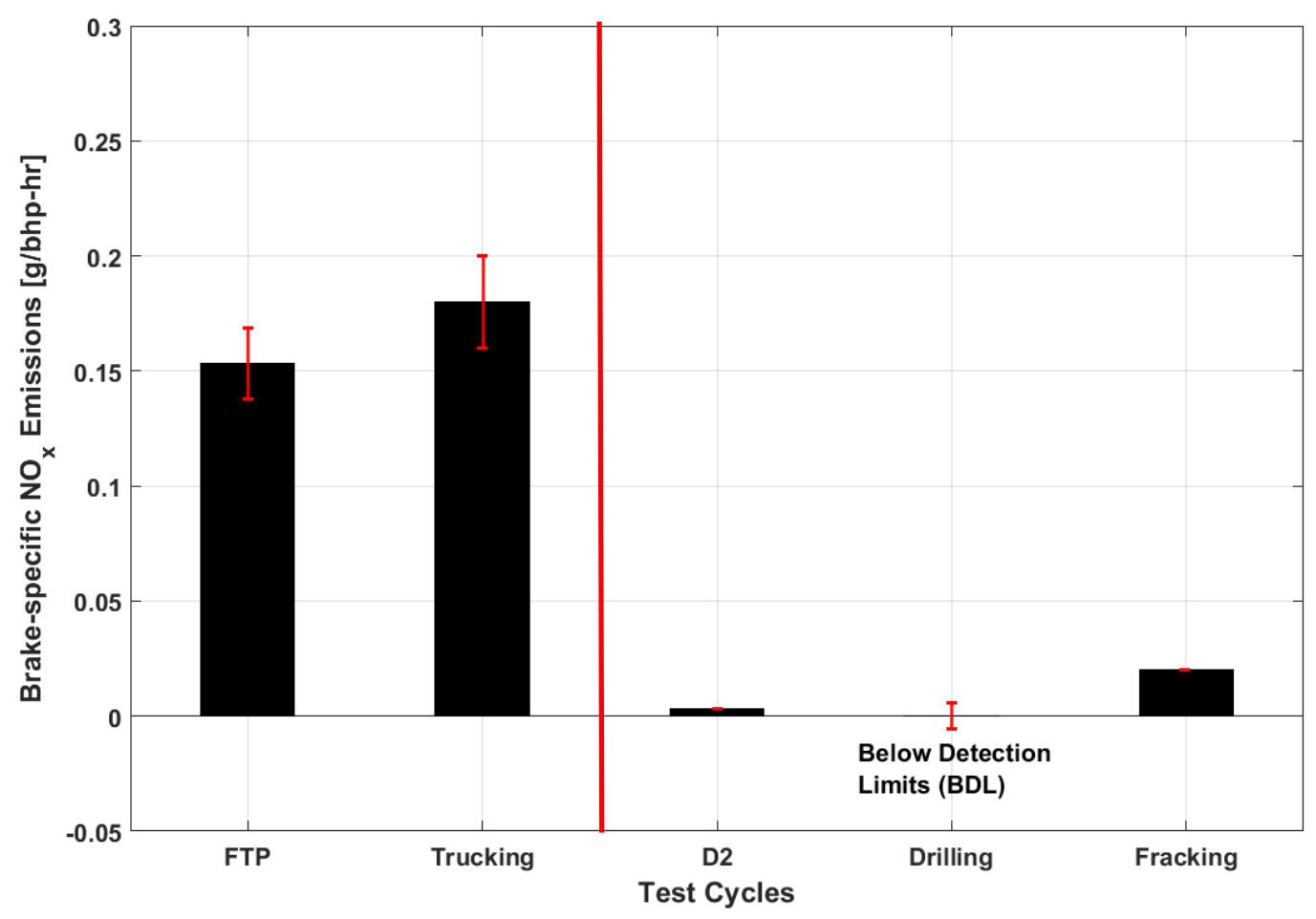

Figure 4.5: NOx Emissions for the Test Cycles with CNG as Fuel

Figure 4.6 shows the THC and $\mathrm{CH}_{4}$ emissions for the different test cycles when the engine is operated with $\mathrm{CNG}$ as fuel. It may be observed that the THC emissions mostly contain $\mathrm{CH}_{4}$, at least $92 \%$ of it for all the test cycles. The trucking cycle yields lower $\mathrm{CH}_{4}$ emissions than the FTP cycle, $38 \%$ lower. The drilling and fracking cycle also yields lower $\mathrm{CH}_{4}$ emissions than the D-2 cycle, $31 \%$ and $24 \%$ respectively. 


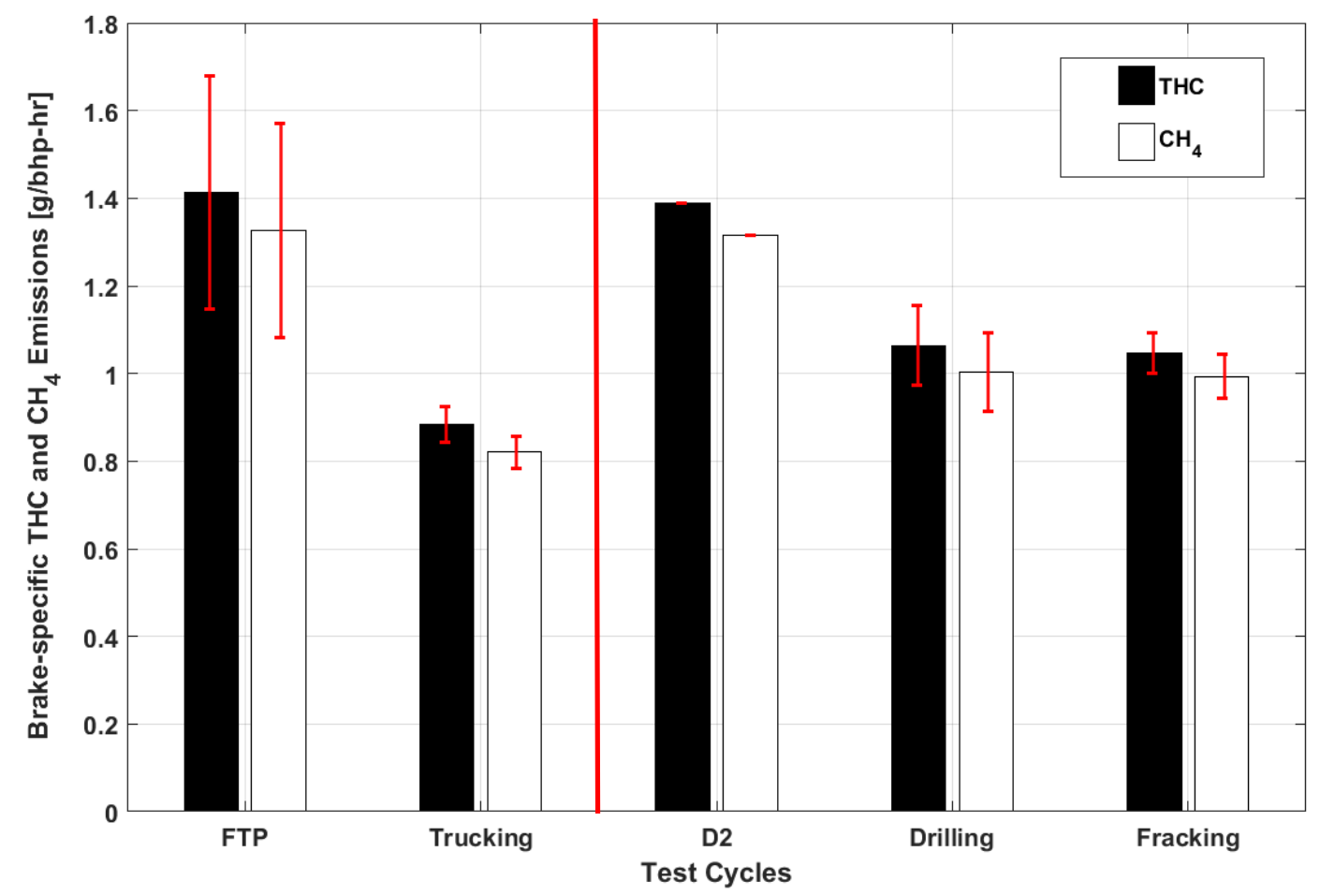

Figure 4.6: $\mathrm{THC}$ and $\mathrm{CH}_{4}$ Emissions for the Test Cycles with $\mathrm{CNG}$ as Fuel

\subsection{Gaseous Emissions}

All the plots and figures presented below show a comparison of the emissions from the different compositions of natural gas when compared to CNG. Every plot first shows the emissions for FTP cycle when the engine was operated with CNG as the fuel. Due to fuel quantity limitations, the blends of natural gas were not tested over the FTP cycle. To examine the statistical difference, a two-tailed, two-sample equal variance t-test was conducted to be consistent with the test conducted by Karavalakis et.al [32]. The values were considered to be statistically different if alpha was less than 0.05 and the values were marginally different if alpha was in between 0.05 and 0.1 .

\subsection{1 $\mathrm{CO}_{2}$ Emissions}

It may be observed in Figure 4.3 that the FTP cycle when operated over CNG produces the least $\mathrm{CO}_{2}$ emissions. The difference, when compared to the $\mathrm{CO}_{2}$ emissions of trucking cycle, is about $5.3 \%$ and the result is statistically significant with a confidence of $95 \%$. Figure 4.7 shows the effect of natural gas blends on the $\mathrm{CO}_{2}$ emissions. Blend 1 was observed to have marginally higher $\mathrm{CO}_{2}$ 
emissions for trucking and fracking cycles when compared to the Blend 2 and CNG. However, for drilling cycle, Blend 1 had significantly higher $\mathrm{CO}_{2}$ emissions. This may be attributed, upon closer examination, to the $\mathrm{H} / \mathrm{C}$ ratios of the different fuel blends. It may be observed that the $\mathrm{CO}_{2}$ emissions increase linearly with decrease in the H/C ratio. Similar trends are observed in the research conducted by Karavalakis et.al. [32].

Table 4.1 provides the data used in this study for the analysis of $\mathrm{CO}_{2}$ emissions. The data provides the emissions measured for all the tests carried out with the engine being operated over CNG, Blend 1 and Blend 2 as fuel.

A regression analysis was performed, and a strong correlation was observed between the $\mathrm{CO}_{2}$ emissions and the $\mathrm{H} / \mathrm{C}$ ratio. The $\mathrm{CO}_{2}$ emissions decreased with increasing $\mathrm{H} / \mathrm{C}$ ratio.

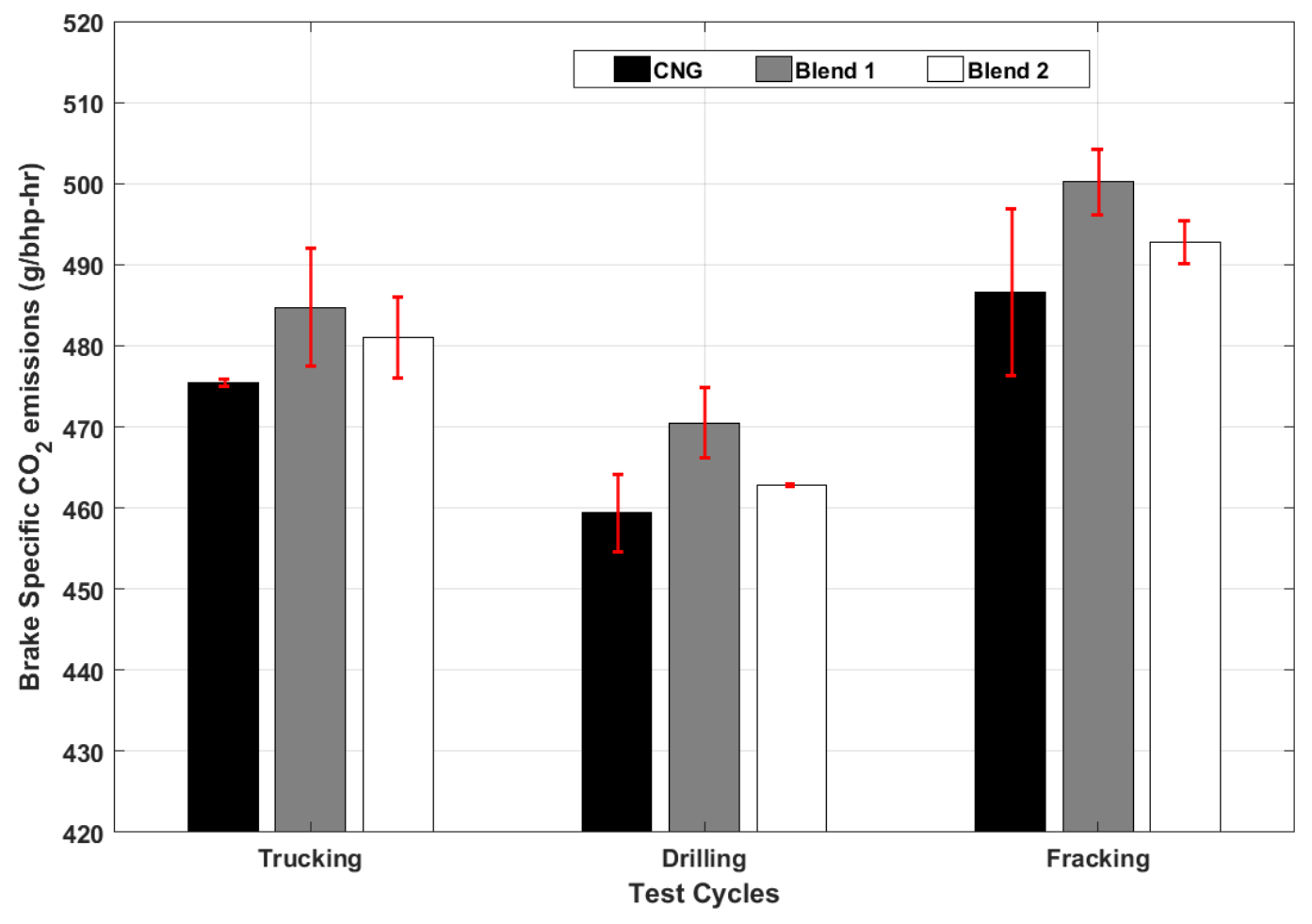

Figure 4.7: Effect of NG fuel blends on $\mathrm{CO}_{2}$ Emissions 
Table 4.1: $\mathrm{CO}_{2}$ Emissions Data used in this study

\begin{tabular}{|c|c|c|c|c|c|c|c|c|c|}
\hline \multicolumn{10}{|c|}{$\mathrm{CO} 2$} \\
\hline & \multicolumn{3}{|c|}{ CNG } & \multicolumn{3}{|c|}{ Blend 1} & \multicolumn{3}{|c|}{ Blend 2} \\
\hline & $\mathrm{g} / \mathrm{bhp}-\mathrm{hr}$ & mean & std dev & $\mathrm{g} / \mathrm{bhp}-\mathrm{hr}$ & mean & std dev & $\mathrm{g} / \mathrm{bhp}-\mathrm{hr}$ & mean & std dev \\
\hline FTP & 449.73 & \multirow{3}{*}{451.48} & \multirow{3}{*}{1.26} & & & & & & \\
\hline FTP & 452.12 & & & & & & & & \\
\hline FTP & 452.60 & & & & & & & & \\
\hline Trucking & 474.99 & \multirow{3}{*}{475.46} & \multirow{3}{*}{0.38} & 491.60 & \multirow{3}{*}{484.73} & \multirow{3}{*}{5.95} & 484.57 & \multirow{3}{*}{481.04} & \multirow{3}{*}{3.54} \\
\hline Trucking & 475.92 & & & 485.50 & & & 477.50 & & \\
\hline Trucking & 475.47 & & & 477.09 & & & & & \\
\hline Drilling & 453.92 & \multirow{3}{*}{459.40} & \multirow{3}{*}{3.88} & 465.48 & \multirow{3}{*}{470.47} & \multirow{3}{*}{3.54} & 462.70 & \multirow{3}{*}{462.83} & \multirow{3}{*}{0.13} \\
\hline Drilling & 462.17 & & & 472.65 & & & 462.96 & & \\
\hline Drilling & 462.11 & & & 473.27 & & & & & \\
\hline Fracking & 493.08 & \multirow{3}{*}{486.64} & \multirow{3}{*}{8.40} & 504.80 & \multirow{3}{*}{500.23} & \multirow{3}{*}{3.30} & 494.62 & \multirow{3}{*}{492.76} & \multirow{3}{*}{1.86} \\
\hline Fracking & 492.06 & & & 498.80 & & & 490.90 & & \\
\hline Fracking & 474.78 & & & 497.10 & & & & & \\
\hline
\end{tabular}

\subsubsection{CO Emissions}

Figure 4.8, shows the effect of the fuel blends on $\mathrm{CO}$ emissions. It may be observed that, for the trucking cycle, Blend 2 had increased $\mathrm{CO}$ emissions by $27.96 \%$ when compared to $\mathrm{CNG}$ and Blend 1. For the drilling cycle, the $\mathrm{CO}$ emissions for Blend 1 and $\mathrm{CNG}$ were marginally different and the emissions of Blend 1 was higher than CNG by $22.83 \%$. The $\mathrm{CO}$ emissions for Blend 2 were statistically higher than both Blend 1 and CNG by $17.94 \%$ and $44.86 \%$ respectively. For the fracking cycle, there was no statistical difference between the $\mathrm{CO}$ emissions of Blend 1 and $\mathrm{CNG}$. Blend 2 showed marginally higher emissions compared to Blend 1 and CNG. The CO emissions of Blend 2 were 28.46\% higher than CNG and 18.09\% higher than Blend 2 emissions.

Table 4.2 provides the data used in this study for the analysis of $\mathrm{CO}$ emissions. The data provides the emissions measured for all the tests carried out with the engine being operated over CNG, Blend 1 and Blend 2 as fuel. When a regression analysis was performed, a strong correlation was observed between the $\mathrm{CO}$ emissions and WI. The $\mathrm{CO}$ emissions increased with increasing WI. The $\mathrm{R}^{2}$ significance was 0.9985 and 0.9305 for trucking and fracking cycle and was 0.7746 for the drilling cycle. 


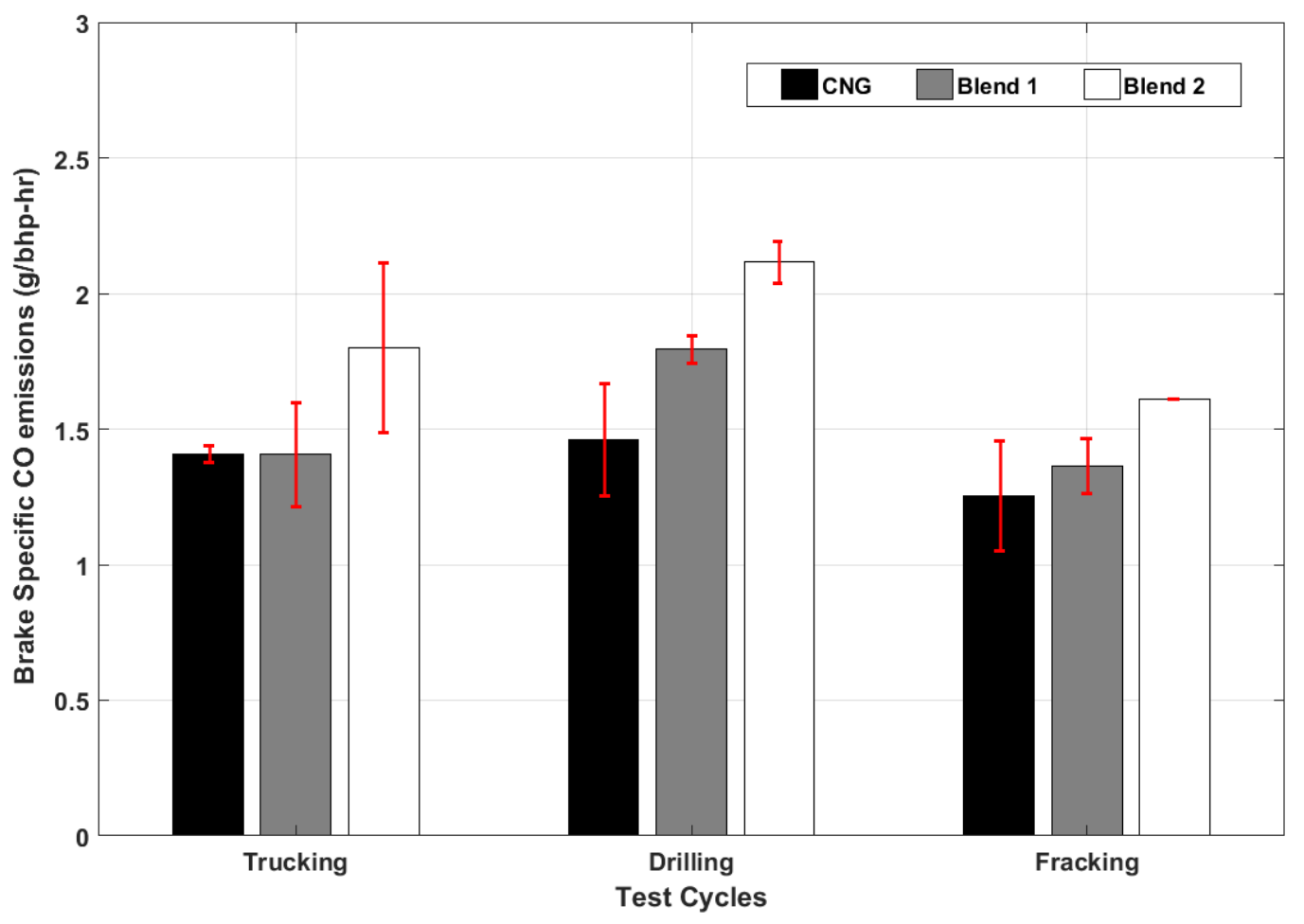

Figure 4.8: Effect of NG fuel blends on CO emissions

Table 4.2: CO emissions data used in this study

\begin{tabular}{|c|c|c|c|c|c|c|c|c|c|}
\hline \multicolumn{10}{|c|}{$\mathrm{CO}$} \\
\hline & \multicolumn{3}{|c|}{ CNG } & \multicolumn{3}{|c|}{ Blend 1} & \multicolumn{3}{|c|}{ Blend 2} \\
\hline & g/bhp-hr & mean & std dev & g/bhp-hr & mean & std dev & g/bhp-hr & mean & std dev \\
\hline FTP & 1.46 & \multirow{3}{*}{1.23} & \multirow{3}{*}{0.20} & & & & & & \\
\hline FTP & 1.25 & & & & & & & & \\
\hline FTP & 0.97 & & & & & & & & \\
\hline Trucking & 1.38 & \multirow{3}{*}{1.41} & \multirow{3}{*}{0.02} & 1.35 & \multirow{3}{*}{1.41} & \multirow{3}{*}{0.16} & 1.58 & \multirow{3}{*}{1.80} & \multirow{3}{*}{0.22} \\
\hline Trucking & 1.44 & & & 1.25 & & & 2.02 & & \\
\hline Trucking & 1.40 & & & 1.62 & & & & & \\
\hline Drilling & 1.69 & \multirow{3}{*}{1.46} & \multirow{3}{*}{0.17} & 1.85 & \multirow{3}{*}{1.79} & \multirow{3}{*}{0.04} & 2.17 & \multirow{3}{*}{2.12} & \multirow{3}{*}{0.05} \\
\hline Drilling & 1.29 & & & 1.76 & & & 2.06 & & \\
\hline Drilling & 1.40 & & & 1.77 & & & & & \\
\hline Fracking & 1.07 & \multirow{3}{*}{1.25} & \multirow{3}{*}{0.16} & 1.32 & \multirow{3}{*}{1.36} & \multirow{3}{*}{0.08} & 1.61 & \multirow{3}{*}{1.61} & \multirow{3}{*}{0.00} \\
\hline Fracking & 1.47 & & & 1.29 & & & 1.61 & & \\
\hline Fracking & 1.22 & & & 1.48 & & & & & \\
\hline
\end{tabular}




\subsubsection{NO $\mathrm{N}_{\mathrm{x}}$ Emissions}

Figure 4.9 shows the effects of fuel blends on the $\mathrm{NO}_{\mathrm{x}}$ emissions. For the trucking cycle, both the blends had lower $\mathrm{NO}_{\mathrm{x}}$ emissions than $\mathrm{CNG}$. Ignoring one outlier data measured for Blend 1, it may be observed that the CNG emissions are $51.85 \%$ higher than Blend 1 and $69.44 \%$ higher than Blend 2 emissions. There is no significant difference between the $\mathrm{NO}_{\mathrm{x}}$ emissions of Blend 1 and Blend 2 for the trucking cycle. For the drilling cycle, the $\mathrm{NO}_{\mathrm{x}}$ emissions were below the detection limit (close to noise). The low $\mathrm{NO}_{\mathrm{x}}$ may be attributed to the steady-state operating cycle where the three-way catalyst could perform efficiently in reducing the $\mathrm{NO}_{\mathrm{x}}$ emissions. For the fracking cycle, the $\mathrm{CNG}$ yielded higher $\mathrm{NO}_{\mathrm{x}}$ emissions than the two fuel blends. But the results were significantly lower than the emissions of trucking and FTP cycles. To examine these trends closely, the nonbackground corrected $\mathrm{NO}_{\mathrm{x}}$ emissions along with the background corrected $\mathrm{NO}_{\mathrm{x}}$ emissions were illustrated to show that the $\mathrm{NO}_{\mathrm{x}}$ levels detected were below detection limits. Figure 4.10 shows the non-background corrected and background corrected NOx emissions for drilling cycle when the engine was operated over CNG as fuel.

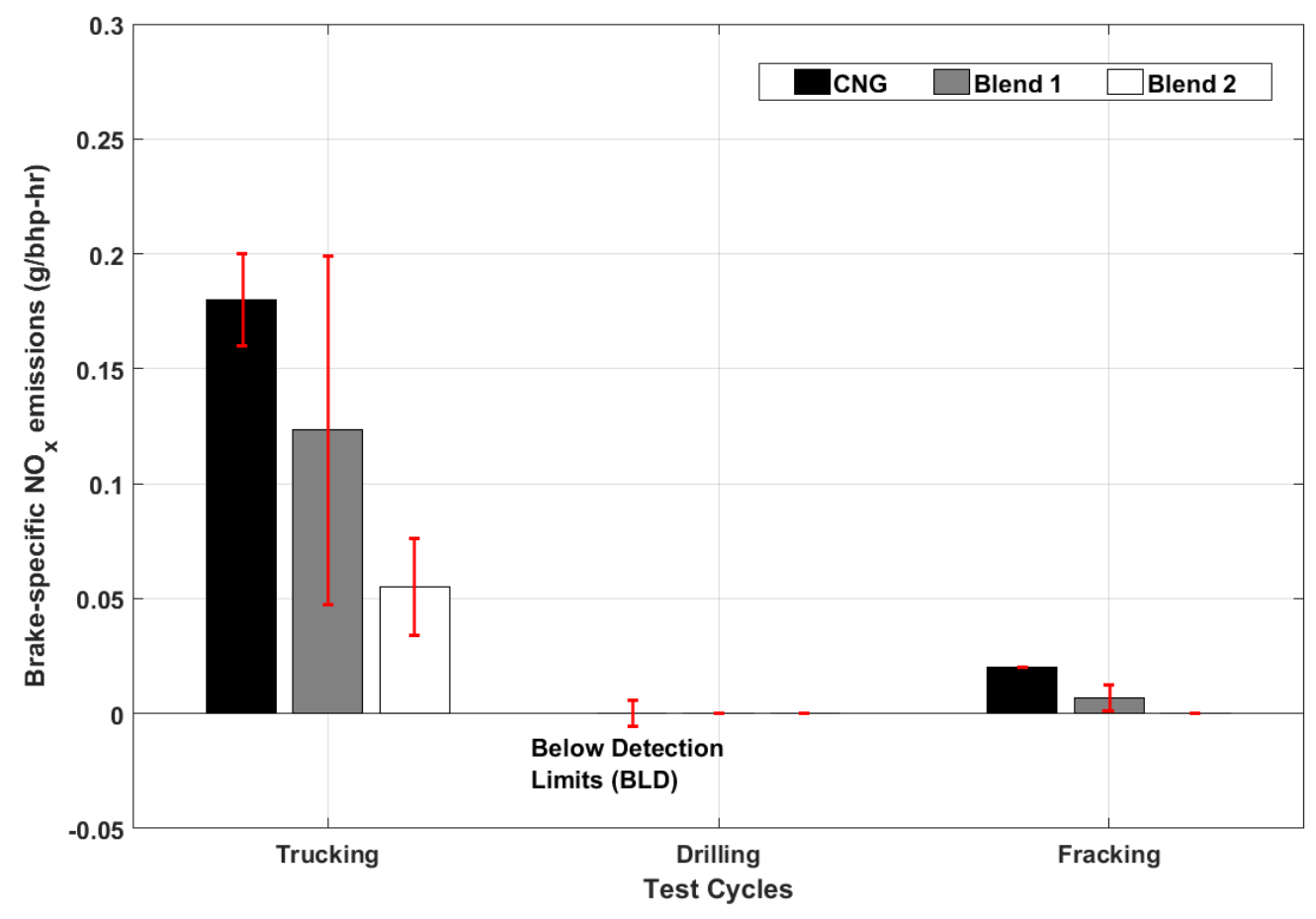

Figure 4.9: Effects of NG fuel blends on NOx Emissions 


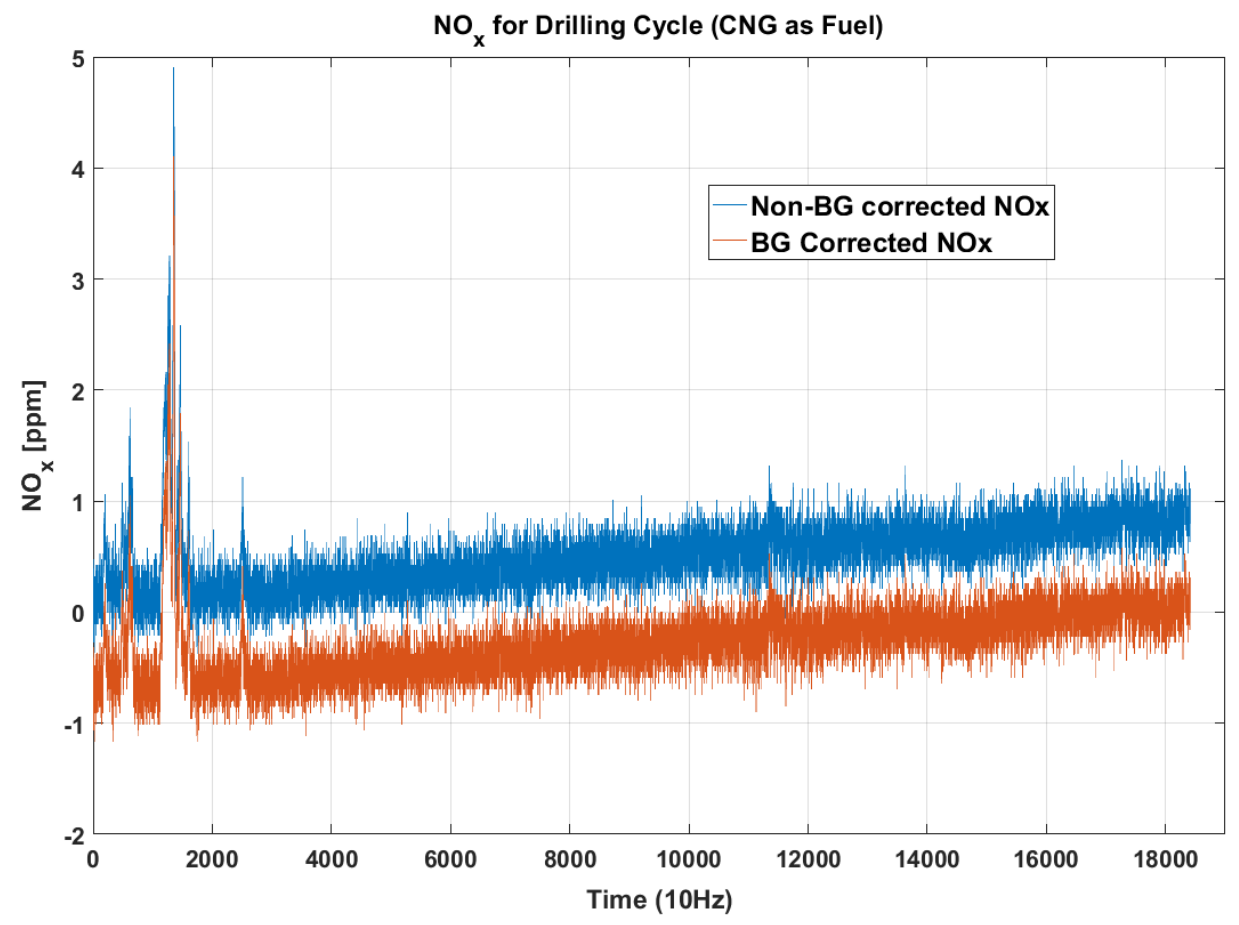

Figure 4.10: Comparison of measured raw $\mathrm{NO}_{\mathrm{x}}$ and background corrected $\mathrm{NO}_{\mathrm{x}}$ emissions

It can be observed from the Figure 4.10 that the $\mathrm{NO}_{\mathrm{x}}$ levels are mostly noise (background $\mathrm{NOx}$ ) and thus the corrected $\mathrm{NO}_{\mathrm{x}}$ values are very low. These trends are in-line with the emissions observed from the in-use engines used for unconventional well development [36].

Table 4.3 provides the data used in this study for the analysis of $\mathrm{NO}_{\mathrm{x}}$ emissions. The data provides the emissions measured for all the tests carried out with the engine being operated over CNG, Blend 1 and Blend 2 as fuel.

A regression analysis was performed to analyze the effect of the fuel properties on $\mathrm{NO}_{\mathrm{x}}$ emissions. The strongest correlation was observed for WI and $\mathrm{MN}$. $\mathrm{NO}_{\mathrm{x}}$ emissions decreased for increasing WI. The $\mathrm{R}^{2}$ significance was $0.8258 . \mathrm{NO}_{\mathrm{x}}$ emissions were also observed to increase with increasing $\mathrm{MN}$. The $\mathrm{R}^{2}$ significance was 0.7181 . It should be noted that the analysis was performed for trucking and fracking cycles only as the $\mathrm{NO}_{\mathrm{x}}$ emissions were close to minimum or below detection limits for the drilling cycle. 
Table 4.3: $\mathrm{NO}_{\mathrm{x}}$ Emissions data used in this study

\begin{tabular}{|c|c|c|c|c|c|c|c|c|c|}
\hline \multicolumn{10}{|c|}{ NOx } \\
\hline & \multicolumn{3}{|c|}{ CNG } & \multicolumn{3}{|c|}{ Blend 1} & \multicolumn{3}{|c|}{ Blend 2} \\
\hline & g/bhp-hr & mean & std dev & g/bhp-hr & mean & std dev & $\mathrm{g} / \mathrm{bhp}-\mathrm{hr}$ & mean & std dev \\
\hline FTP & 0.14 & \multirow{3}{*}{0.15} & \multirow{3}{*}{0.01} & & & & & & \\
\hline FTP & 0.17 & & & & & & & & \\
\hline FTP & 0.15 & & & & & & & & \\
\hline Trucking & 0.20 & \multirow{3}{*}{0.18} & \multirow{3}{*}{0.02} & 0.21 & \multirow{3}{*}{0.12} & \multirow{3}{*}{0.06} & 0.04 & \multirow{3}{*}{0.06} & \multirow{3}{*}{0.02} \\
\hline Trucking & 0.16 & & & 0.07 & & & 0.07 & & \\
\hline Trucking & 0.18 & & & 0.09 & & & & & \\
\hline Drilling & 0.00 & \multirow{3}{*}{0.00} & \multirow{3}{*}{0.00} & 0.00 & \multirow{3}{*}{0.00} & \multirow{3}{*}{0.00} & 0.00 & \multirow{3}{*}{0.00} & \multirow{3}{*}{0.00} \\
\hline Drilling & 0.00 & & & 0.00 & & & 0.00 & & \\
\hline Drilling & -0.01 & & & 0.00 & & & & & \\
\hline Fracking & 0.02 & \multirow{3}{*}{0.02} & \multirow{3}{*}{0.00} & 0.01 & \multirow{3}{*}{0.01} & \multirow{3}{*}{0.00} & 0.00 & \multirow{3}{*}{0.00} & \multirow{3}{*}{0.00} \\
\hline Fracking & 0.02 & & & 0.01 & & & 0.00 & & \\
\hline Fracking & 0.02 & & & 0.00 & & & & & \\
\hline
\end{tabular}

\subsubsection{THC and $\mathrm{CH}_{4}$ Emissions}

Figure 4.11, shows the effects of fuel blends on the THC emissions. The CNG fuel yields the highest THC emissions for all the cycles. For trucking cycle, CNG yields higher emissions than the Blend 1, and is $26.41 \%$ higher. There is no significant difference between the THC emissions from CNG and Blend 2. The two fuel blends yield almost similar levels of THC emissions for trucking cycle. For the drilling cycle, there is no statistical difference between the emission levels from $\mathrm{CNG}$ and Blend 1 . However, the CNG yields marginally higher THC emissions than Blend 2, that is about $27.12 \%$ higher. For the fracking Cycle, the CNG yield statistically higher THC emissions than both the fuel blends. Table 4.4 provides the THC emissions measured for all the tests carried out with the engine being operated over CNG, Blend 1 and Blend 2 as fuel.

Majority of the THC emissions was $\mathrm{CH}_{4}$. It was observed that at least $93 \%$ of the THC emissions was $\mathrm{CH}_{4}$. For trucking cycle, $\mathrm{MN}$ had the strongest effect with THC emissions increasing with increasing MN. The $\mathrm{R}^{2}$ significance was 0.8817 . For steady-state cycles, THC emissions decreased with increasing WI $\left(\mathrm{R}^{2}>0.86\right)$. 


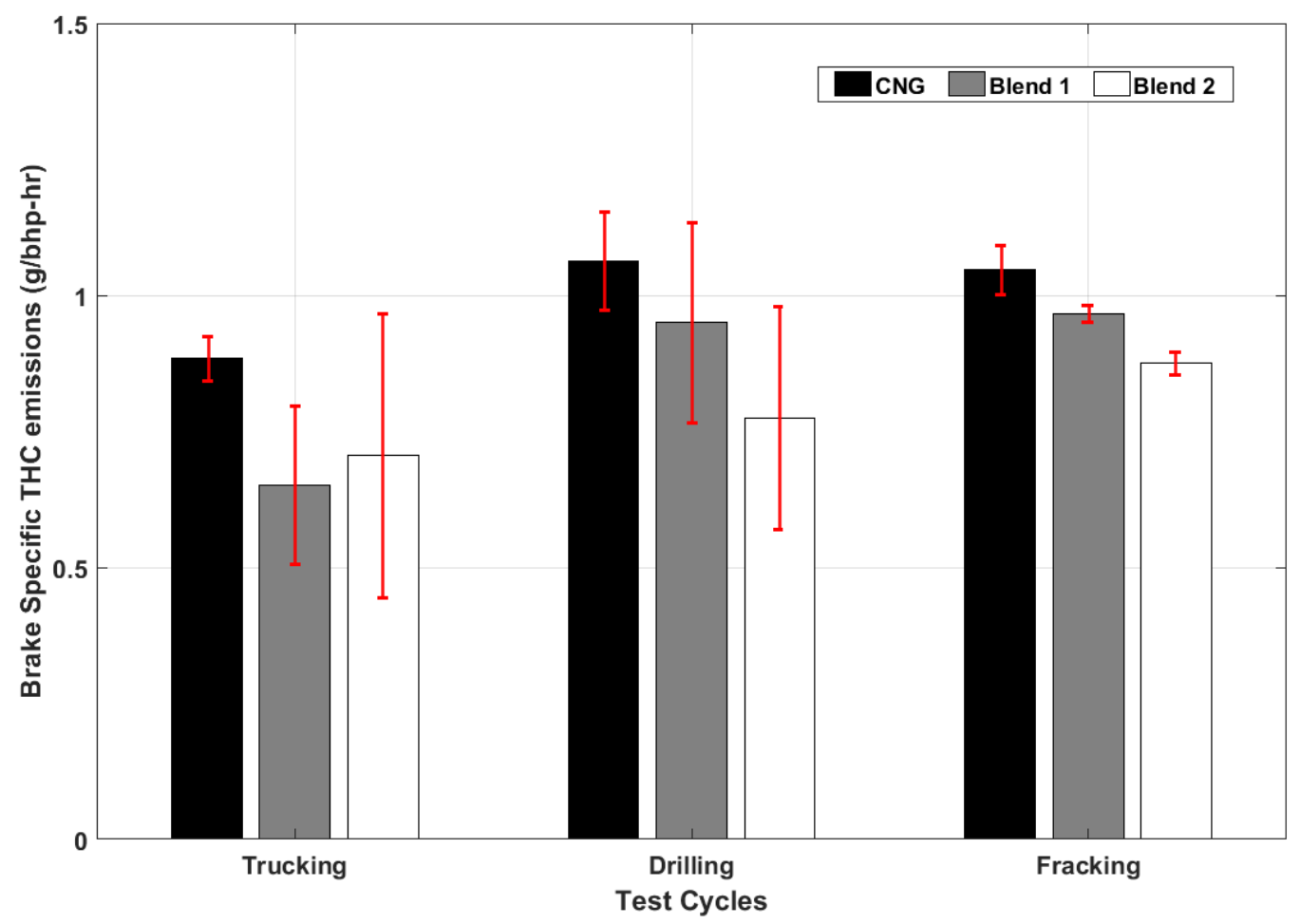

Figure 4.11: Effects of NG fuel blends on THC Emissions

Table 4.4: THC Emissions data used in this study

\begin{tabular}{|c|c|c|c|c|c|c|c|c|c|}
\hline \multicolumn{10}{|c|}{ THC } \\
\hline & \multicolumn{3}{|c|}{ CNG } & \multicolumn{3}{|c|}{ Blend 1} & \multicolumn{3}{|c|}{ Blend 2} \\
\hline & g/bhp-hr & mean & std dev & $\mathrm{g} / \mathrm{bhp}-\mathrm{hr}$ & mean & std dev & g/bhp-hr & mean & std dev \\
\hline FTP & 1.12 & \multirow{3}{*}{1.41} & \multirow{3}{*}{0.22} & & & & & & \\
\hline FTP & 1.64 & & & & & & & & \\
\hline FTP & 1.48 & & & & & & & & \\
\hline Trucking & 0.92 & \multirow{3}{*}{0.88} & \multirow{3}{*}{0.03} & 0.64 & \multirow{3}{*}{0.65} & \multirow{3}{*}{0.12} & 0.52 & \multirow{3}{*}{0.71} & \multirow{3}{*}{0.19} \\
\hline Trucking & 0.89 & & & 0.51 & & & 0.89 & & \\
\hline Trucking & 0.84 & & & 0.80 & & & & & \\
\hline Drilling & 0.98 & \multirow{3}{*}{1.06} & \multirow{3}{*}{0.07} & 0.74 & \multirow{3}{*}{0.95} & \multirow{3}{*}{0.15} & 0.63 & \multirow{3}{*}{0.78} & \multirow{3}{*}{0.15} \\
\hline Drilling & 1.05 & & & 1.03 & & & 0.92 & & \\
\hline Drilling & 1.16 & & & 1.08 & & & & & \\
\hline Fracking & 1.00 & \multirow{3}{*}{1.05} & \multirow{3}{*}{0.04} & 0.97 & \multirow{3}{*}{0.97} & \multirow{3}{*}{0.01} & 0.86 & \multirow{3}{*}{0.88} & \multirow{3}{*}{0.02} \\
\hline Fracking & 1.09 & & & 0.95 & & & 0.89 & & \\
\hline Fracking & 1.05 & & & 0.98 & & & & & \\
\hline
\end{tabular}


The highest $\mathrm{CH}_{4}$ emissions were observed for the FTP cycle, Figure 4.6, among all the other cycles. Methane emissions for the fuel blends are represented in Figure 4.12. It may be observed that test cycles operating over $\mathrm{CNG}$ as fuel, tend to have slightly higher $\mathrm{CH}_{4}$ emissions than the fuel blends.

For the trucking cycle, $\mathrm{CNG}$ yielded statistically higher (25.61\%) $\mathrm{CH}_{4}$ emissions than Blend 1 but there was no significant statistical difference between the emission levels from CNG and Blend 2. Blend 1 and Blend 2 also did not have any statistical difference between their $\mathrm{CH}_{4}$ emission levels. For the drilling cycle, $\mathrm{CNG}$ yielded marginally higher $\mathrm{CH}_{4}$ emissions than Blend 2, that was $27.74 \%$ higher. There was no statistical difference between the $\mathrm{CH}_{4}$ emissions of Blend 1 and Blend 2. For the fracking cycle, the $\mathrm{CH}_{4}$ emissions for $\mathrm{CNG}$ and Blend 1 were marginally different, with $\mathrm{CNG}$ 's emissions being $7.71 \%$ higher. The $\mathrm{CH}_{4}$ emissions of $\mathrm{CNG}$ were $17.45 \%$ higher than Blend 2. Blend 1 yielded $10.55 \%$ higher $\mathrm{CH}_{4}$ emissions than Blend 2.

Table 4.5 provides the data used in this study for the analysis of $\mathrm{CH}_{4}$ emissions. The data provides the emissions measured for all the tests carried out with the engine being operated over CNG, Blend 1 and Blend 2 as fuel.

As $\mathrm{CH}_{4}$ was the major content of THC emissions, the trends of $\mathrm{CH}_{4}$ emissions and the effect of fuel properties were similar to that of THC emissions.

Table 4.5: $\mathrm{CH}_{4}$ Emissions data used in this study

\begin{tabular}{|c|c|c|c|c|c|c|c|c|c|}
\hline \multicolumn{10}{|c|}{$\mathrm{CH}_{4}$} \\
\hline & \multicolumn{3}{|c|}{ CNG } & \multicolumn{3}{|c|}{ Blend 1} & \multicolumn{3}{|c|}{ Blend 2} \\
\hline & g/bhp-hr & mean & std dev & $\mathrm{g} / \mathrm{bhp}-\mathrm{hr}$ & mean & std dev & g/bhp-hr & mean & std dev \\
\hline FTP & 1.06 & \multirow{3}{*}{1.33} & \multirow{3}{*}{0.20} & & & & & & \\
\hline FTP & 1.54 & & & & & & & & \\
\hline FTP & 1.38 & & & & & & & & \\
\hline Trucking & 0.85 & \multirow{3}{*}{0.82} & \multirow{3}{*}{0.03} & 0.60 & \multirow{3}{*}{0.61} & \multirow{3}{*}{0.10} & 0.50 & \multirow{3}{*}{0.68} & \multirow{3}{*}{0.18} \\
\hline Trucking & 0.83 & & & 0.49 & & & 0.85 & & \\
\hline Trucking & 0.78 & & & 0.74 & & & & & \\
\hline Drilling & 0.92 & \multirow{3}{*}{1.00} & \multirow{3}{*}{0.07} & 0.70 & \multirow{3}{*}{0.90} & \multirow{3}{*}{0.14} & 0.59 & \multirow{3}{*}{0.73} & \multirow{3}{*}{0.14} \\
\hline Drilling & 0.99 & & & 0.97 & & & 0.86 & & \\
\hline Drilling & 1.10 & & & 1.03 & & & & & \\
\hline Fracking & 0.94 & \multirow{3}{*}{0.99} & \multirow{3}{*}{0.04} & 0.92 & \multirow{3}{*}{0.92} & \multirow{3}{*}{0.01} & 0.81 & \multirow{3}{*}{0.82} & \multirow{3}{*}{0.01} \\
\hline Fracking & 1.04 & & & 0.90 & & & 0.83 & & \\
\hline Fracking & 1.00 & & & 0.93 & & & & & \\
\hline
\end{tabular}




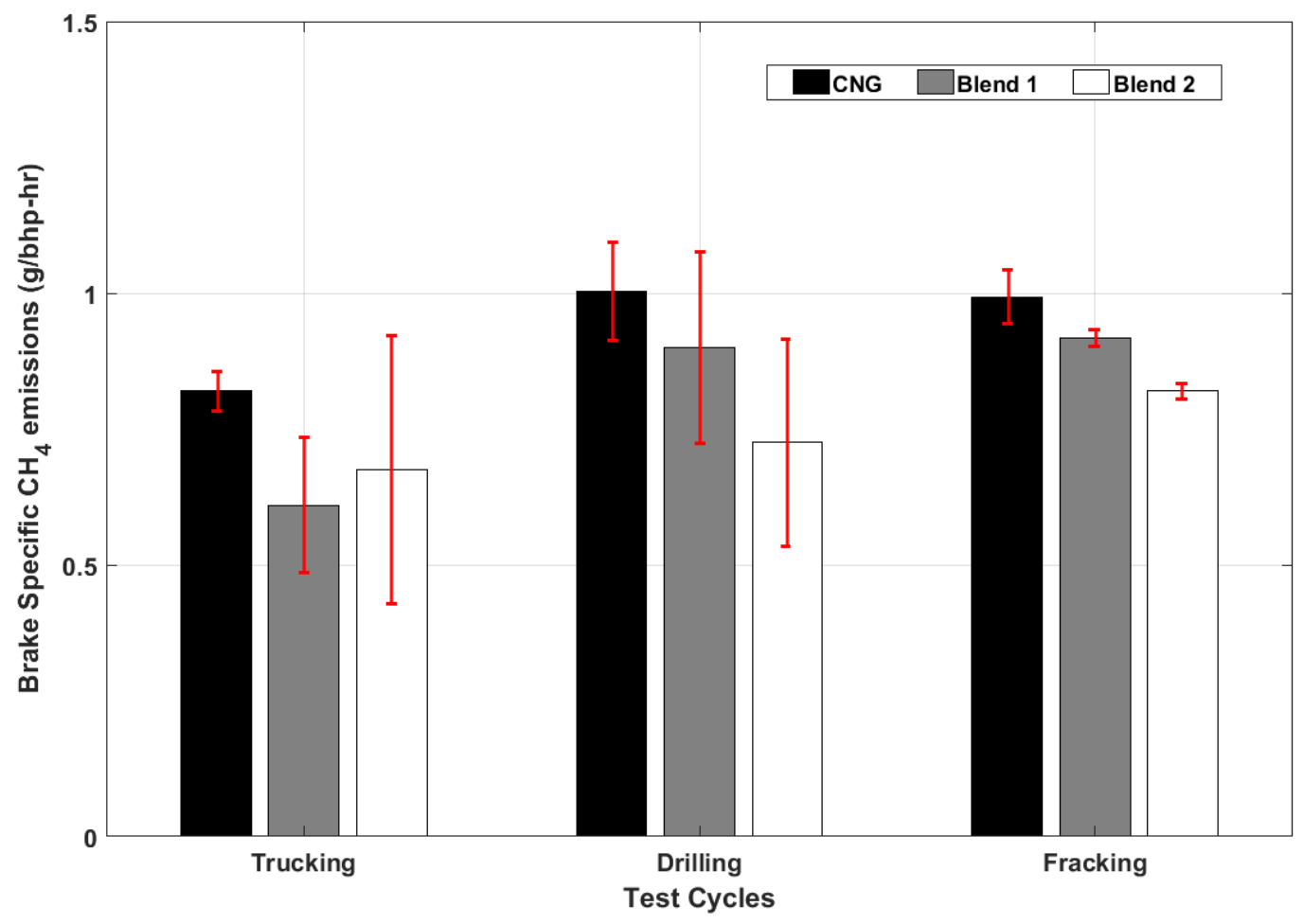

Figure 4.12: Effect of NG fuel blends on $\mathrm{CH}_{4}$ emissions

\subsection{Crankcase Emissions and Tailpipe Emissions}

Crankcase ventilation is necessary to balance the air pressure between the engine crankcase and the atmospheric pressure and ensure that there are no negative effects of the higher or lower pressure developed [55]. The combustion byproducts and the exhaust fumes escape around the piston rings and into the crankcase. When vented out, these fumes result in crankcase emissions [55]. In our study, a comparison of the crankcase emissions of natural gas (which would be mostly methane) and the tailpipe emissions of methane has been presented to analyze the amount of methane lost and determine the cases in which the crankcase emissions are higher than the tailpipe methane emissions. 


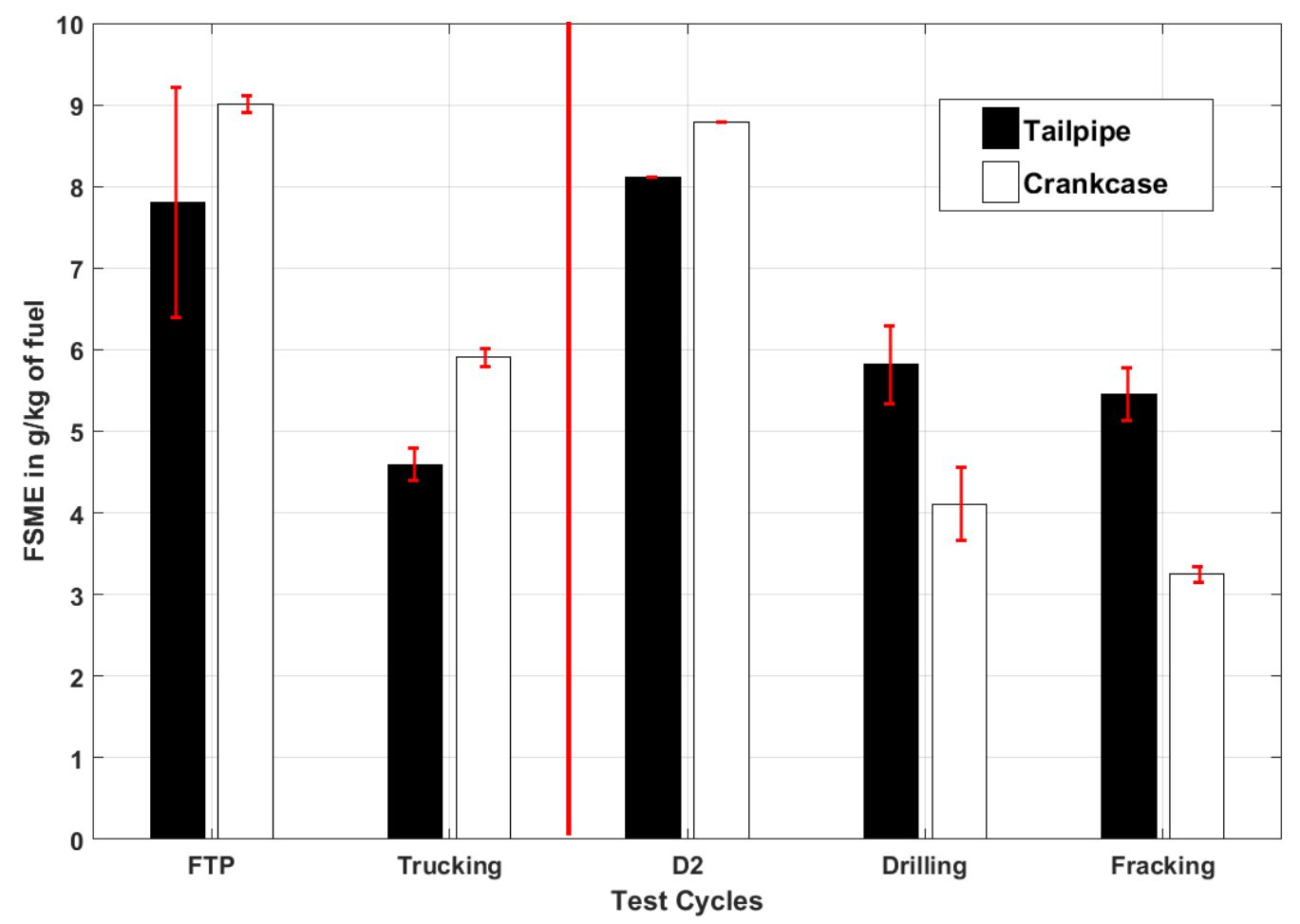

Figure 4.13: Crankcase Methane Emissions in comparison to Tailpipe Methane Emissions (CNG as fuel)

For this study, it was decided to compare the Fuel-specific Methane Emissions (FSME) from the crankcase (CC) and tailpipe (TP). Figure 4.13 shows the crankcase FSME in comparison to the tailpipe FSME when the engine is operated with CNG as fuel. The crankcase emissions are higher for the transient cycles (FTP, trucking) while it is lower for the steady-state cycles (drilling, fracking). This slip of crankcase emissions during the FTP and trucking cycle may be accounted to the transiency of the test where the speed and load are varying constantly. Though, FTP and trucking cycles are characterized by their transiency, the initial $45 \%$ of trucking cycle is characterized by steady-state operation. This may explain the difference of emissions levels between FTP and trucking cycle. During the steady-state operation of drilling and fracking cycle, very little change of speed and load is present and thus there may be lower chances of slip of gases from the piston rings. However, D-2 cycle, being a steady-state cycle has higher crankcase FSME than the tailpipe FSME. This may be attributed to the transiency involved in D-2 cycle while operating over the five steady-state modes. 
Figure 4.14 shows the crankcase FSME in comparison to the tailpipe FSME when the engine is operated with Blend 1 as the fuel. The trends are similar to the trends when the engine is operated over CNG. The Blend 1 seems to have no other effect when compared to CNG.

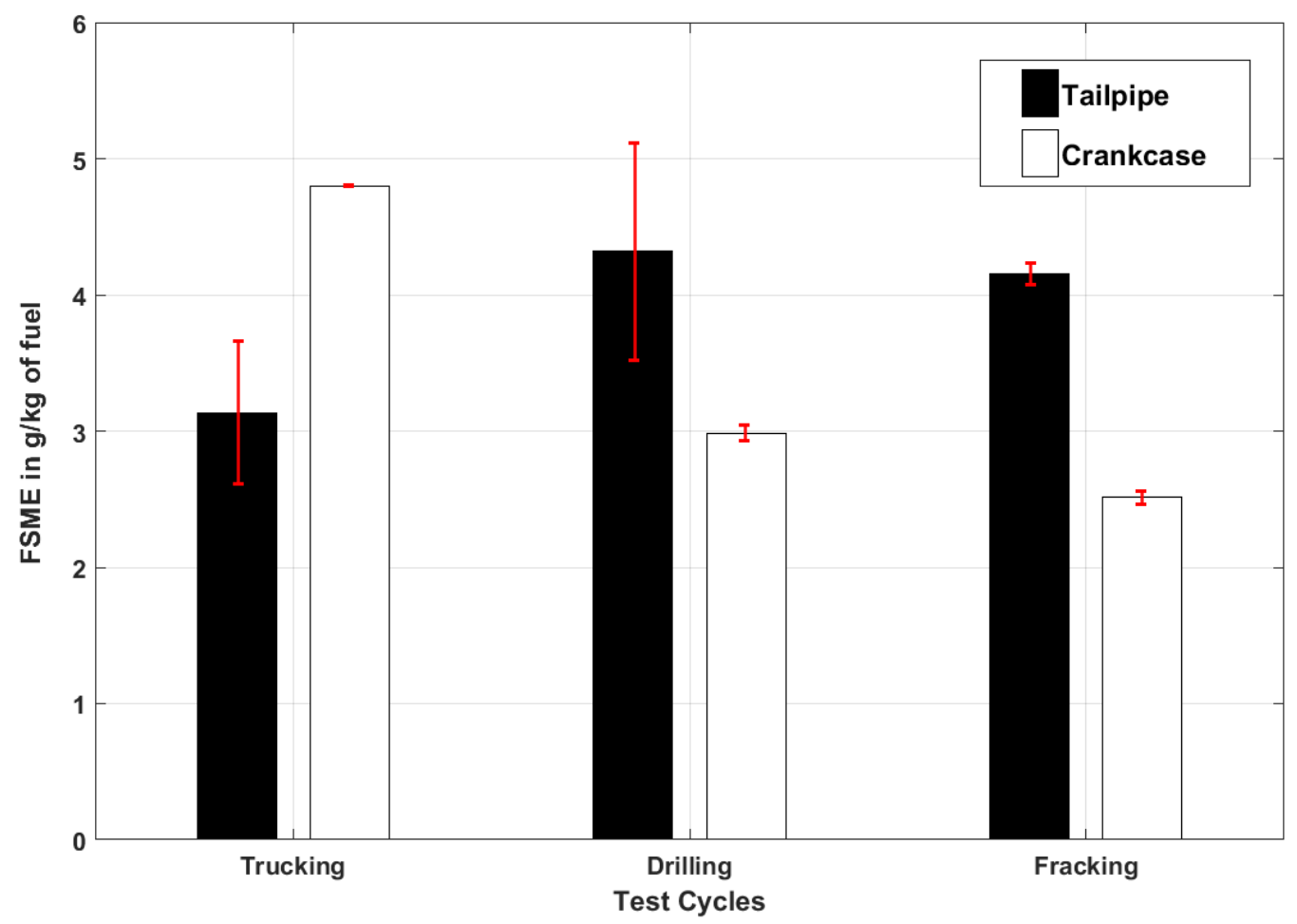

Figure 4.14: Crankcase FSME in comparison to the Tailpipe FSME (Blend 1 as fuel)

Figure 4.15 represents the comparison between the crankcase FSME and the tailpipe FSME when the engine is operated with Blend 2 as fuel. Here too, the trends are similar to that of CNG fuel. Blend 2 has no other effect on the crankcase emissions of the engine. Though the crankcase and tailpipe methane emissions for trucking and drilling cycle, when the engine was operated over Blend 1 and Blend 2 appear to vary, it was evaluated that there was no statistical difference between the emissions of the two blends.

To elaborate further on the difference of emissions from crankcase and tailpipe, Table 4.6 has been provided. This table provides a comprehensive information on the crankcase emissions when the engine was operated with CNG and the natural gas blends as fuel. 


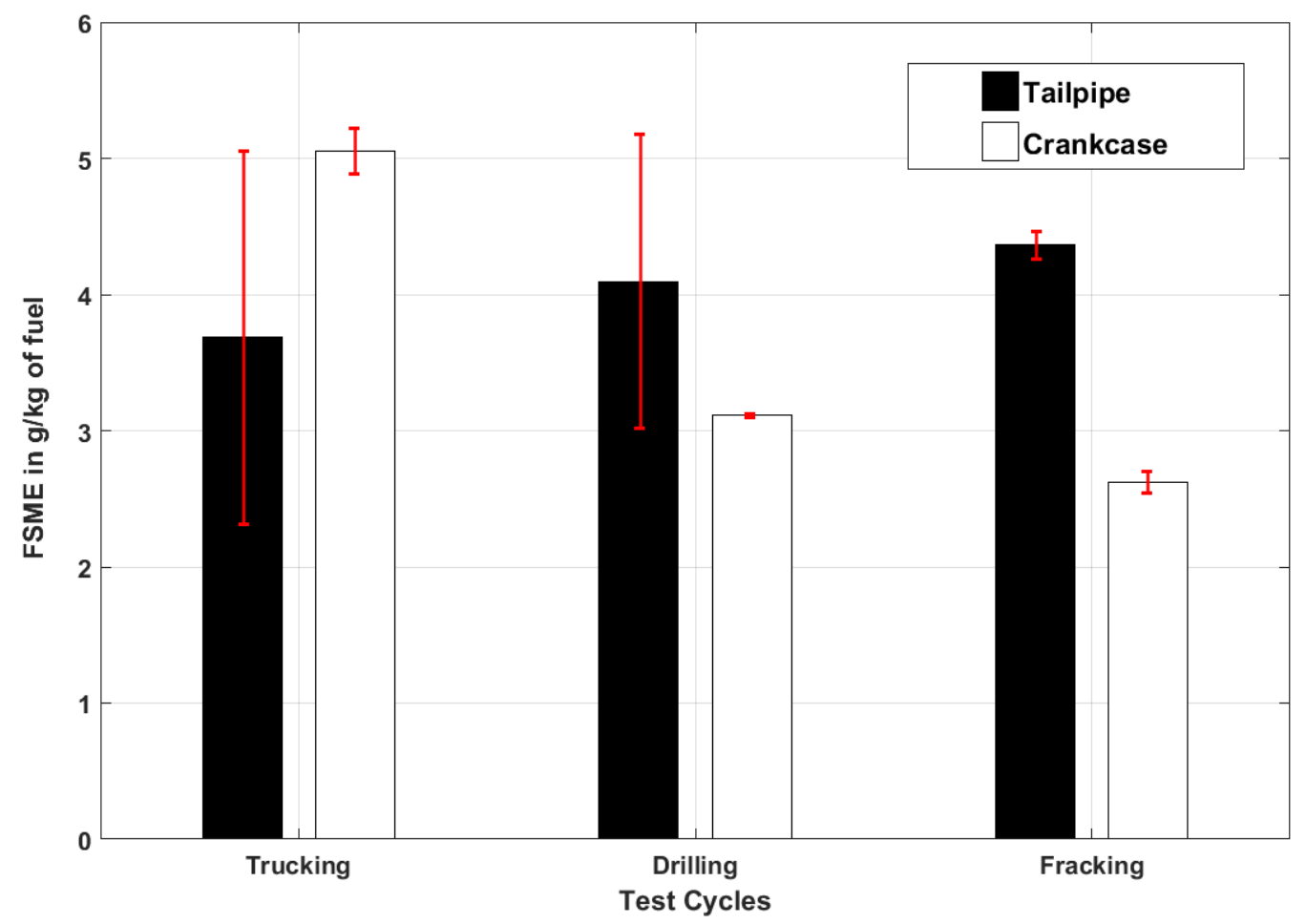

Figure 4.15: Crankcase FSME in comparison to Tailpipe FSME (Blend 2 as fuel)

Table 4.6: Comparison of total methane emissions from $\mathrm{CC}$ and TP with comparison of the $\mathrm{CC}$ and TP emissions

\begin{tabular}{|c|r|r|r|r|r|}
\hline For CNG as Fuel (avg) & & & & & \\
\hline & \multicolumn{1}{|c|}{$C$ C } & \multicolumn{1}{c|}{$T$ P } & \multicolumn{1}{c|}{ Total } & \multicolumn{1}{c|}{ CC/TP } & CC/Total \\
\hline FTP & 9.00 & 7.80 & 16.80 & $115 \%$ & $54 \%$ \\
\hline Trucking & 5.90 & 4.59 & 10.50 & $129 \%$ & $56 \%$ \\
\hline D2 & 8.78 & 8.11 & 16.89 & $108 \%$ & $52 \%$ \\
\hline Drilling & 4.11 & 5.82 & 9.93 & $71 \%$ & $41 \%$ \\
\hline Fracking & 3.25 & 5.46 & 8.71 & $60 \%$ & $37 \%$ \\
\hline For B1 as Fuel (avg) & & & & & \\
\hline & $C C$ & $T P$ & $T$ Total & CC/TP & CC/Total \\
\hline Trucking & \multicolumn{1}{|c|}{4.80} & 3.14 & 7.94 & $153 \%$ & $60 \%$ \\
\hline Drilling & 2.99 & 4.32 & 7.30 & $69 \%$ & $41 \%$ \\
\hline Fracking & 2.51 & 4.15 & 6.67 & $61 \%$ & $38 \%$ \\
\hline For B2 as Fuel (avg) & & & & & \\
\hline & $C C$ & $T P$ & Total & CC/TP & CC/Total \\
\hline Trucking & 5.05 & 3.68 & 8.74 & $137 \%$ & $58 \%$ \\
\hline Drilling & 3.11 & 4.10 & 7.21 & $76 \%$ & $43 \%$ \\
\hline Fracking & 2.62 & 4.36 & 6.98 & $60 \%$ & $38 \%$ \\
\hline
\end{tabular}




\subsection{Particle Emissions}

Natural gas engines are traditionally low-soot emitting engines [31]. A part of this research included comparing the particle size and characteristics for the gaseous fuel blends to that of CNG.

\subsubsection{Gravimetric Particulate Mass}

Figure 4.16 shows the effect of the different fuel blends on the PM emissions. The FTP cycle data uses CNG as fuel. Due to limited availability, the natural gas fuel blends could not be tested over the FTP cycle.

For the trucking cycle, the PM emissions for CNG and Blend 1 are marginally different with the $\mathrm{PM}$ emissions of $\mathrm{CNG}$ being 25\% lower than that of Blend 1. The difference in the PM emissions between CNG and Blend 2 and between Blend 1 and Blend 2 were not statistically different. For the drilling Cycle, the CNG yielded the highest PM emissions. They were 32\% and 34\% higher than the PM emissions of Blend 1 and Blend 2 respectively. For the fracking cycle, CNG yielded significantly higher PM emissions than Blend 1, 15.38\% higher than that of Blend 1. The PM emissions of $\mathrm{CNG}$ and Blend 2 were about the same. Also, there was no significant difference in the PM emission levels of Blend 1 and Blend 2. No clear trend could be observed for the PM emissions for the three fuel blends. This is in line with the observations presented by Karavalakis et.al. [32].

Table 4.7 provides the complete details of the PM emissions measured in this study for analysis and comparison of the effect of NG blends.

For trucking cycle, the PM emissions decreased with increasing $H / C$ ratio $\left(R^{2}=0.8369\right)$. It was, further, observed that with increasing propane content, the PM emissions increased for trucking cycle. The strongest correlation, for drilling cycle, was observed with MN, where the PM emissions increased with increasing $\mathrm{MN}\left(\mathrm{R}^{2}=0.9988\right)$. For fracking cycle, the PM emissions were observed to be increasing with $H / C$ ratio $\left(R^{2}=0.9396\right)$. Further, it was observed that the PM emissions decreased with increasing propane content $\left(R^{2}=0.9987\right)$. 


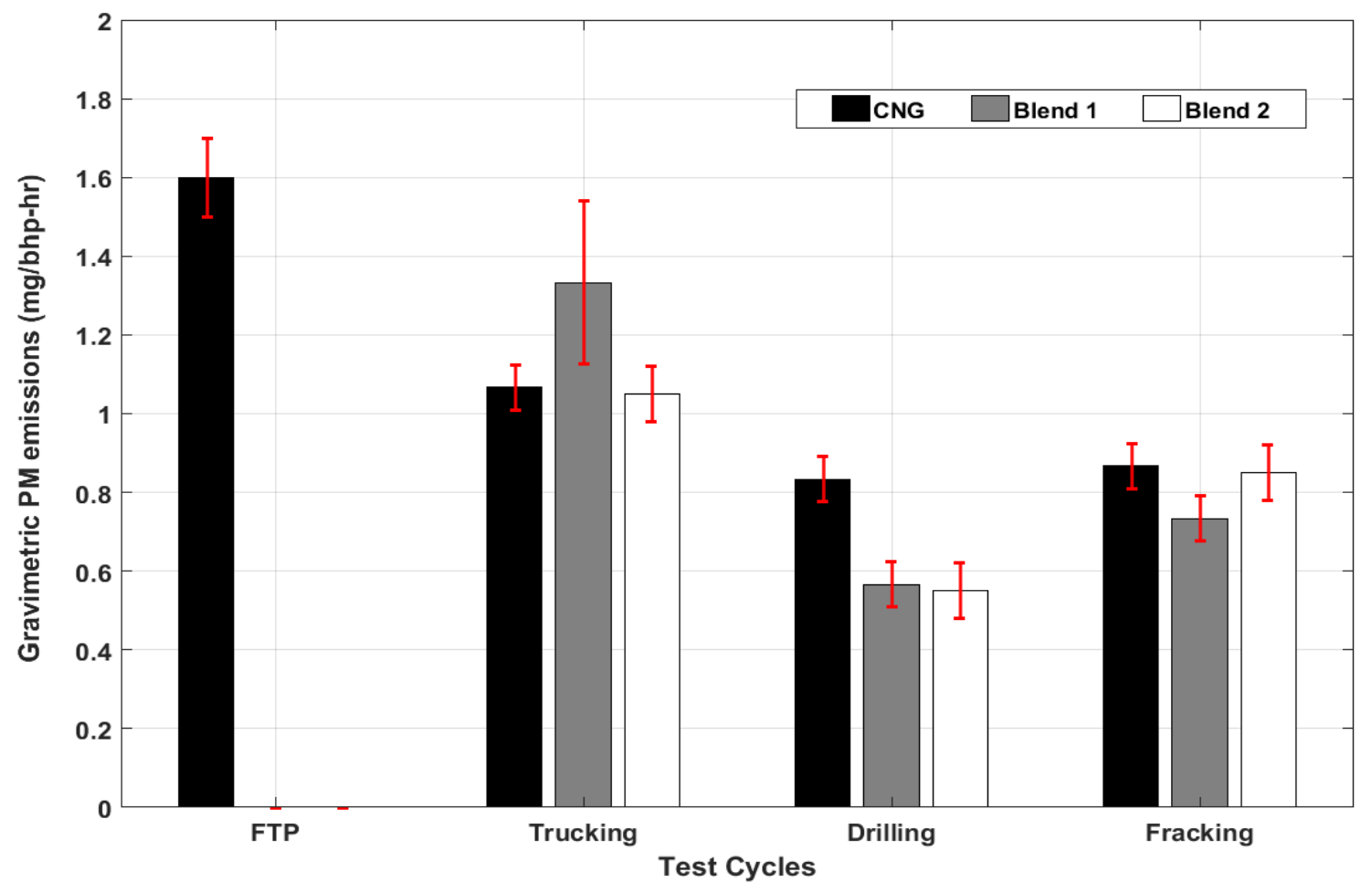

Figure 4.16: Effect of NG Blends on the particulate matter mass emissions (in milligrams)

Table 4.7: Gravimetric PM emissions data used in this study

\begin{tabular}{|c|c|c|c|c|c|c|c|c|c|}
\hline \multicolumn{10}{|c|}{ Gravimetric PM } \\
\hline & \multicolumn{3}{|c|}{ CNG } & \multicolumn{3}{|c|}{ Blend 1} & \multicolumn{3}{|c|}{ Blend 2} \\
\hline & $\mathrm{mg} / \mathrm{bhp}-\mathrm{hr}$ & mean & std dev & $\mathrm{mg} / \mathrm{bhp}-\mathrm{hr}$ & mean & std dev & $\mathrm{mg} / \mathrm{bhp}-\mathrm{hr}$ & mean & std dev \\
\hline FTP & 1.70 & \multirow{3}{*}{1.60} & \multirow{3}{*}{0.08} & & & & & & \\
\hline FTP & 1.50 & & & & & & & & \\
\hline FTP & 1.60 & & & & & & & & \\
\hline Trucking & 1.10 & \multirow{3}{*}{1.07} & \multirow{3}{*}{0.05} & 1.50 & \multirow{3}{*}{1.33} & \multirow{3}{*}{0.17} & 1.10 & \multirow{3}{*}{1.05} & \multirow{3}{*}{0.05} \\
\hline Trucking & 1.10 & & & 1.40 & & & 1.00 & & \\
\hline Trucking & 1.00 & & & 1.10 & & & & & \\
\hline Drilling & 0.80 & \multirow{3}{*}{0.83} & \multirow{3}{*}{0.05} & 0.50 & \multirow{3}{*}{0.57} & \multirow{3}{*}{0.05} & 0.50 & \multirow{3}{*}{0.55} & \multirow{3}{*}{0.05} \\
\hline Drilling & 0.90 & & & 0.60 & & & 0.60 & & \\
\hline Drilling & 0.80 & & & 0.60 & & & & & \\
\hline Fracking & 0.90 & \multirow{3}{*}{0.87} & \multirow{3}{*}{0.05} & 0.80 & \multirow{3}{*}{0.73} & \multirow{3}{*}{0.05} & 0.80 & \multirow{3}{*}{0.85} & \multirow{3}{*}{0.05} \\
\hline Fracking & 0.90 & & & 0.70 & & & 0.90 & & \\
\hline Fracking & 0.80 & & & 0.70 & & & & & \\
\hline
\end{tabular}




\subsubsection{Particle Number Emissions}

Figure 4.17 shows how the particle number concentrations vary for CNG and the two blends of natural gas. The PN concentration is represented on a brake-specific unit (\#/bhp-hr).

It may be observed that the PN emissions were the lowest when the engine was operated with CNG as fuel. Also, the PN emissions are the lowest, in general, for the fracking cycle. It is observed, here, that the natural gas blends emit the highest PN emissions, especially, when the engine is operated over the transient trucking cycle and during the high load drilling cycle. In general, for all fuels and test cycles, the PN emissions within the nucleation mode size range are higher than the accumulation mode. Blend 1 and Blend 2, having lower MN of around 75, showed higher PN emissions than $\mathrm{CNG}$ which has a high $\mathrm{MN}$ of 85.2. This trend aligns with the trends presented by Karavalakis et.al. [32]. For fracking cycle, H/C ratio had the strongest correlation, with PN emissions decreasing with increasing $\mathrm{H} / \mathrm{C}$ ratio $\left(\mathrm{R}^{2}=0.8445\right)$.

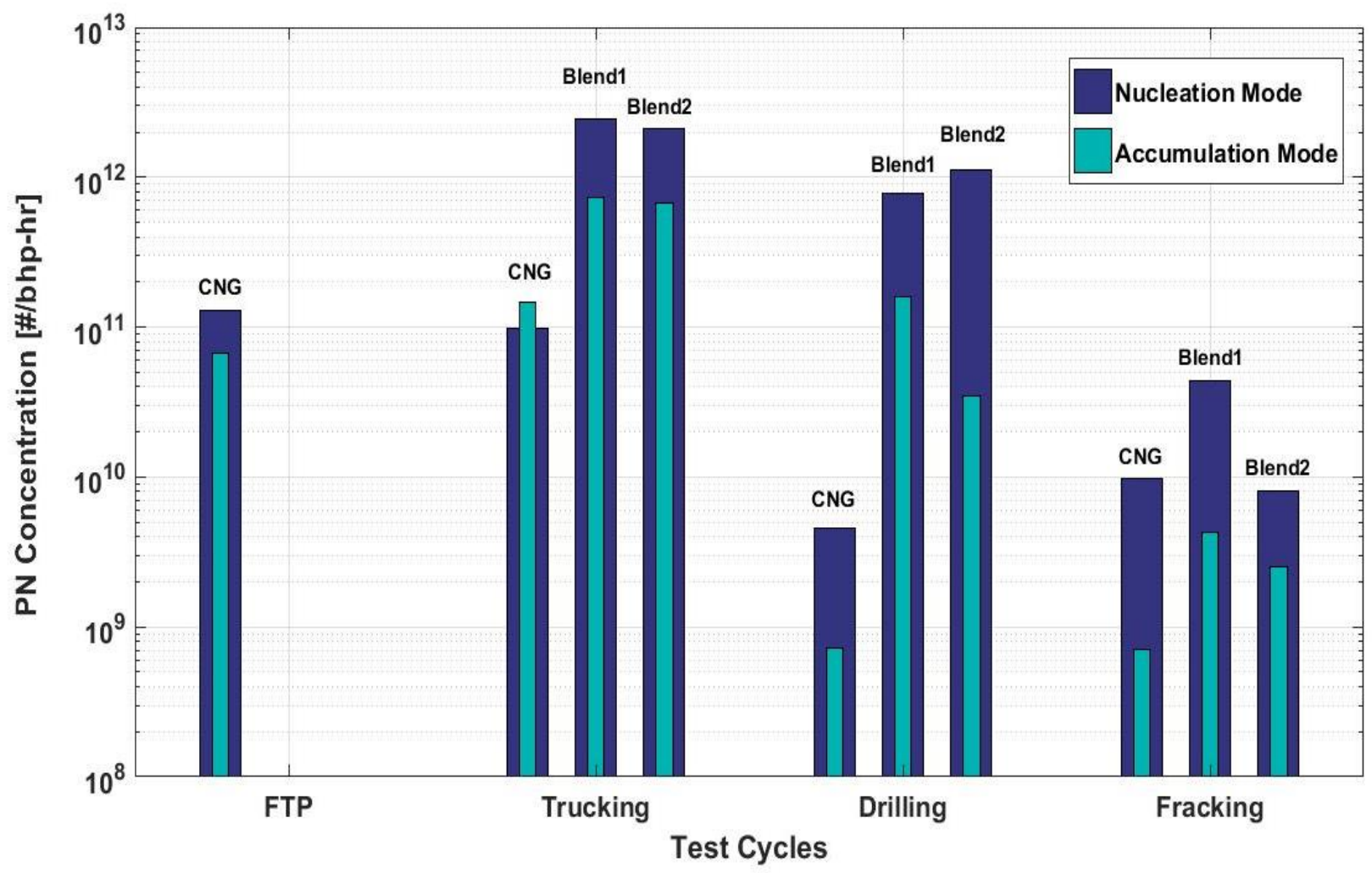

Figure 4.17: Effect of NG blends on the PN Emissions (\#/bhp-hr) 
Table 4.8 and Table 4.9 provide the particle number emissions measured in this study, to represent

PN emissions for nucleation mode and accumulation mode, respectively.

Table 4.8: PN emissions data for nucleation mode particles

\begin{tabular}{|c|c|c|c|c|c|c|c|c|c|}
\hline \multicolumn{10}{|c|}{ PN Nucleation Mode } \\
\hline & \multicolumn{3}{|c|}{ CNG } & \multicolumn{3}{|c|}{ Blend 1} & \multicolumn{3}{|c|}{ Blend 2} \\
\hline & \#/bhp-hr & mean & std dev & \#/bhp-hr & mean & std dev & \#/bhp-hr & mean & std dev \\
\hline FTP & $2.15 \mathrm{E}+11$ & \multirow{3}{*}{$1.30 \mathrm{E}+11$} & \multirow{3}{*}{$6.52 \mathrm{E}+10$} & & & & & & \\
\hline FTP & $1.19 \mathrm{E}+11$ & & & & & & & & \\
\hline FTP & $5.69 \mathrm{E}+10$ & & & & & & & & \\
\hline Trucking & $1.34 \mathrm{E}+11$ & \multirow{3}{*}{$9.71 \mathrm{E}+10$} & \multirow{3}{*}{$2.95 \mathrm{E}+10$} & $2.85 \mathrm{E}+12$ & \multirow{3}{*}{$2.46 \mathrm{E}+12$} & \multirow{3}{*}{$4.39 \mathrm{E}+11$} & $3.66 \mathrm{E}+12$ & \multirow{3}{*}{$2.13 \mathrm{E}+12$} & \multirow{3}{*}{$1.53 \mathrm{E}+12$} \\
\hline Trucking & $9.45 \mathrm{E}+10$ & & & $2.69 \mathrm{E}+12$ & & & $5.98 \mathrm{E}+11$ & & \\
\hline Trucking & $6.24 \mathrm{E}+10$ & & & $1.85 \mathrm{E}+12$ & & & & & \\
\hline Drilling & & \multirow{3}{*}{$4.55 \mathrm{E}+09$} & \multirow{3}{*}{$3.31 \mathrm{E}+09$} & $9.87 \mathrm{E}+11$ & \multirow{3}{*}{$7.78 \mathrm{E}+11$} & \multirow{3}{*}{$4.82 \mathrm{E}+11$} & $2.07 \mathrm{E}+12$ & \multirow{3}{*}{$1.13 \mathrm{E}+12$} & \multirow{3}{*}{$9.41 \mathrm{E}+11$} \\
\hline Drilling & $1.24 \mathrm{E}+09$ & & & $1.24 \mathrm{E}+12$ & & & $1.85 \mathrm{E}+11$ & & \\
\hline Drilling & $7.85 \mathrm{E}+09$ & & & $1.11 \mathrm{E}+11$ & & & & & \\
\hline Fracking & $9.84 \mathrm{E}+09$ & \multirow{3}{*}{$9.79 \mathrm{E}+09$} & \multirow{3}{*}{$1.73 \mathrm{E}+09$} & $4.88 \mathrm{E}+10$ & \multirow{3}{*}{$4.38 \mathrm{E}+10$} & \multirow{3}{*}{$5.78 \mathrm{E}+09$} & $8.29 \mathrm{E}+09$ & \multirow{3}{*}{$8.09 \mathrm{E}+09$} & \multirow{3}{*}{$1.93 \mathrm{E}+08$} \\
\hline Fracking & $1.19 \mathrm{E}+10$ & & & $3.57 \mathrm{E}+10$ & & & $7.90 \mathrm{E}+09$ & & \\
\hline Fracking & $7.63 \mathrm{E}+09$ & & & $4.69 \mathrm{E}+10$ & & & & & \\
\hline
\end{tabular}

Table 4.9: PN Emissions data for accumulation mode particles

\begin{tabular}{|c|c|c|c|c|c|c|c|c|c|}
\hline \multicolumn{10}{|c|}{ PN Accumulation Mode } \\
\hline & \multicolumn{3}{|c|}{ CNG } & \multicolumn{3}{|c|}{ Blend 1} & \multicolumn{3}{|c|}{ Blend 2} \\
\hline & \#/bhp-hr & mean & std dev & \#/bhp-hr & mean & std dev & \#/bhp-hr & mean & std dev \\
\hline FTP & $1.47 \mathrm{E}+11$ & \multirow{3}{*}{$6.69 E+10$} & \multirow{3}{*}{$5.67 \mathrm{E}+10$} & & & & & & \\
\hline FTP & $2.12 \mathrm{E}+10$ & & & & & & & & \\
\hline FTP & $3.26 \mathrm{E}+10$ & & & & & & & & \\
\hline Trucking & $1.51 \mathrm{E}+11$ & \multirow{3}{*}{$1.47 \mathrm{E}+11$} & \multirow{3}{*}{$2.24 \mathrm{E}+10$} & $8.90 \mathrm{E}+11$ & \multirow{3}{*}{$7.31 \mathrm{E}+11$} & \multirow{3}{*}{$1.57 \mathrm{E}+11$} & $1.34 \mathrm{E}+12$ & \multirow{3}{*}{$6.78 \mathrm{E}+11$} & \multirow{3}{*}{$6.59 \mathrm{E}+11$} \\
\hline Trucking & $1.18 \mathrm{E}+11$ & & & $7.87 \mathrm{E}+11$ & & & $1.93 \mathrm{E}+10$ & & \\
\hline Trucking & $1.73 \mathrm{E}+11$ & & & $5.16 \mathrm{E}+11$ & & & & & \\
\hline Drilling & & \multirow{3}{*}{$7.31 \mathrm{E}+08$} & \multirow{3}{*}{$2.63 \mathrm{E}+08$} & $1.85 \mathrm{E}+11$ & \multirow{3}{*}{$1.60 \mathrm{E}+11$} & \multirow{3}{*}{$1.13 \mathrm{E}+11$} & $4.08 \mathrm{E}+10$ & \multirow{3}{*}{$3.45 \mathrm{E}+10$} & \multirow{3}{*}{$6.28 \mathrm{E}+09$} \\
\hline Drilling & $4.68 \mathrm{E}+08$ & & & $2.84 \mathrm{E}+11$ & & & $2.82 \mathrm{E}+10$ & & \\
\hline Drilling & $9.94 \mathrm{E}+08$ & & & $1.11 \mathrm{E}+10$ & & & & & \\
\hline Fracking & $6.93 \mathrm{E}+08$ & \multirow{3}{*}{$7.09 \mathrm{E}+08$} & \multirow{3}{*}{$1.42 \mathrm{E}+08$} & $5.52 \mathrm{E}+09$ & \multirow{3}{*}{$4.29 \mathrm{E}+09$} & \multirow{3}{*}{$8.89 \mathrm{E}+08$} & $4.20 \mathrm{E}+08$ & \multirow{3}{*}{$2.54 \mathrm{E}+09$} & \multirow{3}{*}{$2.12 \mathrm{E}+09$} \\
\hline Fracking & $8.91 \mathrm{E}+08$ & & & $3.44 \mathrm{E}+09$ & & & $4.67 \mathrm{E}+09$ & & \\
\hline Fracking & $5.44 \mathrm{E}+08$ & & & $3.93 \mathrm{E}+09$ & & & & & \\
\hline
\end{tabular}


To understand the size-wise distribution of the PN emissions and its effect on the PM, the data was divided into nucleation mode and accumulation mode.

\section{Trucking Cycle:}

Figure 4.18 shows bin-size normalized the particle concentration (dN/dlogDp) with the size distribution when the engine is operated over the trucking cycle. As shown in Figure 4.18, the particle emissions of the NG blends are higher than that of CNG, especially, in the nucleation mode. But, it may be observed that the particle emissions of CNG increases in the accumulation mode. This shows that larger particles are emitted when the engine is operated with CNG as fuel compared to the fuel blends. These higher diameter particles also account for the PM emissions of CNG, shown in Figure 4.16.

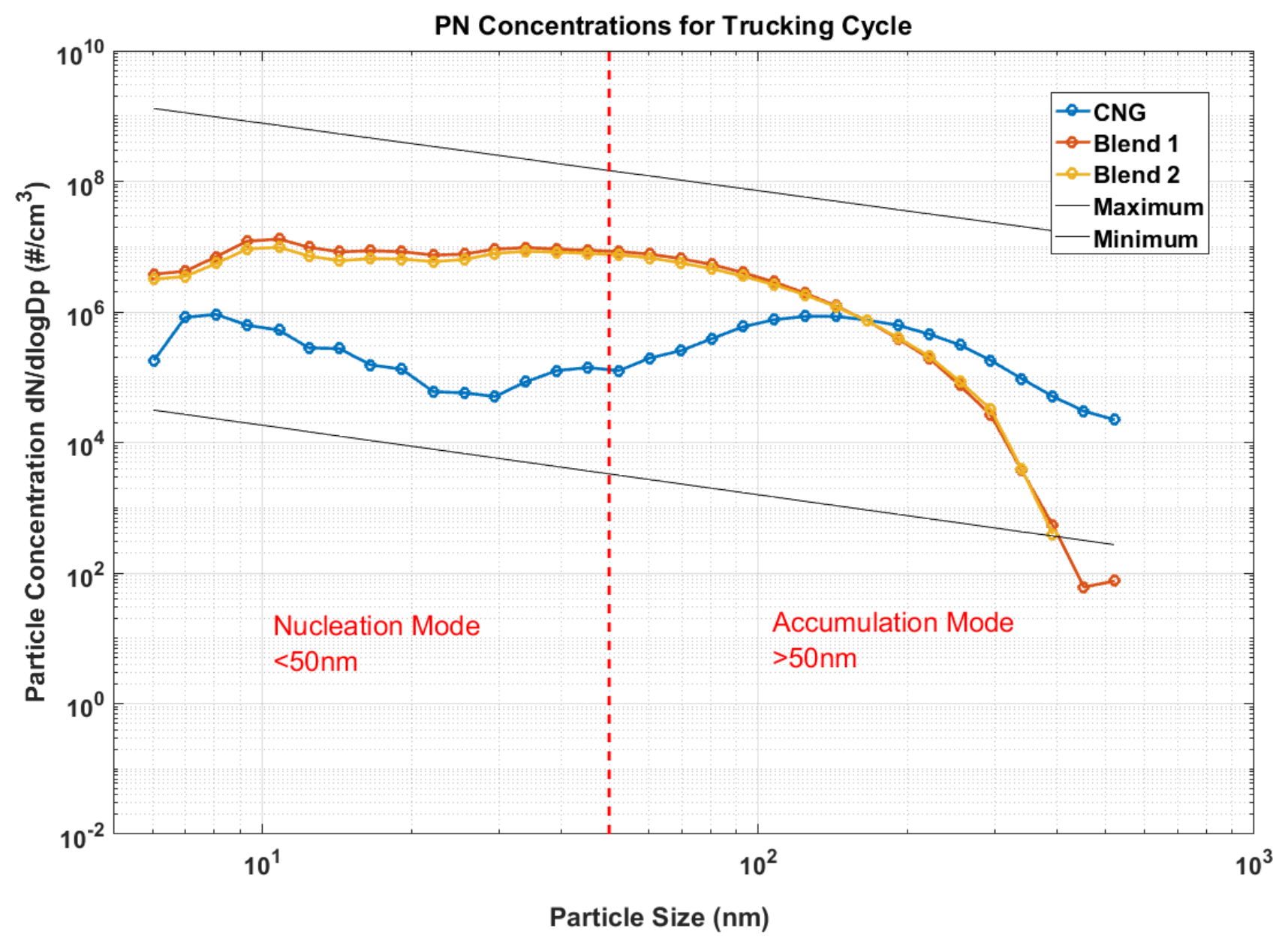

Figure 4.18: Size distribution of PN concentration for Trucking Cycle 


\section{Drilling Cycle:}

Figure 4.19 shows the bin-size normalized particle concentration with the size distribution when the engine is operated over the drilling cycle. It may be observed here that the PN emissions from $\mathrm{CNG}$ are close to the minimum detection limits of the instrument whereas the PN emissions of the NG blends are higher. A similar trend is observed in Figure 4.17. The gravimetric PM, shown in Figure 4.16, indicates that the PM emissions of CNG are almost $35 \%$ more than that of the NG blends. This opposing trend of particle emissions (mass and number) may be attributed to the hydro-carbon emissions of the CNG. As shown in Figure 4.11, the THC emissions of CNG are marginally higher than that of the NG blends, which may result in higher PM emissions.

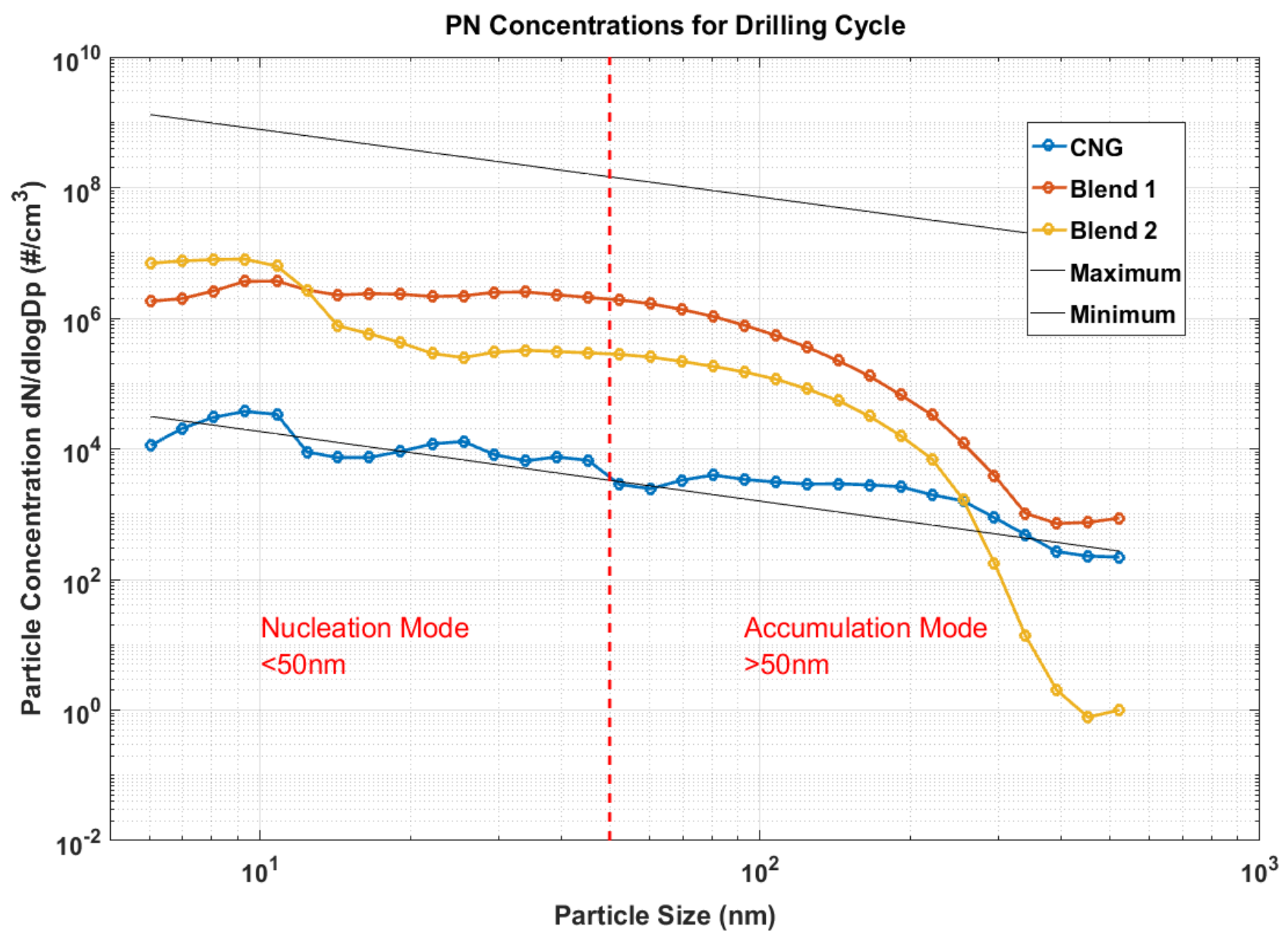

Figure 4.19: Size distribution of PN concentration for Drilling Cycle 


\section{Fracking Cycle:}

Figure 4.20 shows the bin-size normalized particle concentration with the size distribution, when the engine is operated over the fracking cycle. Low levels of PN emissions can be observed for CNG and the NG blends. Figure 4.17 corresponds to the same.

Higher gravimetric PM is observed for the fracking cycle, see Figure 4.16. This may be attributed to the higher THC emissions produced when the engine is operated over the fracking cycle, see Figure 4.11.

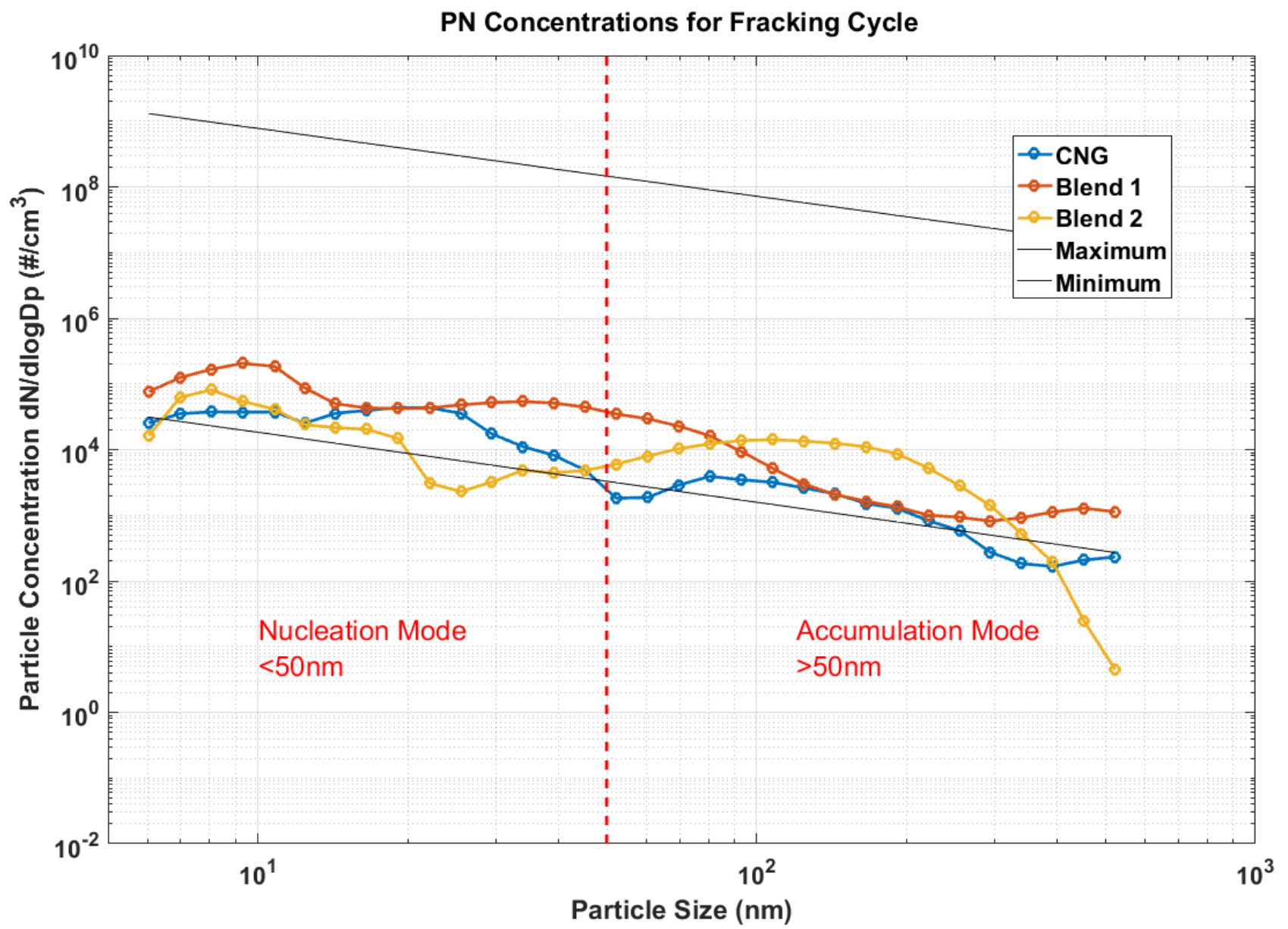

Figure 4.20: Size distribution of PN concentration for Fracking Cycle 


\section{Conclusions and Recommendations}

\subsection{Summary}

The process of unconventional well development is highly power intensive and, currently, is a fairly expensive process due to diesel fuel prices. Hence, the hydrocarbon-producing industry is opting to use dedicated natural gas engines for the well development processes. The prime-movers employed by unconventional well development industry include OTR trucks as well as the high horsepower drilling and the hydraulic fracturing engines. Replacing these diesel-fueled prime movers with natural gas engines may pose a challenge from a GHG perspective as natural gas is primarily composed of methane, a potent GHG. This has led the government agencies such as the DOE to obtain information on this issue and quantify the emissions associated with unconventional well development. The government agencies are also interested in utilizing the natural gas obtained from the wells as fuel for the prime movers. As part of a project opportunity from DOE, WVU was tasked to quantify the in-use and laboratory-based emissions factors for typical prime movers of the unconventional well development industry. This study involved the selection of natural gas fuel blends that would represent the natural gas composition of the shale play regions along with a detailed comparison of emissions of these blends with commercially available the pump-quality CNG. Also, a comparison of the crankcase methane emissions and tailpipe methane emissions was included to shed light on the potential GHG emissions. Furthermore, particle emissions data (both PM and PN) were also collected and analyzed.

The engine was operated over different test cycles that had been custom generated to represent actual in-use activity of the prime movers. The cycles included, the OTR cycle, the drilling cycle and the fracking cycle. The test engine was operated with CNG, a high propane blend (Blend 1) and a high ethane blend (Blend 2) and the gaseous and particle emissions data was collected.

The results were analyzed in four sections. First, it involved the comparison of the custom generated cycles with the standard regulatory cycles. Second, the gaseous emissions of the engine with CNG as fuel was compared to the emissions of engine with the natural gas blends as fuel. Third, the crankcase methane emissions were compared to the tailpipe methane emissions. Further data was provided to show the crankcase methane emissions with respect to the total methane 
emissions of the engine. Fourth, the particle emissions of the engine for CNG and the natural gas fuel blends were presented. Both, the PM and PN emissions were measured and analyzed.

\subsection{Conclusions}

Drilling and fracking cycle were the more work intensive test cycles when compared to FTP and trucking cycles. The developed trucking cycle produced more $\mathrm{CO}_{2}, \mathrm{CO}$ and $\mathrm{NO}_{\mathrm{x}}$ emissions than FTP, while THC and $\mathrm{CH}_{4}$ emissions were lower. The drilling and fracking cycle produced more CO emissions than D-2 cycle while the other emissions tended to be lower.

Blend 1 produced higher $\mathrm{CO}_{2}$ emissions when compared to $\mathrm{CNG}$ and Blend 2. This may be due to the low $\mathrm{H} / \mathrm{C}$ ratio of Blend 2. $\mathrm{CO}$ emissions were the highest for Blend 2. $\mathrm{NO}_{\mathrm{x}}$ emissions were the highest when the engine was operated over the FTP and trucking cycle with CNG as fuel. For the drilling cycle, the $\mathrm{NO}_{\mathrm{x}}$ emissions were below detection limit due to the high load steady-state operation equipped with a three-way catalyst. The THC emissions were the highest for CNG for all the cycles though the difference was marginal for the fracking cycle. Methane emissions were also higher for $\mathrm{CNG}$ for all the cycles though the difference was marginal for methane emissions of CNG and Blend 1.

Crankcase emissions were higher for transient test cycles (FTP and trucking cycle) when compared to the steady-state test cycles (drilling and fracking cycles). This may be due to the slip of piston rings due to the varying speed and load during a transient operation.

PM emissions were higher when the engine was operated with CNG as fuel, except for the trucking cycle where Blend 1 had marginally higher PM emissions compared to CNG and Blend 2. PN emissions were higher for the natural gas fuel blends when compared to CNG. When the size distribution is observed, it may be seen that the particle concentration is highest in the nucleation mode.

To analyze the effects of fuel composition as a function of $\mathrm{H} / \mathrm{C}$ ratio, WI and $\mathrm{MN}$, a Pearson correlation analysis was performed. The Pearson correlation presents the strength of the correlation $(\mathrm{r})$, where $\mathrm{r}$ ranges from +1 to -1 . ' $\mathrm{r}=0$ ' indicates that there is no relation between the observed variables. Positive sign indicates a positive correlation, where one variable increases with increasing second variable and negative sign indicates negative correlation, where one variable decreases with increasing second variable. Table 5.1 provides a summary of the Pearson 
correlations for different fuel properties to explain their effect on the gaseous and particle emissions.

Table 5.1 Summary of correlations of fuel properties with the gaseous and particle emissions

\begin{tabular}{|c|c|c|c|c|c|c|c|c|}
\hline & Test Cycles & $\mathbf{r}, \mathbf{H} / \mathrm{C}$ & p, H/C & $\mathbf{r}, \mathbf{W I}$ & p, WI & $\mathbf{r}, \mathrm{MN}$ & p, MN & Correlation \\
\hline \multirow{3}{*}{$\mathrm{CO}_{2}$} & Trucking & -0.96 & 0.18 & 0.16 & 0.90 & -0.91 & 0.27 & Strong, H/C, negative \\
\hline & Drilling & -1.00 & 0.04 & -0.18 & 0.89 & -0.73 & 0.48 & Strong, H/C, negative \\
\hline & Fracking & -0.99 & 0.07 & -0.02 & 0.99 & -0.83 & 0.38 & Strong, H/C, negative \\
\hline \multirow{3}{*}{$\mathrm{CO}$} & Trucking & 0.16 & 0.90 & 1.00 & 0.02 & -0.52 & 0.66 & Strong, WI, positive \\
\hline & Drilling & -0.36 & 0.76 & 0.88 & 0.31 & -0.88 & 0.32 & Strong, WI, positive \\
\hline & Fracking & -0.15 & 0.91 & 0.96 & 0.17 & -0.75 & 0.46 & Strong, WI, positive \\
\hline \multirow{3}{*}{$\mathbf{N O}_{\mathbf{x}}$} & Trucking & 0.30 & 0.80 & -0.91 & 0.27 & 0.85 & 0.36 & Strong, MN, positive \\
\hline & Drilling & \multicolumn{7}{|c|}{ N/A } \\
\hline & Fracking & 0.53 & 0.65 & -0.78 & 0.43 & 0.95 & 0.20 & Strong, MN, positive \\
\hline \multirow{3}{*}{$\mathrm{CH}_{4}$} & Trucking & 0.94 & 0.22 & -0.23 & 0.85 & 0.94 & 0.22 & Strong, MN, positive \\
\hline & Drilling & 0.21 & 0.86 & -0.94 & 0.21 & 0.79 & 0.42 & Strong, WI, negative \\
\hline & Fracking & 0.26 & 0.83 & -0.93 & 0.24 & 0.82 & 0.39 & Strong, WI, negative \\
\hline \multirow{3}{*}{ PM } & Trucking & -0.91 & 0.26 & -0.51 & 0.66 & -0.44 & 0.71 & Strong, H/C, negative \\
\hline & Drilling & 0.74 & 0.47 & -0.58 & 0.61 & 1.00 & 0.02 & Strong, MN, positive \\
\hline & Fracking & 0.97 & 0.16 & 0.36 & 0.76 & 0.58 & 0.60 & Strong, H/C, positive \\
\hline \multirow{3}{*}{ PN } & Trucking & -0.85 & 0.36 & 0.43 & 0.72 & -0.99 & 0.09 & Strong, MN, negative \\
\hline & Drilling & -0.65 & 0.55 & 0.68 & 0.53 & -0.99 & 0.11 & Strong, MN, negative \\
\hline & Fracking & -0.94 & 0.23 & -0.46 & 0.69 & -0.49 & 0.68 & Strong, H/C, negative \\
\hline
\end{tabular}

The 'p' value indicates the confidence level with which the correlations may be attributed to the respective fuel property. A 'p' value of less than 0.05 indicates that the correlation is statistically significant at $95 \%$ confidence level. Similarly, 'p' value between 0.05 and 0.3 indicates that the correlation is statistically significant with a confidence interval between $95 \%-70 \%$.

$\mathrm{H} / \mathrm{C}$ ratio had the strongest effect on $\mathrm{CO}_{2}$ emissions with $\mathrm{CO}_{2}$ emissions decreasing with increasing $\mathrm{H} / \mathrm{C}$ ratio. $\mathrm{MN}$ had the strongest effect on $\mathrm{NO}_{\mathrm{x}}, \mathrm{THC}$ and $\mathrm{CH}_{4}$ emissions with the emissions increasing with increasing MN. PN emissions were also affected by MN, with lower MN fuel blends yielding higher PN emissions. WI had the strongest effect on $\mathrm{CO}$ emissions, with $\mathrm{CO}$ emissions decreasing with increasing WI. When the engine was operated over non-road, steadystate cycles, $\mathrm{NO}_{\mathrm{x}}$ and hydro-carbon emissions were observed to be increasing with increasing WI. 


\subsection{Recommendations for Future Work}

The major limitation while conducting this study was the availability of different compositions of natural gas fuel blends. One way to improve the understanding of this work would be test the engine on more custom natural gas blends that would be representative of the natural gas produced at the shale play regions. This would help to predict the effects of intermediate ethane and propane content. Newer technology engines that could respond to the composition of natural gas blend and change its combustion characteristics as a function of $\mathrm{MN}$, WI and $\mathrm{H} / \mathrm{C}$ ratio offers potential to utilized at the shale play natural gas development and produce lower emissions.

PM from particle number count, based on the particle density distribution, may provide a comparison of the effect of fuel composition on gravimetric PM with respect to the PM obtained from integrated particle number distribution. It would also provide insight into any solid/absorbed mass on the PM sampling filter. 


\section{References}

[1] U.S. EIA, "Frequently Asked Questions "How much natural gas does the United States have, and how long will it last?"," US EIA, 09 April 2018. [Online]. Available: https://www.eia.gov/tools/faqs/faq.php?id=58\&t=8. [Accessed 09 April 2018].

[2] U.S. DOE, "U.S. Department of Energy," 13 May 2013. [Online]. Available: https://energy.gov/natural-gas.

[3] EIA, "US Energy Information Administration," 31 March 2017. [Online]. Available: https://www.eia.gov/dnav/ng/ng_prod_wells_s1_a.htm. [Accessed 2 April 2017].

[4] R. S. Heltzel, "Development of Engine Activity Cycles for the Prime-Movers of Unconventional Well Completion," WVU, Morgantown, "Thesis", 2016.

[5] U.S. EIA, "U.S. Energy Information Administration," 19 April 2018. [Online]. Available: https://www.eia.gov/naturalgas/weekly/. [Accessed 25 April 2018].

[6] U.S. DOE, Argonne National Laboratory, "Life-Cycle Analysis of Shale Gas and Natural Gas," U.S. Department of Energy, Chicago, 2011.

[7] D. R. Johnson, R. Heltzel, A. Nix and R. Barrow, "Development of engine activity cycles for the prime movers of unconventional natural gas well development," Journal of the Air \& Waste Management Association, vol. 67, no. 3, pp. 371-388, 2017.

[8] NETL, "Exploration and Production Technologies,"Assessing Fugitive Methane Emissions using Natural Gas Engines in Unconventional Resource Development"," NETL, December 2017. [Online]. Available: https://www.netl.doe.gov/research/oil-andgas/project-summaries/natural-gas-resources/fe0013689-WVU. [Accessed 09 April 2018].

[9] K. Bullin and P. Krouskop, "Composition Variety Complicates Processing Plans for US Shale Gas," Gas Processors Association, Houston, 2008. 
[10] EPA, "EPA," 1 March 2016. [Online]. Available: https://nepis.epa.gov/Exe/ZyPDF.cgi?Dockey=P100O9ZZ.pdf. [Accessed 20 November 2017].

[11] EPA, "Nepis EPA," 01 March 2016. [Online]. Available: https://nepis.epa.gov/Exe/ZyPDF.cgi?Dockey=P100OA05.pdf. [Accessed 08 April 2018].

[12] Air Resource Board, CA, "Fleet Reporting Tool Instructions," [Online]. Available: https://www.arb.ca.gov/portable/perp/fleetemissions/calculatorinstructions.htm. [Accessed 08 April 2018].

[13] EPA, 01 March 2016. [Online]. Available: https://nepis.epa.gov/Exe/ZyPDF.cgi?Dockey=P1000A08.pdf.

[14] P. Eastwood, Particulate Emissions from Vehicles, John Wiley \& Sons Ltd., 2008.

[15] M. T. Kleimnn. Robert A. Michaels, "Incidence and Apparent Health Significance of Brief Airborne Particle Excursions," Aerosol Science \& Technology, vol. 32, no. 2, pp. 93-105, 2000.

[16] D. B. Kittelson, "Engines and Nanaoparticles: A Review," Journal of Aerosol Science, pp. 575-588, 1998.

[17] C. Myung, A. Ko and S. Park, "Review on characterization of nano-particle emissions and PM morphology from internal combustion engines: Part 1," International Journal of Automotive Technology, pp. 203-218, 2014.

[18] S. Choi, C. Myung and S. Park, "Review on the characterization of nano-particle emissions and PM morphology from internal combustion engines: Part 2," International Journal of Automotive Technology, pp. 219-227, 2014.

[19] CFR, "Electronic Code of Federal Regulations "1065.145 Gaseous and PM probes, transfer lines, and sampling system components"," Government Publishing Office, 06 April 2018. [Online]. Available: https://www.ecfr.gov/cgi-bin/text-idx?SID= 
6ea0a1091feaaeab57b427601fb4cb54\&mc $=$ true \&node $=$ se40.37.1065_1145\&rgn= div8. [Accessed 10 April 2018].

[20] EPA, "US EPA," 1 January 2014. [Online]. Available: https://cfpub.epa.gov/roe/indicator_pdf.cfm?i=19. [Accessed 29 November 2017].

[21] Official Journal of the European Union, "Amendments to Regulation (EC) No 595/2009," 25 June 2011. [Online]. [Accessed 08 April 2018].

[22] U.S. EPA, "Regualtions for Emissions from Nonroad Vehicles and Engines," EPA, 16 August 2017. [Online]. Available: https://www.epa.gov/regulations-emissions-vehiclesand-engines/regulations-emissions-nonroad-vehicles-and-engines. [Accessed 10 April 2018].

[23] CFR, "Electronic Code of Federal Regulations, Part 1048-Control of Emissions from New, Large Nonroad Spark-Ignition Engines," Government Publishing Office, 09 April 2018. [Online]. Available: https://www.ecfr.gov/cgi-bin/textidx?SID=20d5aadca149e74f96dafc5a731399d7\&mc=true \&node=se40.36.1048_1501\&rg n=div8. [Accessed 10 April 2018].

[24] CFR, "Electronic Code of Federal Regulations Title 40 CFR part 1039 "Appendix II Steady State Duty Cycles"," 13 July 2005. [Online]. Available: https://www.ecfr.gov/cgibin/text-

idx?SID=5bd49186c6de428e7d6446a56baab96c \&mc=true \&node=pt40.36.1039\& $\mathrm{rgn}=\mathrm{di}$ v5\#ap40.36.1039_1825.ii. [Accessed 08 April 2018].

[25] CARB, "Appendix D - Methane Number and Fuel Composition," 21 February 2002. [Online]. Available: https://www.arb.ca.gov/regact/cng-lpg/appd.pdf. [Accessed 10 August 2017].

[26] U. Kramer, T. Lorenz, C. Hofmann, H. Ruhland, R. Kelin and C. Weber, "Methane Number Effect on the Efficiency of a Downsized, Dedicated, High Performance Compressed Natural Gas (CNG) Direct Injection Engine," SAE Technical Paper, Vols. 2017-01-0776, 2017. 
[27] Cummins, "Fuel Quality Calculator," Cummins, November 2015. [Online]. Available: http://www.cumminswestport.com/fuel-quality-calculator. [Accessed 09 April 2018].

[28] "International Gas Union" 10 January 2011. [Online]. Available: http://www.igu.org/sites/default/files/node-pagefield_file/Guidebook\%20to\%20Gas\%20Interchangeability\%20and\%20Gas\%20Quality\% 2C\%20August\%202011.pdf. [Accessed 18 January 2018].

[29] J. D. Hailey, "Fundamentals of Energy Determination," Cosa Instrument \& Xeataur Group, Houston, 2016.

[30] "Hobre Instruments" 18 January 2018. [Online]. Available: https://www.hobre.com/files/products/Wobbe_Index_General_Information_rev.1.pdf. [Accessed 18 January 2018].

[31] A. Thiruvengadam, M. C. Besch, S. Yoon, J. Collins, H. Kappanna, D. K. Carder, A. Ayala, J. Herner and M. Gautam, "Characterization of Particulate Matter Emissions from a Current Technology Natural Gas Engine "dx.doi.org/10.1021/es5005973"," Environmental Science \& Technology, vol. 48, pp. 8235-8242, 2014.

[32] G. Karavalakis, N. Gysel, M. Hajbabaei, T. Durbin, K. Johnson and W. Miller, "Influence of Different Natural Gas Compositions on the Regulated Emissions, Aldehydes and Particle Emissions from a Transit Bus," SAE International, no. doi:10.4271/2013-011137, 2013.

[33] W. G. Wang, N. Clark, D. Lyons, R. Yang, M. Gautam and R. B. a. J. Loth, "Emissions Comparison from Alternative Fuel Buses and Diesel Buses with a Chassis Dynamometer Testing Facility," Environmental Science Technology, pp. 3132-3137, 1997.

[34] B. H. Min, J. T. Chung, H. Y. Kim and S. Park, "Effects of Gas Composition on the Performance and Emissions of Compressed Natural Gas Engines," KSME International Journal, pp. 219-226, 2002. 
[35] M. D. Fiest, M. Landau and E. Harte, "The Effect of Fuel Composition on Performance and Emissions of a Variety of Natural Gas Engines," SAE International, pp. 100-117, 2010.

[36] D. Johnson, R. Heltzel, A. Nix, N. Clark and M. Darzi, "Regulated Gaseous Emissions from In-use High Horsepower Drilling and Hydraulic Fracturing Engines," Journal of Pollution Effects \& Control, no. 10.4176/2375-4397.1000187, pp. 1-7, 2017.

[37] P. Kulkarni, "Gas Processing News," 20 May 2013. [Online]. Available: http://www.gasprocessingnews.com/features/201307/gas-driven-hydraulic-fracturingand-drilling-cut-costs,-reduce-environmental-impact.aspx. [Accessed 4 April 2017].

[38] Cummins, "Cummins Westport," 10 January 2015. [Online]. Available: http://www.cumminswestport.com/content/506/ISX12\%20G\%204971500_0315.pdf. [Accessed 4 April 2017].

[39] Westport, "Westport," 10 January 2017. [Online]. Available: http://www.westport.com/is/core-technologies/hpdi-2. [Accessed 4 April 2017].

[40] Cummins, 10 January 2013. [Online]. Available: https://cumminsengines.com/isx15heavy-duty-truck-2013\#overview. [Accessed 4 April 2017].

[41] Cummins, "Cummins Engines," 10 January 2017. [Online]. Available: https://cumminsengines.com/qsk60-oil-and-gas?\#ratings. [Accessed 6 April 2017].

[42] Caterpillar, "Caterpillar," 13 April 2012. [Online]. Available: http://s7d2.scene7.com/is/content/Caterpillar/3512_IND-C_1119bkW. [Accessed 6 April 2017].

[43] GEPower, "GE Power," 12 April 2016. [Online]. Available: https://powergen.gepower.com/content/dam/gepowerpgdp/global/en_US/documents/product/Reciprocating\%20Engines/waukesha-mobileflex15794-17044gsi-epa-product-sheet.pdf. [Accessed 6 April 2017]. 
[44] Cummins, 10 April 2015. [Online]. Available:

http://www.cumminswestport.com/content/430/ISL\%20G\%204971499_0315.pdf.

[Accessed 6 April 2017].

[45] U.S. EIA, "Review of Emerging Resources: U.S. Shale Gas and Shale Oil Plays," U.S. Department of Energy, Washington, DC, 2011.

[46] CFR, "Government Publishing Office," 24 July 2017. [Online]. Available: https://www.ecfr.gov/cgi-bin/textidx?SID=a35f87057676bf3fae285662775af1 da\&mc=true \&tpl=/ecfrbrowse/Title40/40tab _02.tpl. [Accessed 26 July 2017].

[47] N. N. Clark, W. S. W. David L. McKain, H. Li, D. R. Johnson, V. Akkerman, C. Sandoval, A. N. Covington, R. A. Mongold, J. T. Hailer and O. J. Ugarte, "Pump-toWheels Methane Emissions from the Heavy-Duty Transportation Sector," Environmental Science \& Technology, vol. 51, no. 10.1021/acs.est.5b06059, pp. 968-976, 2016.

[48] D. Johnson, A. N. Covington and N. N. Clark, "Methane Emissions from Leak and Loss Audits of Natural Gas Compressor Stations and Storage Facilities," Environmental Science and Technology, pp. 8132-8138, 2017.

[49] Sierra Instruments, "SmartTrak 100 Series "Instruction Manual"," Sierra, Monterey, CA, 2013.

[50] CFR, "PART 1065 - Engine Testing Procedures "1065.140"," ecfr, 06 April 2018. [Online]. Available: https://www.ecfr.gov/cgi$\mathrm{bin} /$ retrieveECFR gp=\&SID=d8e74dd92018a2021b461963815574af\&mc=true \&n=pt40. 37.1065\&r=PART\&ty=HTML. [Accessed 10 April 2018].

[51] United Nations, "UNECE Regulation 49, Revision 7, Addendum 48, Annex 4CAppendix 1,"Particulate number emissions measurement equipment"," United Nations, Geneva, 2015. 
[52] TSI, "TSI Incorporated," 01 January 2005. [Online]. Available:

http://www.tsi.com/uploadedFiles/Product_Information/Literature/Spec_Sheets/3090_29 80244A.pdf.

[53] T. Johnson, R. Caldow, A. Pocher, D. A. Mirme and D. D. B. Kittleson, "An Engine Exhaust Particle Sizer Spectrometer for Transient Emision Particle Measurements," in 9th Diesel Engine Emissions Reduction (DEER) Workshop, Newport, 2003.

[54] D. O. E. US, "AFDC Energy," US Department of Energy, 22 November 2014. [Online]. Available: https://www.afdc.energy.gov/fuels/equivalency_methodology.html. [Accessed 24 April 2018].

[55] Caterpillar, "CAT," 01 January 2015. [Online]. Available: www.cat.com/power-systems. [Accessed 15 November 2017]. 